\title{
ANALYSIS OF CHARACTERISTICS OF THE ZINC OXIDE MATERIAL IN \\ NANOSCALE
}

by

\author{
Shreeja Kelam \\ Bachelor of Technology, Indira Gandhi National University (2015) \\ A project \\ presented to Ryerson University \\ in partial fulfilment of the \\ requirements for the degree of \\ Master of Engineering \\ in the program of \\ Aerospace Engineering
}

Toronto, Ontario, Canada, 2019

CShreeja Kelam, 2019 


\section{AUTHOR'S DECLARATION FOR ELECTRONIC SUBMISSION OF A PROJECT}

I hereby declare that I am the sole author of this project. This is a true copy of the project including any required final revisions. I authorize Ryerson University to lend this project to other institutions or individuals for the purpose of scholarly research. I further authorize Ryerson University to reproduce this project by photocopying or by other means, in total or in part, at the request of other institutions or individuals for the purpose of scholarly research. I understand that my project may be made electronically available to the public. 


\title{
ANALYSIS OF THE CHARACTERISTICS OF THE ZINC OXIDE MATERIAL IN \\ NANO SCALE
}

\author{
Shreeja Kelam
}

Master of Engineering, Aerospace Engineering, Ryerson University, Toronto (2019)

\begin{abstract}
This project involves the examination and analysis of the characteristics of zinc oxide material using different software's like Image J, GATAN, SPECTRAGRYPH and Origin to examine the properties in the detailed literature research after concluding the characteristics. The different microscopy techniques were used to conduct the experiments like FESEM, HRTEM, SAED, FTIR and XPS by a Ph.D. student Rupa Haldavnekar. This project involves the investigation of the results obtained from those experiments on the material zinc oxide. The project also involves detailed study after exploring the features of the material and comparing it with the existing industry demands in the case of properties of materials. The main focus was on the Aerospace market requirements. Therefore, the better ideas were derived through literature review to manufacture the zinc oxide material with the better quality and properties as required by industry than the existing ones.
\end{abstract}




\section{ACKNOWLEDGEMENT}

I would like to express my sincere gratitude to my supervisor Dr. Bo Tan for providing her invaluable guidance, comments and suggestions throughout the course of the project. I would especially thank my supervisor and Ms. Rupa Haldavnekar for constantly motivating me to work

better. Also, I would like to thank them for their assistance in gaining knowledge in a short period of time and to complete the project. 
TABLE OF CONTENTS

AUTHOR'S DECLARATION FOR ELECTRONIC SUBMISSION OF A PROJECT ..... II

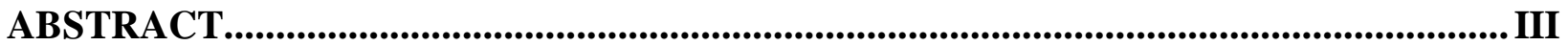

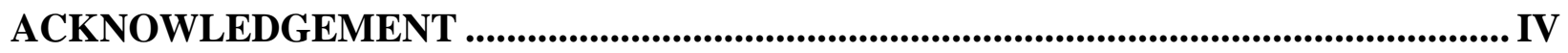

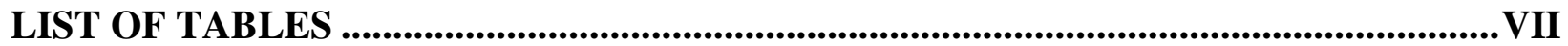

LIST OF FIGURES .................................................................................................. VIII

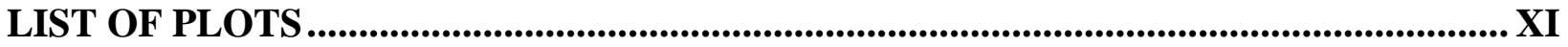

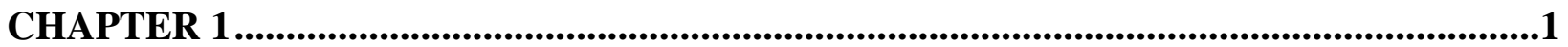

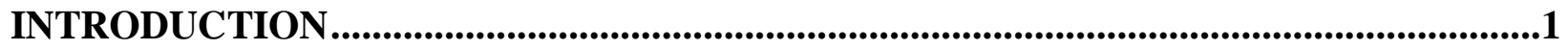

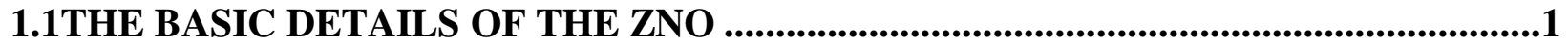

1.2 PROPERTIES OF ZINC OXIDE: .........................................................................4

1.3 MECHANICAL PROPERTIES: ...................................................................................7

1.4 SEMICONDUCTOR PROPERTIES OF ZINC OXIDE...............................................7

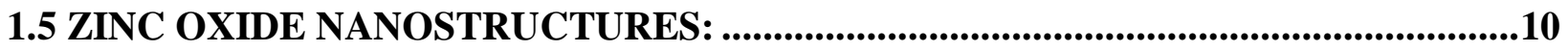

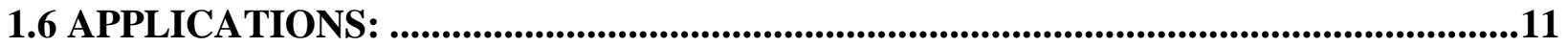

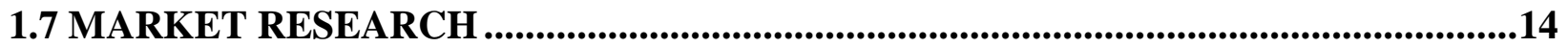

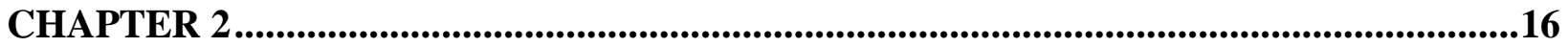




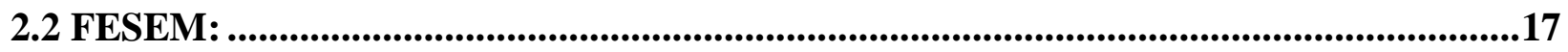

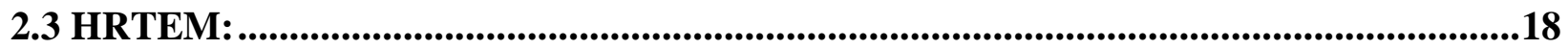

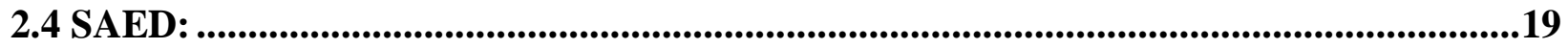

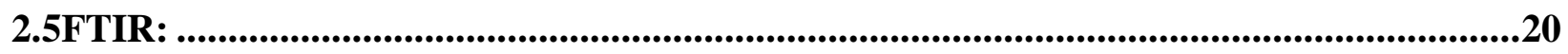

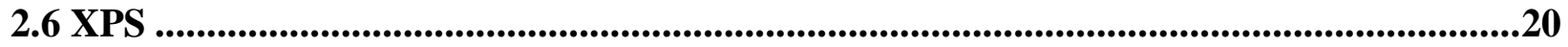

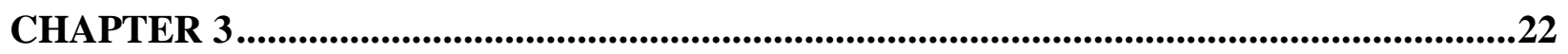

RESULTS AND DISCUSSION ...................................................................................................22

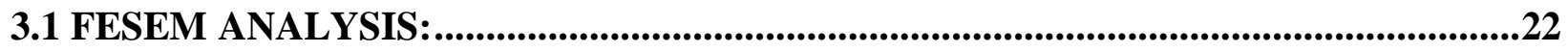

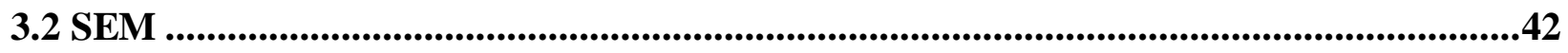

3.3 HRTEM ANALYSIS: ................................................................................................................49

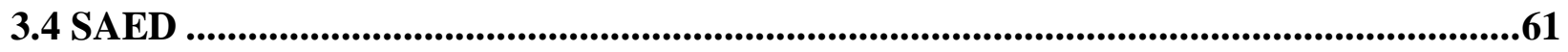

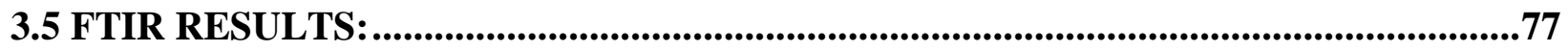

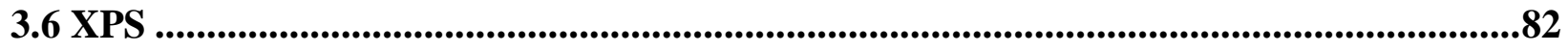

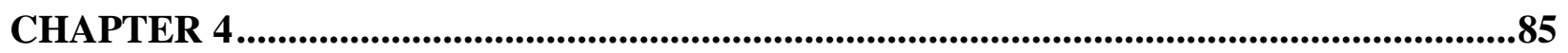

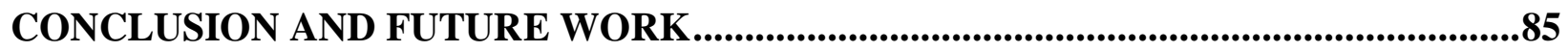

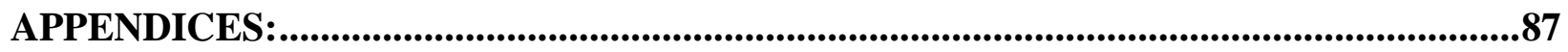

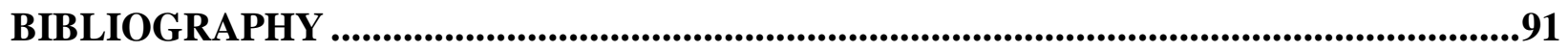




\section{LIST OF TABLES}

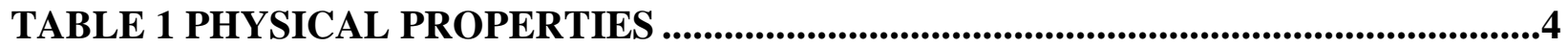

TABLE 2 THERMAL PROPERTIES ...............................................................................................4

TABLE 3 CHEMICAL PROPERTIES .......................................................................................5

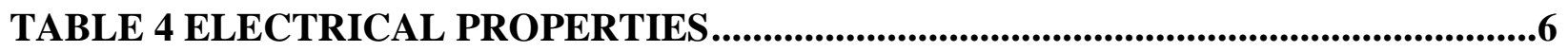

TABLE 5 HRTEM EXPERIMENTAL SET UP FEATURES ...........................................18

TABLE 6 SUMMARY OF THE AVERAGES OF AREA AND LENGTHS OF THE RODS

TABLE 7 SUMMARY OF PARTICLE COUNT AND MEAN PARTICLE SIZE ...............41

TABLE 8 SUMMARY OF THE SEM NANO PARTICLE DISTRIBUTION.......................48

TABLE 9 D-SPACING VALUES FROM HRTEM IMAGES...........................................61

TABLE 10 SUMMARY OF SAED RESULT WITH AMPLITUDES OF BRIGHTEST

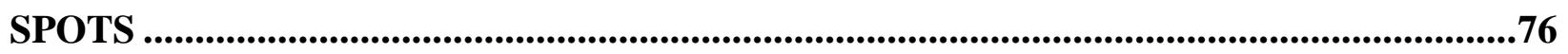


LIST OF FIGURES

FIGURE 1 LATTICE STRUCTURE OF ZINC OXIDE AND LATTICE STRUCTURE OF

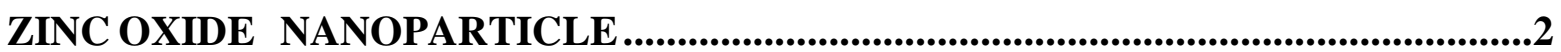

FIGURE 2 DIFFERENT BLENDS OF LATTICE STRUCTURE .........................................3

FIGURE 3 DIFFERENT APPLICATIONS OF ZINC OXIDE ........................................13

FIGURE 4 REVENUE AND VOLUME CHART FOR ZINC OXIDE PRODUCTION

FROM 2014 TO 2022 .14

FIGURE 5 COMPARISON OF DIFFERENT METAL OXIDE MARKET FOR YEARS

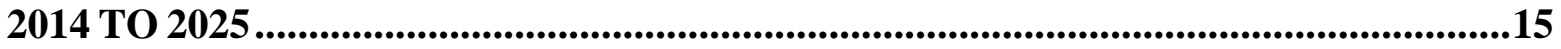

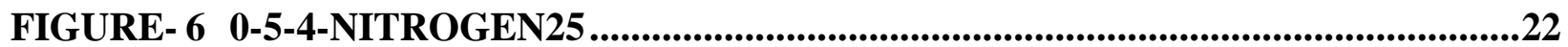

FIGURE 7 RESULTS OF LENGTH OF THE RODS 0_5_4_NITROGEN25......................24

FIGURE 8 ILLUMINATED FIGURE OF THE FESEM IMAGE AFTER APPLYING

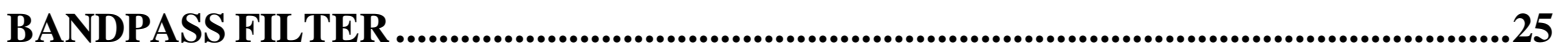

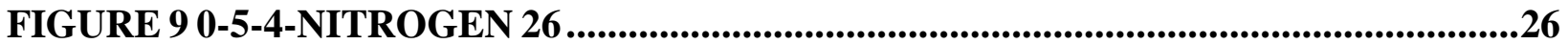

FIGURE 10 RESULTS OF LENGTHS OF RODS OF 0_5_4_NITROGEN 26.....................27

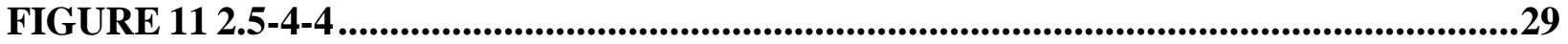

FIGURE 12 RESULTS OF THE LENGTHS OF THE RODS OF 2.5_4_4 ...........................30

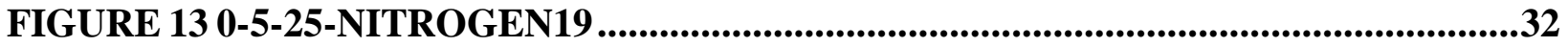

FIGURE 14 RESULTS OF THE LENGTHS OF THE RODS OF 0_5_25_NITROGEN 19.33

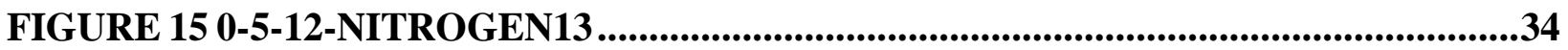

FIGURE16 RESULTS OF THE LENGTHS OF THE RODS 0_5_12_NITROGEN 13........35

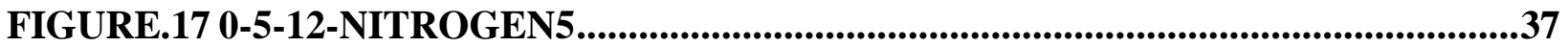


FIGURE 18 RESULTS OF THE LENGTHS OF THE RODS 0_5_12NITROGEN5. 37

FIGURE 19 2.5-4-6 ...........................................................................................................38

FIGURE 20 RESULTS OF THE LENGTHS OF THE RODS 2.5_4_6.............................39

FIGURE 21 0_5_12_0006 .......................................................................................................42

FIGURE 22 THRESHOLD APPLIED TO ILLUMINATE FOR THE IMAGE CLARITY 43

FIGURE 23 ILLUMINATED IMAGE WITH THE BANDPASS FILTER .......................43

FIGURE 24 PARTICLES INDICATED FOR THE ANALYSIS ......................................44

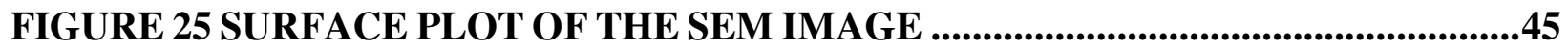

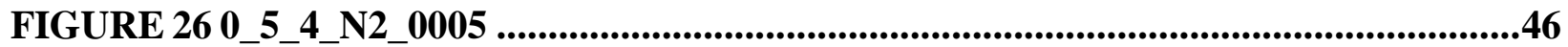

FIGURE 27 ILLUMINATED IMAGE WITH THE BANDPASS FILTER .......................47

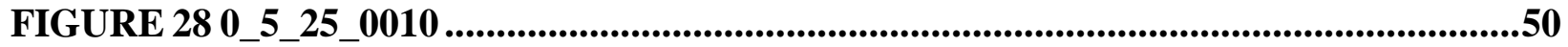

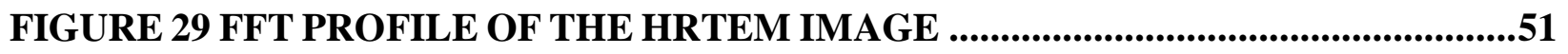

FIGURE 30 FFT SURFACE PROFILE OF HRTEM IMAGE .......................................52

FIGURE 31 SURFACE PROFILE IN 3D.......................................................................52

FIGURE 32 FFT MATRIX VALUES OF THE HRTEM ANALYSIS FOR THE D-

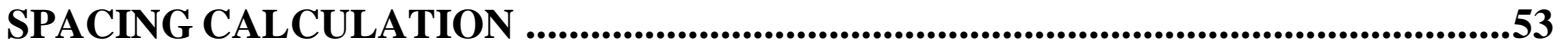

FIGURE 33: HIGHLIGHTED PARTICLES IN THE USAGE OF MASKING TOOL .......54

FIGURE 34 HIGH RESOLUTION IMAGE OF THE FRINGES TO CALCULATE THE D-

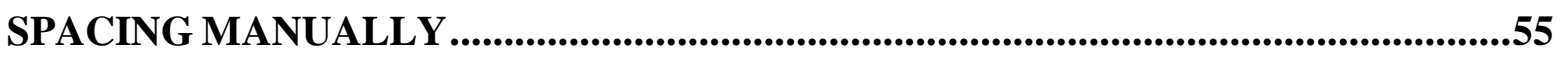

FIGURE 35 PROFILE OF IFFT

FIGURE 36 0_5_25_0013 ........................................................................................57

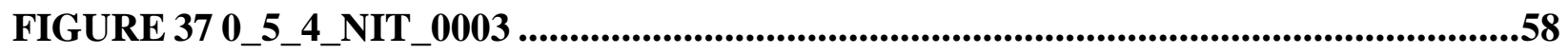

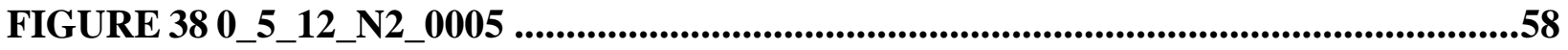


FIGURE 39 0_5_12_N2_0010 ........................................................................................................59

FIGURE 40 0_5_25_NIT_0018 ...............................................................................................................60

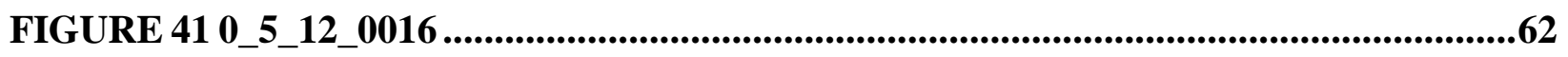

FIGURE 42 RESULTS OF THE SAED INDEXING OF 0_5_12_0016 .................................63

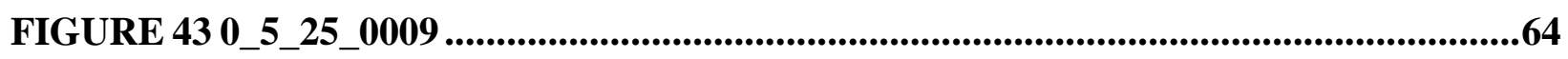

FIGURE 44 RESULTS OF SAED INDEXING OF 0_5_25_0009 _............................................64

FIGURE 45 0_5_4_A_0001 ..................................................................................................................65

FIGURE 46 RESULTS OF SAED INDEXING OF 0_5_4_A_0001 ............................................66

FIGURE 47 0_5_4_N2_0002 .............................................................................................................67

FIGURE 48 RESULTS OF SAED INDEXING OF 0_5_4_N2_0002 .........................................67

FIGURE 49 0_5_4_N2_0003 ..............................................................................................................68

FIGURE 50 RESULTS OF SAED INDEXING OF THE 0_5_4_N2_0003 ..............................68

FIGURE 51 0_5_12_N2_0001 ..........................................................................................................69

FIGURE 52 RESULTS OF SAED INDEXING OF 0_5_12_N2_0001 .....................................70

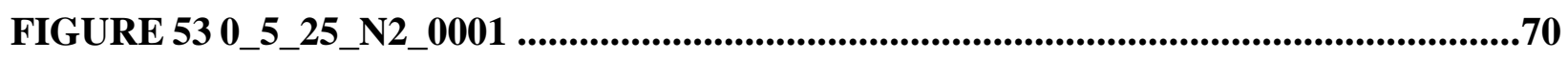

FIGURE 54 RESULTS OF SAED INDEXING OF 0_5_25_N2_0001 ......................................71

FIGURE 55 0_5_25_N2_0002 .....................................................................................................71

FIGURE 56 RESULTS OF THE SAED INDEXING OF 0_5_25_N2_0002...........................72

FIGURE 57 2_5_4_A1 ........................................................................................................................73

FIGURE 58 RESULTS OF SAED INDEXING OF THE 2_5_4_A1 .........................................73

FIGURE 59 2_5_4_A2 ......................................................................................................................74

FIGURE 60 RESULTS OF SAED INDEXING OF 2_5_4_A2 ....................................................75 


\section{LIST OF PLOTS}

PLOT 1 SPECTROGRAPH ANALYSIS OF 0_5_4 ZINC OXIDE MATERIAL. ..................77

PLOT 2 SPECTRAGRAPH ANALYSIS OF 0_5_12 ZINC OXIDE MATERIAL ................78

PLOT 3 SPECTRAGRYPH RESULTS OF 0_5_25 ZINC OXIDE MATERIAL ..................78

PLOT 4 SPECTRAGRYPH RESULTS OF 2_5_4 ZINC OXIDE MATERIAL ....................80

PLOT 5 SPECTROGRAPH RESULTS OF 2_5_4 ZINC OXIDE MATERIAL ....................81

PLOT 6 SPECTROGRAPH RESULTS OF XPS 0_5_4....................................................82

PLOT 7 SPECTRAGRYPH RESULTS OF XPS 0_5_2 _......................................................83

PLOT 8 SPECTROGRAPH RESULTS OF XPS 0_5_25..................................................... 


\section{CHAPTER 1}

\section{INTRODUCTION}

\subsection{THE BASIC DETAILS OF THE ZnO}

The raw material of $\mathrm{ZnO}$ is Zincite. It is a coarse-grained material. Usually, it is produced by oxidation of zinc or zinc vapour with atmospheric oxygen or other process is by calcination of different components like zinc carbonate, zinc hydroxide or zinc nitrate. Zinc oxide contains lead in its ideal state. Zinc oxide is either available as powder or dispersions in industry. Coming to the basic characteristics of Zinc and oxygen element in the periodic table to understand the properties. Zinc is a D Block element, 4th Period element while Oxygen is a P Block, $2^{\text {nd }}$ Period element. The other names of zinc oxide nanoparticles are ox datum, zincin oxicam, permanent white ketonic and oxo zinc. (Wang, 2004)

Structure:

The hexagonal structure has a 6 group (Hermann-Mauguin notation)) or the location of the $\mathrm{C}-6 \mathrm{~V}$ (Shoeflies notation), and the space group $\mathrm{P}_{63} \mathrm{MC}$ or $\mathrm{C}_{6} \mathrm{~V}_{4}$. The lattice constants are $\mathrm{a}=3.25 \mathrm{~A}$ and $\mathrm{c}=5.2 \mathrm{~A}$; Their ratio is close to the norm of $\mathrm{c} / \mathrm{a} \sim 1.60$ hexagonal cells $\mathrm{c} / \mathrm{a}=1.633$. For most groups such as II-VI material, the bond between $\mathrm{ZnO}$ is mostly ionic $\left(\mathrm{Zn}^{2+}-\mathrm{O}^{2-}\right)$ and its corresponding $\mathrm{Zn}^{2+} 0.074 \mathrm{~nm}$ radii and $\mathrm{O}^{2+} 0.140 \mathrm{~nm}$. It is for the strong piezoelectricity of the property $\mathrm{ZnO}$, besides the addition of zinc mixtures instead of wurtzite composition. Polar Zen-o is charged with electricity due to bonds, zinc and oxygen planes. To maintain optimum neutrality, 
these ships produce the highest atomic level, but not in $\mathrm{ZnO}$ its copies do not make the aircraft nuclear, stable and do not rebuild any. This anomaly of $\mathrm{ZnO}$ was not fully explained. However, while using the wurtzite framework, the newspapers explained the absence of reconstruction at $\mathrm{ZnO}$ wurtzite surfaces in addition to the origin of charges on $\mathrm{ZnO}$ planes.
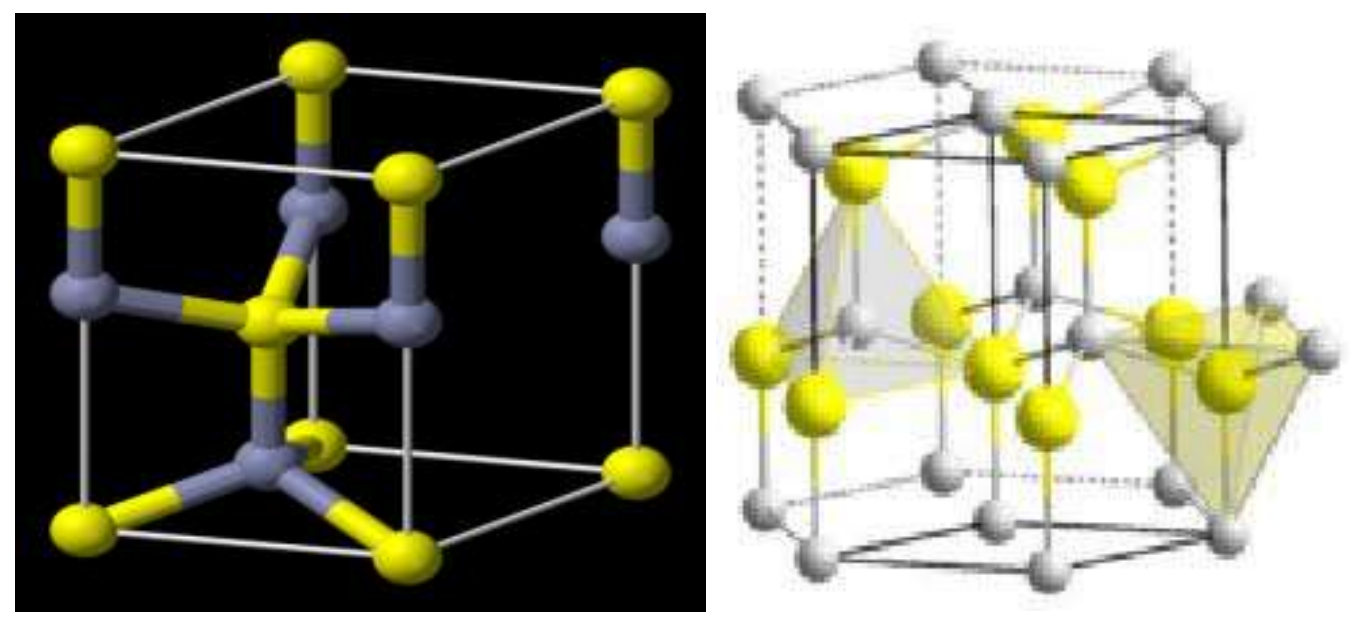

FIGURE 1 LATTICE STRUCTURE OF ZnO AND LATTICE STRUCTURE OF ZnO NANOPARTICLE (Prateek Uikey, n.d.)

The above figure 1 shows the lattice structure of both bulk $\mathrm{ZnO}$ and the nanoparticle $\mathrm{ZnO}$. There is difference in both the structures. The bulk $\mathrm{ZnO}$ has the square phases in 3 sides and the other 2 phases are hexagonal structure phases. The nanoparticle lattice structure has the complete hexagonal structures. 


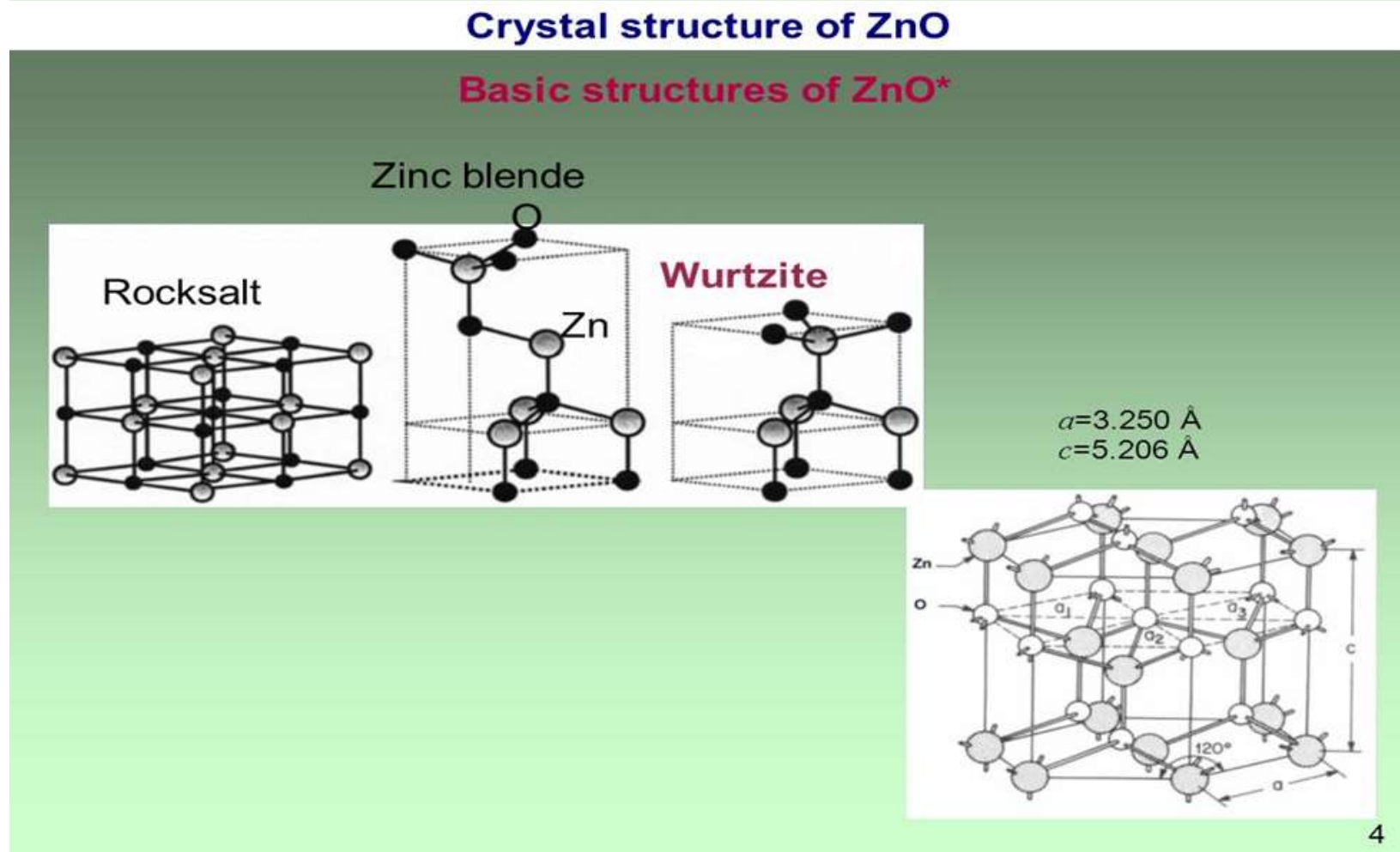

FIGURE 2 DIFFERENT BLENDS OF LATTICE STRUCTURE (Crawford, 2016)

The above figure 2 shows the two forms of the Zinc blende with the lattice constants for both structures of zinc blende. 
1.2 PROPERTIES OF ZINC OXIDE:

PHYSICAL PROPERTIES

\begin{tabular}{|l|l|l|}
\hline PROPERTY & VALUE & UNIT \\
\hline DENSITY & 5600 & $\mathrm{Kg} / \mathrm{m} 3$ (metric) \\
\hline DENSITY & 0.202 & $\mathrm{lb} /$ in3(imperial) \\
\hline MOLAR MASS & 0.08140 & $\mathrm{Kg} / \mathrm{mol}$ \\
\hline
\end{tabular}

\section{TABLE 1 PHYSICAL PROPERTIES}

(Zinc Oxide - Properties, Applications and the Future for ZnO, 2011)

\section{THERMAL PROPERTIES}

\begin{tabular}{|l|l|l|}
\hline PROPERTY & VALUE & UNIT \\
\hline MELTING POINT & 1975 & deg Celsius \\
\hline BOILING POINT & 2360 & deg Celsius \\
\hline
\end{tabular}

\section{TABLE 2 THERMAL PROPERTIES}

(Zinc Oxide - Properties, Applications and the Future for $\mathrm{ZnO}$, 2011) 


\section{CHEMICAL PROPERTIES}

\begin{tabular}{|l|l|l|}
\hline PROPERTY & ELEMENT & VALUE \\
\hline GROUP NUMBER & ZINC & 12 \\
\hline GROUP NUMBER & OXYGEN & 16 \\
\hline CONFIGURATION & ZINC & {$[\mathrm{AR}] 3 \mathrm{~d} 104 \mathrm{~s} 2$} \\
\hline ELECTRONIC & & {$[\mathrm{He}] 2 \mathrm{~s} 22 \mathrm{p} 4$} \\
\hline CONFIGURATION & OXYGEN & \\
\hline COMPOSITION & & $80.34 \%$ \\
\hline CHEMICAL & ZINC & $19.6 \%$ \\
\hline COMPOSITION & & $0.16 \mathrm{mg} / 100 \mathrm{ml}(30 \mathrm{deg}$ C) \\
\hline SOLUBILITY IN H2O & ZINC OXIDE & \\
\hline
\end{tabular}

TABLE 3 CHEMICAL PROPERTIES

(Zinc Oxide - Properties, Applications and the Future for $\mathrm{ZnO}, 2011$ ) 


\section{ELECTRICAL PROPERTIES}

\begin{tabular}{|l|l|l|}
\hline PROPERTY & VALUE & UNIT \\
\hline BAND GAP & 3.3 & $\mathrm{eV}$ \\
\hline REFRACTIVE INDEX & 2.0041 & $(\mathrm{nD})$ \\
\hline DIELECTRIC CONSTANT & 8.66 & \\
\hline EXCITATION BINDING & 60 & $\mathrm{meV}$ \\
\hline ENERGY & & \\
\hline ELECTRON/HOLE & $0.24 \mathrm{~m} 0 / 0.59 \mathrm{~m} 0$ & \\
\hline EFFECTIVE MASS & & $\mathrm{cm} 2 \mathrm{~V} / \mathrm{s}$ \\
\hline HOLE MOBILITY (300K) & $5-50$ & $\mathrm{~cm} 2 \mathrm{~V} / \mathrm{s}$ \\
\hline
\end{tabular}

TABLE 4 ELECTRICAL PROPERTIES

(Zinc Oxide - Properties, Applications and the Future for $\mathrm{ZnO}, 2011$ )

The table number 1,2,3,4 shows the physical, thermal, chemical and electrical properties of the material zinc oxide. 
Advantages related to the larger band gap include high breakdown voltage, the ability to maintain large power fields, low electronic noise, and high temperature and high-power operations. Magnesium oxide or cadmium oxide the bandgap of $\mathrm{ZnO}$ can further be tuned to $\sim 3-4 \mathrm{eV}$.

The high yielding binding of $\mathrm{ZnO}$ will allow excitonic transitions changes at room temperature, which could mean high radiative rebuilding capacity for low threshold voltage for laser emission along with natural evacuation

\subsection{MECHANICAL PROPERTIES:}

Zinc Oxide has approximate hardness of 4.5 on the Mohs scale and that's why its soft material. The elastic constants of Zinc Oxide are smaller than those of semiconductors such as GaN which come under relevant III-V. Due to high heat capacity and heat conductivity, low thermal expansion and high melting temperature of $\mathrm{ZnO}$ ceramics are most exploiting products of $\mathrm{ZnO}$.

The $\mathrm{E} 2$ optical phonon in $\mathrm{ZnO}$ exhibits long lifetime of $133 \mathrm{ps}$ at $10 \mathrm{~K}$, a strangely unique property.

Zinc Oxide has the highest piezoelectric tensor among tetrahedrally shaped semiconductors comparable to that of GaN and AlN. This property makes it a demanding in industry for many piezoelectrical applications, which requires a large electromechanical coupling.

\subsection{SEMICONDUCTOR PROPERTIES OF ZINC OXIDE}

Even in the absence of the majority of ZnO's psychological doping, there are many n-type characters. N-type character produces nonstoichiometric subject, but subject matter is controversial. 
A comprehensive explanation based on theoretical calculations has been proposed, which is responsible for the inaccuracy of unintentional substitutional hydrogen. $\mathrm{Zn}$ associated with controllable anti-doping groups can be easily replaced by altering such as $\mathrm{Al}, \mathrm{Ga}$, or group--VII elements by changing the oxygen with chlorine or iodine.

Existing limitations of the p-doping limit, electronic and optoelectronic applications of $\mathrm{ZnO}$, which usually require n-type junction and junction of P-type material. In the well-known P-type dopants, the group-I elements Li, Na, K; group-V elements N, P and as; Along with copper and Silver, however, many of these form deep acceptors and do not carry significant P-type transport at room temperature.

Zinc oxide room temperature at $3.37 \mathrm{eV}$ band gap, one of the most important n-type semiconductor material and $60 \mathrm{MeV}$ produced binding energy, which is in the UV region and this nanoparticle is made into an effective UV absorber. Semiconductor nanomaterials have been given a lot of attention. Zinc oxide is a multilayered material in these different semiconductor nanomaterials because its chemicals-such as mechanical, electrical, optical, magnetic, and chemical-indigenous properties- zincite, a natural mixture of zinc oxide naturally in its mineral Cost has attracted more attention in recent times as it can be achieved by the general techniques Managing. Chemical synthesis is one of the most important techniques that can be done by measuring various precursors and different conditions such as temperature, time, reactions, and so on. As a result of the diversity of these parameters, there are morphological differences in the size and geometries of the nanoparticles. In nanoscale metal oxide, zinc oxide is a common hosted material that has been widely used for its excellent chemical and thermal stability, low cost, and environmentally friendly. The lack of symmetry center in Wurtzite, which comes with the larger electromechanical 
couple, results in stronger piezoelectric and pyroelectric properties, and therefore $\mathrm{ZnO}$ used in mechanical acquiring and piezoelectric sensors.

Electron mobility of $\mathrm{ZnO}$ strongly varies with temperature and has a maximum of $\sim 2000 \mathrm{~cm}^{2} /(\mathrm{V} \cdot \mathrm{s}$ ) at $80 \mathrm{~K}$. Data on hole mobility are scarce with values in the range $5-30 \mathrm{~cm}^{2} /(\mathrm{V} \cdot \mathrm{s})$.Zinc Oxide discs, acting as a varistor, are the active material in most surge arresters. Zinc oxide is the one of the most important n-type semiconductor materials with a $3.37 \mathrm{eV}$ band gap at room temperature and $60 \mathrm{meV}$ excitation binding energy that is in the UV region and makes this nanoparticle as an efficient UV absorber. Semiconductor nanomaterials have been received great attentions. Among these various semiconductor nanomaterials zinc oxide is a versatile material because of its physicchemical properties such as mechanical, electrical, optical, magnetic and chemical sensing properties. Zinc oxide a chemical compound found naturally in the mineral called zincite has attracted much attention in recent times due to its low cost and because it can be obtained by simple techniques. Chemical synthesis is one of the most important techniques which can be performed by using a range of precursors and different conditions like temperature, time, concentration of reactants, and so forth. Variation of these parameters leads to morphological differences in size and geometries of resulting nanoparticles. Among the nanoscale metal oxides, zinc oxide is a common host material that has been widely used due to its excellent chemical and thermal stability, low cost and environmental-friendliness. The lack of a centre of symmetry in wurtzite, combined with a large electromechanical coupling, results in strong piezoelectric and pyroelectric properties and hence the use of $\mathrm{ZnO}$ in mechanical actuators and piezoelectric sensors. 


\subsection{ZINC OXIDE NANOSTRUCTURES:}

ZnO's nanostructures can be included in a variety of morphologies including nanowires, nanorods, tetrapod's, nanobelts, nanoflowers, nanoparticles, and so on. Nanomaterials can be obtained with some high-quality techniques, in some cases, as well as in a vapor-liquid-solid way. Synthesis is usually taken at approximately 90 degree Centigrade, a homogeneous solution of the zinc nitrate and hexamine, later providing a basic environment. Certain substances such as polythene glycol or polyethyleneimine can improve the size ratio of $\mathrm{ZnO}$ nanowires. $\mathrm{ZnO}$ nanowires doping has been achieved by combining second metal nitrates in development solutions. Parameters related to the resulting structure (such as zinc concentration and $\mathrm{pH}$ ) or thermal treatment (such as temperature and heating rate) can be transformed into morphology of defined nanostructure.

Using Zinc Nitrate and Zinc Acetate, accelerated $\mathrm{ZnO}$ nanowires in the basic environment have created pre-seeded silicon, glass and gallium nitrite substrates. Pre-seeding substrates with $\mathrm{ZnO}$, during the synthesis, creates a site for $\mathrm{ZnO}$ crystal's nuclear nucleation. Common pre-seeding methods include the disruption of the zinc acetate crystallites to the thermal disorder, $\mathrm{ZnO}$ Nanoparticles spin coating and the use of physical vapor accumulation methods to store thin films. Pre-seeding can be used in ways of the above arrangement, such as electron beam lithography and nanosphere lithography, which is to be set up to develop a nuclear site prior to development. Accumulated $\mathrm{ZnO}$ nanowires can be used in dye-sensitized solar cells and field emission devices. 


\subsection{APPLICATIONS:}

Zinc oxide is used in cigarette filters due to its anti-bacterial and anti-fungal properties. Zinc oxide is used in Breakfast Cereals due to the long-term preservation to seal the bacterial activity in the cereals. Zinc Oxide is used in paint pigments as it has the unique property of absorbing and emitting the UV rays so that the paint pigments withstand for long term without any cracks and defects. Zinc Oxide paint coatings enhance the absorbability of the heat or any other rays from the outside environment according to the demands like sunscreen and UV ray protection. Zinc Oxide has the unique property of Piezoelectricity (delivering alternating current by stretching and releasing zinc oxide nanowires) it accumulates certain amount of the electric charge in the solid in response to the applied mechanical stress and this major reason for the heat and chemical detecting ability of the Zinc oxide. Zinc Oxide used in Laser diodes and Light emitting diodes (LEDs) due to is semiconductor property. It has most n-type property-type zinc oxide is used in Spintronics due to its ferromagnetism property along with the optical and electronic properties. To achieve the desired magneto moment. Used in creams used for allergy and rash protections as well due to its anti-fungal and anti-bacterial and anti-rash and sun screen protection property. Zinc oxide is used in the manufacture of rubber manufacturing in the vulcanization process. Cigarette filters are manufactured for maintaining the cigarette flavour for long term. Zinc Oxide with iron oxide helps in the removal of hydrogen sulfide and hydrogen cyanide due to its reactivity to those materials. Popularly known calamine lotion is made out of zinc Oxide Powder. It is also used in other medical diseases and ointments that are used to treat skin diseases. As an additive in the manufacture of concrete, plastics, ceramics, glass, cement, rubber, lubricants, paints, ointments, adhesive, sealants, manufacturing, pigments, foods, batteries, fire retardants. 
Various paints use zinc oxide as a coating agent. Due to its electrical and optical properties those are ideal systems for design of various devices such as: light emitting diodes, transistors or sensors of UV light, selected gases and biosensors. Among the various $\mathrm{ZnO}$ nanomaterials, the nanolayers obtained by the sol-gel process and subsequent calcination have attracted considerable interest in different applications as a result of their facile synthesis, polycrystalline nature and a high surface area to volume ratio.

In aerospace industry the $\mathrm{ZnO}$ application are also in very important sectors as in UV ray's protection coating in space industry. Fire retardant coating in many places both majorly in space industry and other industries as well. Used in different flammable gases leakage detection in sensors either poisonous or fuel leakage for saving the propellant for the further use both in aircrafts and spacecrafts and rockets as well. Those gases include ethanol and hydrazine mostly. The Solar photocatalysis Process has received increasing focus due to its great capacity as a green and eco-friendly process for the elimination of POPs that the safety of clean water can be increased. In this context, $\mathrm{ZnO}$ nanostructures are depicted as prominent photocatalyst candidates, which are likely to be used in photodegradation, they are low-cost, non-toxic and more active, in the absorption across a large fraction of the solar spectrum compared to $\mathrm{TiO} 2$. 


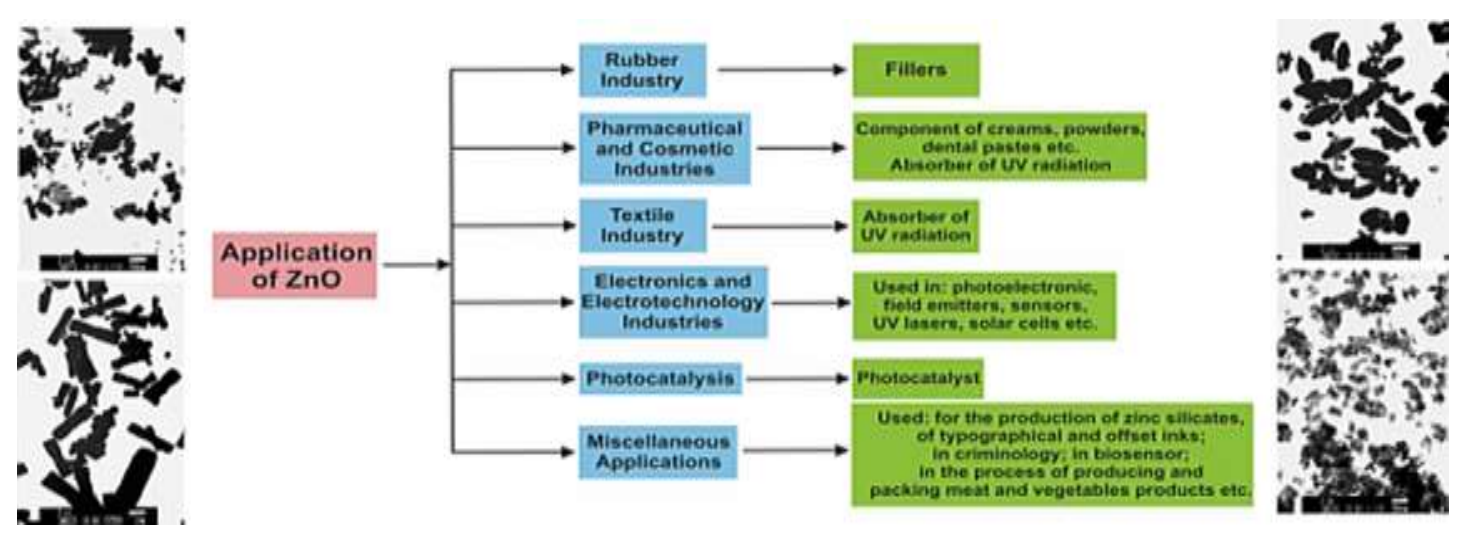

\section{FIGURE 3 DIFFERENT APPLICATIONS OF ZnO}

(Zinc Oxide - Properties, Applications and the Future for $\mathrm{ZnO}, 2011$ )

In the above figure number 3 the different applications of the Zinc oxide are shown. The different industries which are using $\mathrm{ZnO}$ predominantly is seen. 


\subsection{MARKET RESEARCH}

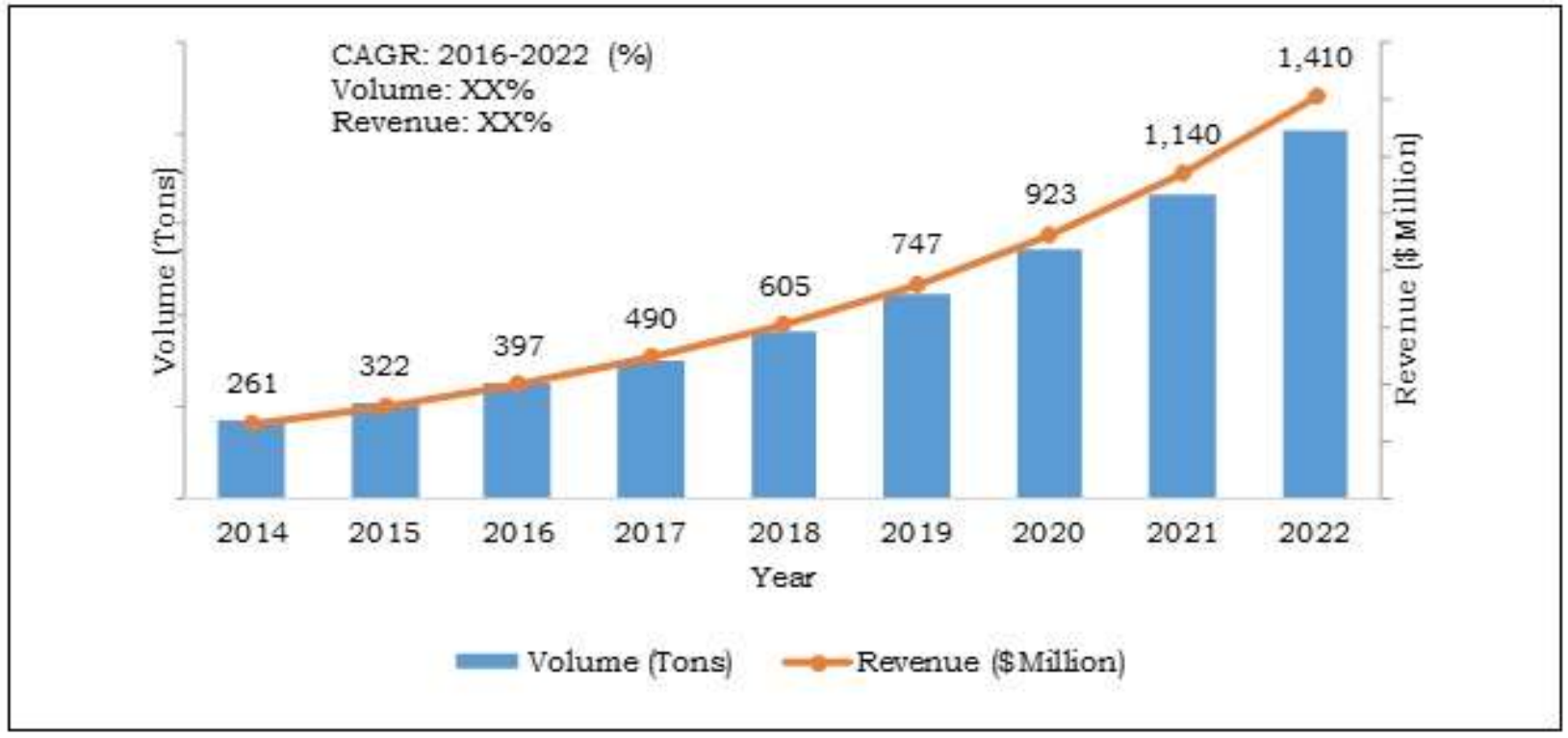

\section{FIGURE 4 REVENUE AND VOLUME CHART FOR ZINC OXIDE PRODUCTION FROM 2014 TO 2022 (Sahu, n.d.)}

In the above figure number 4 there has been substantial increase in the market demands and supplying of the Nano zinc oxide materials in the industry from 2014 and the extrapolated chart of the same is seen until 2022.It can be seen the demands is increasing gradually. 


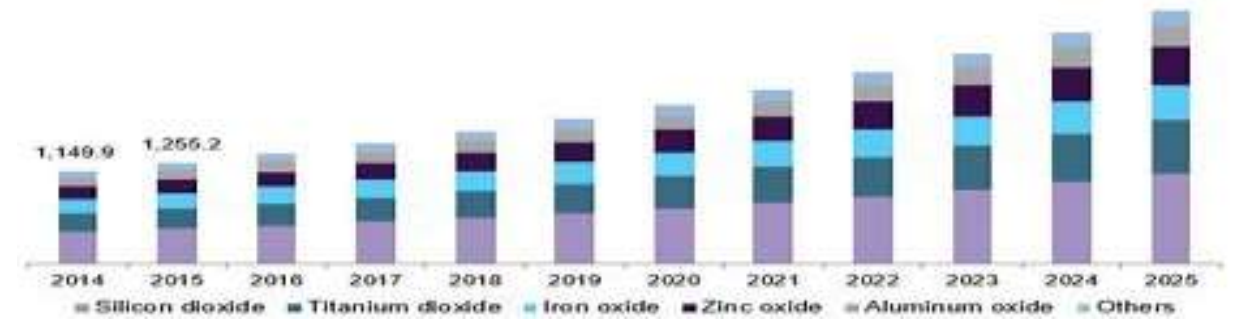

FIGURE 5 COMPARISON OF DIFFERENT METAL OXIDE MARKET FOR YEARS 2014 TO 2025 (Sahu, n.d.)

In the above figure number 5 though zinc oxide doesn't have as much as market levels of Silicon dioxide or other metal oxide, but it cannot be replaced with the other metal oxide nanomaterials due to its unique properties. Due to this there is vast increase in demand of zinc oxide in the industries. 


\section{CHAPTER 2}

\section{ZINC OXIDE SYNTHESIS AND CHARACTERIZATION.}

\subsection{EXPERIMENTAL SETUP:}

In this project, the Zinc sheet which was used for the experiment was purchased from McMaster-Carr and small sample pieces were made to fit in petri plates. Clark-MXR IMPULSE pulsed Yb-doped fiber-amplified femtosecond laser to ionize zinc sheets in ambient conditions synthesized nanostructures. The below parameters were kept constant-power at 16-watt, laser wavelength at $1030 \mathrm{~nm}$ polarized circular, and pulse width at $214 \mathrm{fs}$. An array of 20 lines of $5 \mathrm{~mm}$ length were fabricated. EzCAD software was used along with the piezo-driven scanner for plotting the array. Different scanning speeds and repetition rates were used for fabrication and these are indicated in the images names for instance $0 \_5 \_4$ indicates $0.5 \mathrm{~mm} / \mathrm{s}$ of scanning speed and at the repetitions of $4 \mathrm{MHz}$. The etch depth was achieved by changing scanning speed control. By changing repetition rate the Control on generation of peak power for each pulse can be achieved. So, the energy transmitted to the sample surface was controlled. As a result, the morphology of nanostructures can be adjusted and programmed as required. (Rupa Haldavnekar, 2018) 


\subsection{FESEM:}

The both improved spatial resolution and minimized sample charging and damage is achieved by using the field-emission cathode in the electron gun of a scanning electron microscope which provides narrower probing beams at low as well as high electron energy, the electrons generated by a Field Emission Source are accelerated in a field gradient under the vacuum conditions. The beam passes through Electromagnetic Lenses, focussing onto the specimen. As a result of this bombardment different types of electrons are emitted from the specimen. The secondary electrons are detected by the detector and an image of the sample surface is constructed by comparing the intensity of these secondary electrons to the scanning primary electron beam. At last the image will be displayed on a monitor.

These images were used to analyse the morphology of the material with the GATAN software to see the characteristics of particles and rods of the material. Field Emission Scanning Electron Microscope (FE-SEM)

An FE-SEM (Hitachi SU8230) was used to perform ultra-high-resolution imaging of the nanomaterials. The minimal heating of the filament is obtained by cold field emission source of electrons in an FE-SEM. This helps in obtaining better resolution images of the specimen. The better understanding of the 3D structure of the nanonetworks was achieved with the help of better resolution images. Furthermore, to observe the extent of coverage due to hybridisation highly contrasting images of the plasmon hybridised nanomaterial were acquired. 


\subsection{HRTEM:}

The specifications of experimental setup used to test the samples are from University of Toronto,

(Zinc Oxide - Properties, Applications and the Future for ZnO, 2011)

\begin{tabular}{|l|}
\hline Features of HRTEM \\
\hline JOEL 2010 JEM \\
\hline 200kV high resolution TEM \\
\hline LaB6 filament \\
\hline Lattice resolution-0.14nm \\
\hline Routine automatic lattice imaging \\
\hline Thermo Noran System 6EDX \\
\hline AMT 8M Digital camera \\
\hline
\end{tabular}

\section{TABLE 5 HRTEM EXPERIMENTAL SET UP FEATURES}

Table 5 shows the specifications of the experimental setup used for the HRTEM. A High Resolution-Transmission Electron Microscope can generate an interference image by using both transmitted and scattered beam of electrons. This enables phase contract images to be created which can project 2D images of a crystal. The HR-TEM (JOEL 2010) was used to study the crystal orientations of the nanospheres in the nanomaterial and measure the d-spacing of the crystal lattice. The HR-TEM is also an ideal tool to image the defects in a crystal. 
The high-resolution transmission electron microscopy (HRTEM) is very powerful tool as it uses both the transmitted and the scattered beams to create an interference image. The image can be as small as the unit cell of crystal as it is a phase contrast. The outgoing modulated electron waves at very low angles interfere with itself during propagation through the objective lens. All electrons emerging from the specimen are combined at a point in the image plane. HRTEM has been used for analyzing crystal structures and lattice imperfections in various kinds of advanced materials on an atomic resolution scale. It is used for the characterization of point defects, stacking faults, dislocations, precipitates grain boundaries, and surface structures. Atomic resolution scale. It can be used for the characterization of point defects, stacking faults, dislocations, precipitates grain boundaries, and surface structures.

\subsection{SAED:}

SAED is the diffraction pattern obtained in the reverse space of lattice pattern. Spreading of waves around obstacles is called the diffraction. The sharp shadows are not produced in the diffraction. The phenomenon is most noticeable when the wavelength of the radiation is comparable to the linear dimensions of the obstacle. When a beam of light falls on the edge of an object, it will be deflected down by the contact, causing a blur at the edge of the shadow of the object. The

amount of bending is proportional to wavelength. The monochromatic beam of light falls on a single edge, a sequence of light and dark bands is produced due to interference; and with white light a sequence of colours much like the Newton colour sequence appears. 
SAED is the interpretation pattern obtained in the Reverse Space of the Lattice pattern. It is used to find the crystal planes d-space, to find radius of the pictures the brightest center SAED pattern was identified. Then the d-spacing was calculated using the camera continuously.

Using the data base, then we can find the exact cell parameter and the distribution pattern's merger index.

SAED is used to determine if the sample is disabled or crystalline if the wider rings are found, it is disorderly and crystalline (shiny spots), poly nanocrystalline (small spots make one ring, each spot is made from a separate crystal, from Bragg's reflection Is produced), find your sample's crystalline page (each stage has a special SAED pattern

\subsection{FTIR:}

This method was used to identify chemical bonds in a molecule by producing infrared absorption spectrum and also reveals the molecular structure. Fourier Transform Infrared Spectroscopy experimental setup was used from ANALEST.FTIR used for this project is by (DRIFT) methodDiffuse Reflectance Infrared Fourier Transform Spectroscopy. The following are the parts used in this method, Perkin Elmer Diffuse Reflectance Sampling Accessory and Harrick Praying Mantis DRIFT Accessory with Ambient Sampling Chamber

\subsection{XPS}

XPS is a surface sensitive technique to determine the chemical state of the material. The characterisation of the functionalised Titanium and nanomaterials was done using an XPS (Themo Scientific K-Alpha). Aluminum k-Alpha X rays are used as beam source to excite the samples and 
cause emission of photoelectrons. An analyser then measures the energy of the photoelectrons. The basic theory of photo-altitude effect was represented by Einstein. There is a frequency under which the light fails to extract the electrons from the metal surface regardless of the severity. hvc> eFm, where h - Planck constant (6.62 x 10-34 j), v-radiation, frequency (Hz) Photo Electron Spectroscopy, such as XPS, Auger and UPS, Photon Energy varies from 20 to $1500 \mathrm{eV}$ In the case of maximum levels, up to $10,000 \mathrm{EV})$ is much higher than the function values $(2-5 \mathrm{EV})$ of a particular task. In these techniques, the speed of the output of the exit photo electrons (i.e., the number of electronic electrons for their speed power function) can be measured using any correct electronic energy analyzer and a photo electron spectrum can be recorded. Using Photo-ionization and Energy-Distributor Analysis, using photo electrons, the surface area of a sample can be composed and studied in the electronic state. 


\section{CHAPTER 3}

\section{RESULTS AND DISCUSSION}

\subsection{FESEM ANALYSIS:}

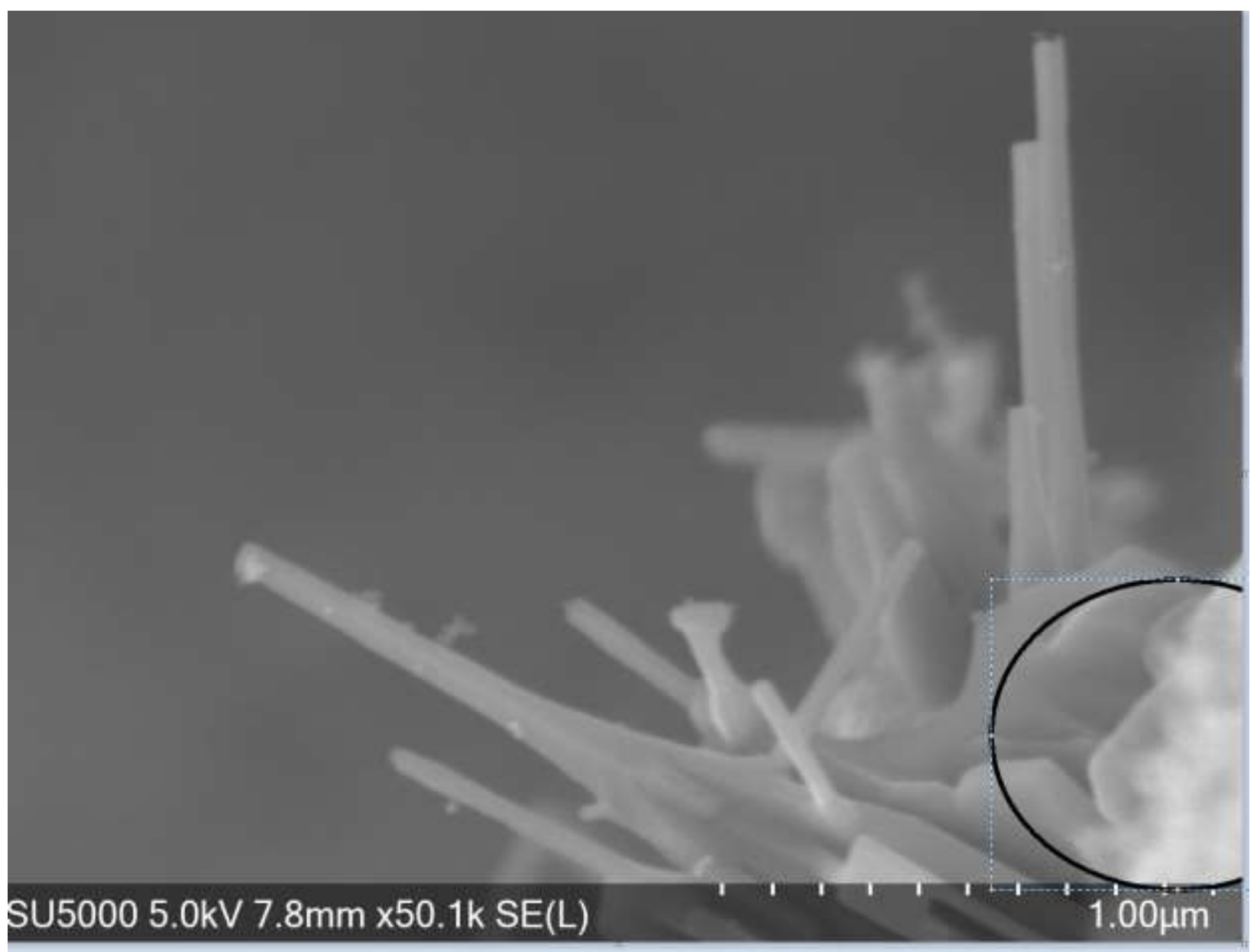

FIGURE- 6 0-5-4-NITROGEN25 (Rupa Haldavnekar, 2018)

For the understanding purpose the numbers indicated for the figure names are as follows 
In the above figure 6 , the first two digits are in the format $0.5 \mathrm{~mm} / \mathrm{seconds}$ of scanning speed and the last digit is in the format of $4 \mathrm{MHz}$ of the repetition rate. Visually, it can be seen that there are some ambiguous areas. In the figure 6 it is indicated by the circle. These can be called as defects. These are illuminated properly using the software's before analysing for the morphology.

FESEM analysis was carried out using the Image $\mathbf{J}$ software. Initially, the scale is set as per the image for example this picture was needed to be set to $1000 \mathrm{~nm}$ which is 1 micrometer scale and the pixels were calibrated automatically when the image was imported. And the line profile tool was used to the draw the lines along the rods to measure the lengths of the rods .Here, 10 number of rods were measured to measure the average length of the rods in that particular image and the respective areas, mean, minimum, maximum and angle of the rods aligned is also derived. Then the average was generated in the excel sheet.

For the nanoparticle distribution, Image $\mathbf{J}$ software was used like the previous case the scales were set according to the image and the pixel calibration was automatically generated by the software. Then the figure number 6 image was duplicated for the clarity of the particles due to its small scale. To make sure the values to be precise the band pass filter was used to neglect the surrounding disturbances to clear the picture further. And, then the threshold was adjusted using image command bar to get the image with the flattened view and circularity was also adjusted either increased or decreased according to the picture demands. The picture was cleared, the extra rods were removed as the motive was to analyse the particles. The image is analysed by using different shapes tools accordance with the visible shape in the image to give the particle analyzation which gives the skews, Kurt and standard deviation, mean median and area of the selected particle or rods are done using the origin and the excel software. The histogram and the scatter plot are seen 
if the bell curve matches with that and the sizes of the particles which were well above the bell curve and below the bell curve were derived

\section{d Results}

\begin{tabular}{l|l|l|l|l|l|l|l}
\multicolumn{2}{c}{ File Edit } & Font & Results \\
\multicolumn{2}{l}{ Area } & Mean & Min & Max & Angle & Length & \\
\hline 1 & 2136.410 & 152.019 & 129 & 181.964 & -26.800 & 1078.269 \\
2 & 652.249 & 145.989 & 137 & 158.442 & -36.663 & 327.669 \\
3 & 628.815 & 156.655 & 119.949 & 171.075 & -72.924 & 316.316 \\
4 & 636.627 & 172.596 & 147 & 185.235 & -58.671 & 319.278 \\
5 & 2101.259 & 138.056 & 123.263 & 154.602 & -86.158 & 1061.673 \\
6 & 695.212 & 132.563 & 101 & 146.983 & -1.618 & 349.941 \\
7 & 1093.592 & 154.039 & 142.240 & 188.716 & -124.202 & 551.981 \\
8 & 851.439 & 121.037 & 81.101 & 255 & -25.974 & 428.675 \\
9 & 1128.743 & 127.053 & 97.965 & 158.480 & -67.977 & 569.200 \\
10 & 566.324 & 128.370 & 117.203 & 169 & -25.137 & 283.794
\end{tabular}

\section{FIGURE 7 RESULTS OF LENGTH OF THE RODS 0_5_4_NITROGEN25}

In the above figure number 7 the area of the rods selected to measure from the image is shown in the first column, the second column shows the mean of the area of the rods selected, the third and fourth column shows the minimum and maximum values of the range from which the mean was derived is shown, fifth column shows the angle with which the rods were aligned to the horizontal axis is shown. The above results from the figure number 7 shows the maximum length which can be noted is $1078.269 \mathrm{~nm}$ and lowest is the $283.794 \mathrm{~nm}$ and the corresponding areas are also minimum and maximum respectively. 


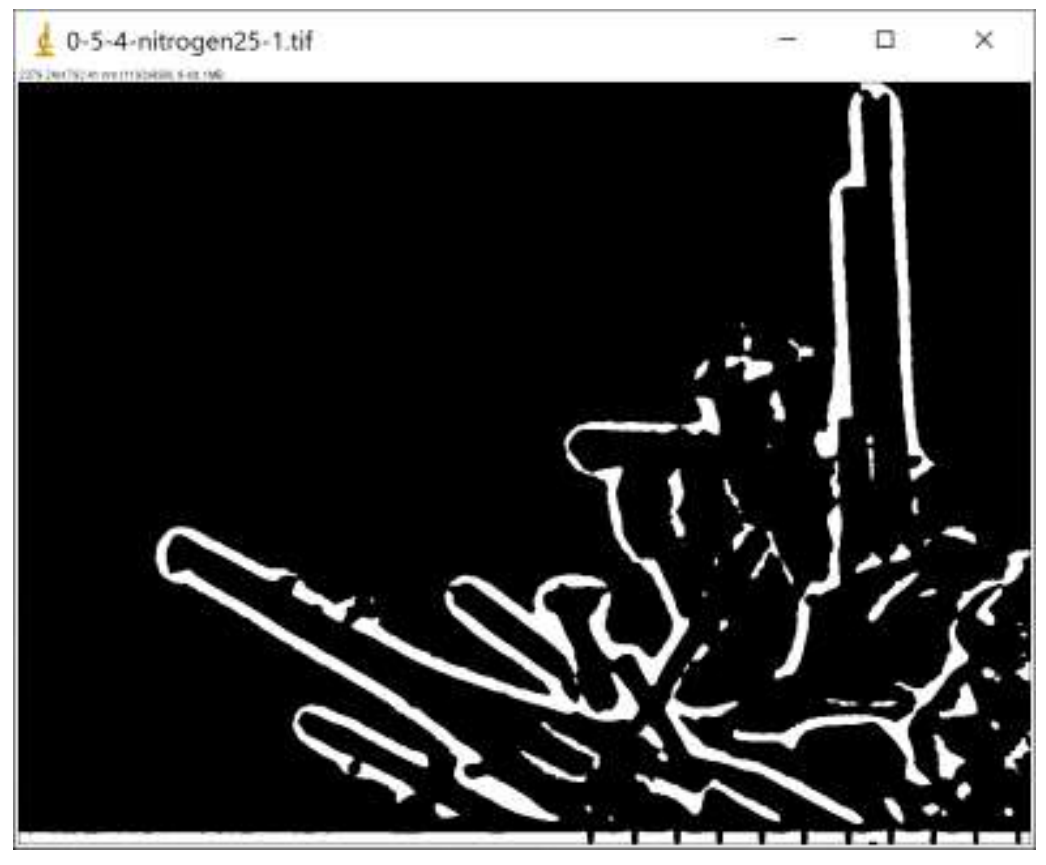

FIGURE 8 ILLUMINATED FIGURE OF THE FESEM IMAGE AFTER APPLYING BANDPASS FILTER

From the figure number 8 the particles were analysed to get the following results. The following is the summary of the results of the figure number 6 . As the particle frequency is large in number in many cases the values are shown in the excel file in appendices clearly. But the summary of those results is given as below.

\section{Summary}

\begin{tabular}{l|l|l|l|l|l|l} 
File Edit & \multicolumn{1}{c}{ Font } \\
\hline Slice & Count & Total Area & Average Size & $\%$ Area & Mean & \\
\hline 0-5-4-nitrogen25-1.tif & 11 & 695.190 & 63.199 & 0.020 & 255
\end{tabular}


In the above summary for the figure number 6 , the software was able to identify 11 particles, the count indicates the number of particles detected. The total area indicates the area analysed. The average size is particle's average size and the \% area is the percentage of the ratio of area analysed to the total area. The mean is the particle size mean. The same process was followed for the rest of the images as well.

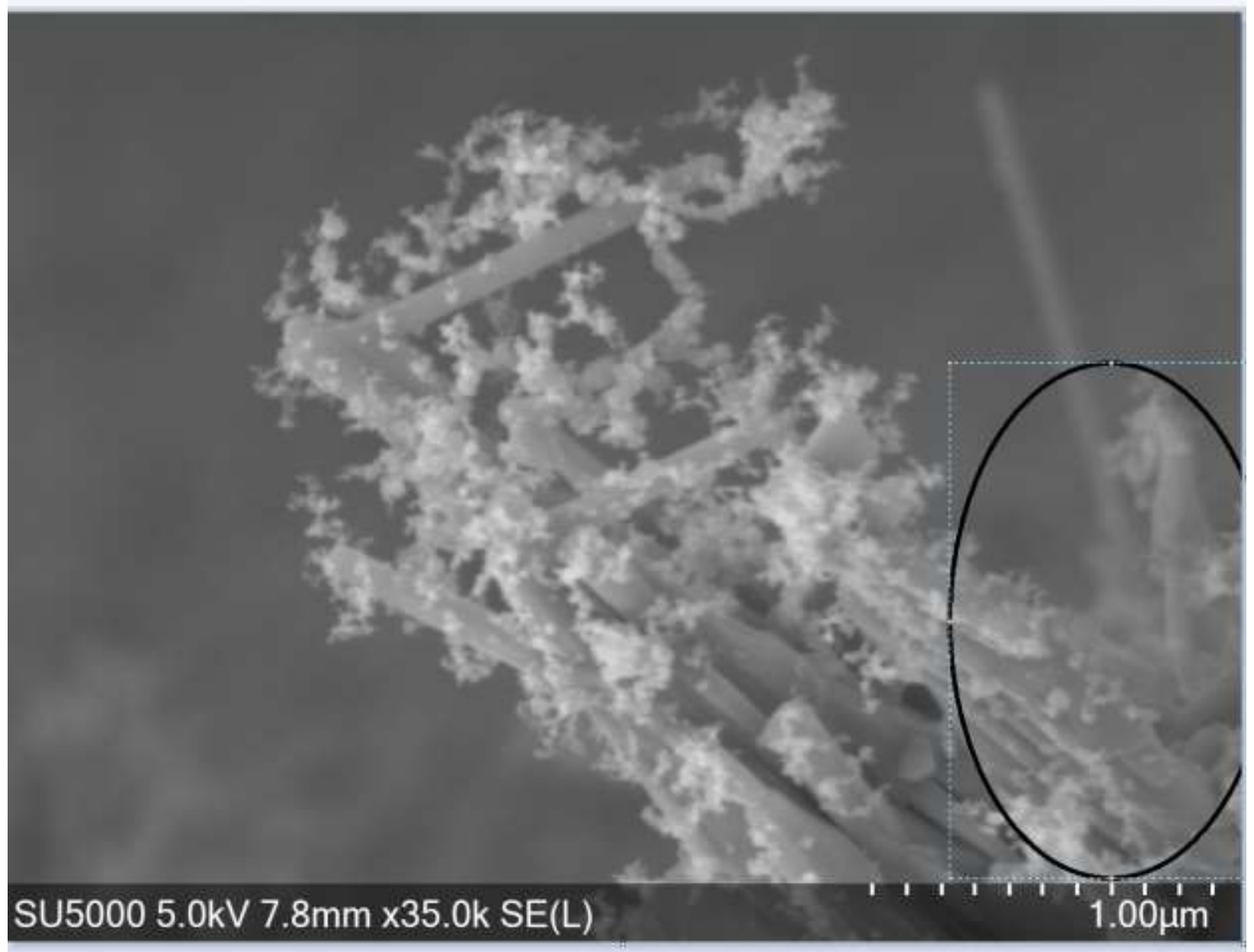

FIGURE 9 0-5-4-NITROGEN 26 (Rupa Haldavnekar, 2018)

Like the previous case, the above figure number 9 was generated at the scanning speed of $0.5 \mathrm{~mm} / \mathrm{s}$ and at the repetition rate of $4 \mathrm{MHz}$.Visually, the rods can be seen and there are misty flakes upon 
the rods which are the particles indication. In the figure 9 it is indicated using circle where the rods bases are not certain. These can be called as defects occurred due to the experimental conditions.

\section{d Results}

\begin{tabular}{l|l|l|l|l|l|l|l}
\multicolumn{2}{c}{ File $\quad$ Edit } & Font & \multicolumn{3}{l}{} \\
\multicolumn{2}{l}{ Results } \\
\hline & Area & Mean & Min & Max & Angle & Length & \\
\hline 1 & 1411.905 & 157.453 & 133.666 & 210 & -37.610 & 489.678 & \\
2 & 3360.498 & 140.612 & 120.404 & 189.727 & 26.502 & 1165.540 & \\
3 & 2006.391 & 158.997 & 140 & 190.622 & -27.306 & 695.270 & \\
4 & 3525.633 & 126.043 & 97.951 & 191.161 & -27.708 & 1223.610 & \\
5 & 3525.633 & 126.043 & 97.951 & 191.161 & -27.708 & 1223.610 & \\
6 & 4004.525 & 111.823 & 96 & 122.782 & -73.664 & 1389.375 & \\
7 & 1882.539 & 129.190 & 94 & 191.162 & -48.387 & 653.362 \\
8 & 891.729 & 118.763 & 101.415 & 149.616 & -40.079 & 307.943 & \\
9 & 3657.741 & 131.115 & 101.525 & 168.073 & -37.000 & 1270.071 \\
10 & 1568.783 & 111.136 & 74.096 & 172.584 & -34.026 & 544.329 &
\end{tabular}

FIGURE 10 RESULTS OF LENGTHS OF RODS OF 0_5_4_NITROGEN 26

In the above figure number 10 , as discussed earlier, the area of the different rods selected are shown.And the mean of the ranges from minimum and maximum values of the area is also shown. The angle at which the rods are oriented to the horizontal axis is shown. The maximum length was noticed to be $1389.375 \mathrm{~nm}$ and the lowest length was noticed to be $307.943 \mathrm{~nm}$. 


\section{d Summary}

\begin{tabular}{l|l|l|l|l|l|l}
\multicolumn{1}{c}{ File Edit } & \multicolumn{1}{l}{ Font } \\
\hline Slice & Count & Total Area & Average Size & $\%$ Area & Mean & \\
\hline 0-5-4-nitrogen26.tif & 711 & 797147.993 & 1121.165 & 8.038 & 252.822 &
\end{tabular}

In the above summary of the results, the number of particles identified by the software for the image in the figure number 9 is 711 indicated by count .This summary is of nanoparticle distribution, it shows the total area was analysed in the image and the average size is the particle's average size and the \%area is the percentage of the area analysed to the whole area of the image and the mean is the mean of the particle's size of all 711 particles. 


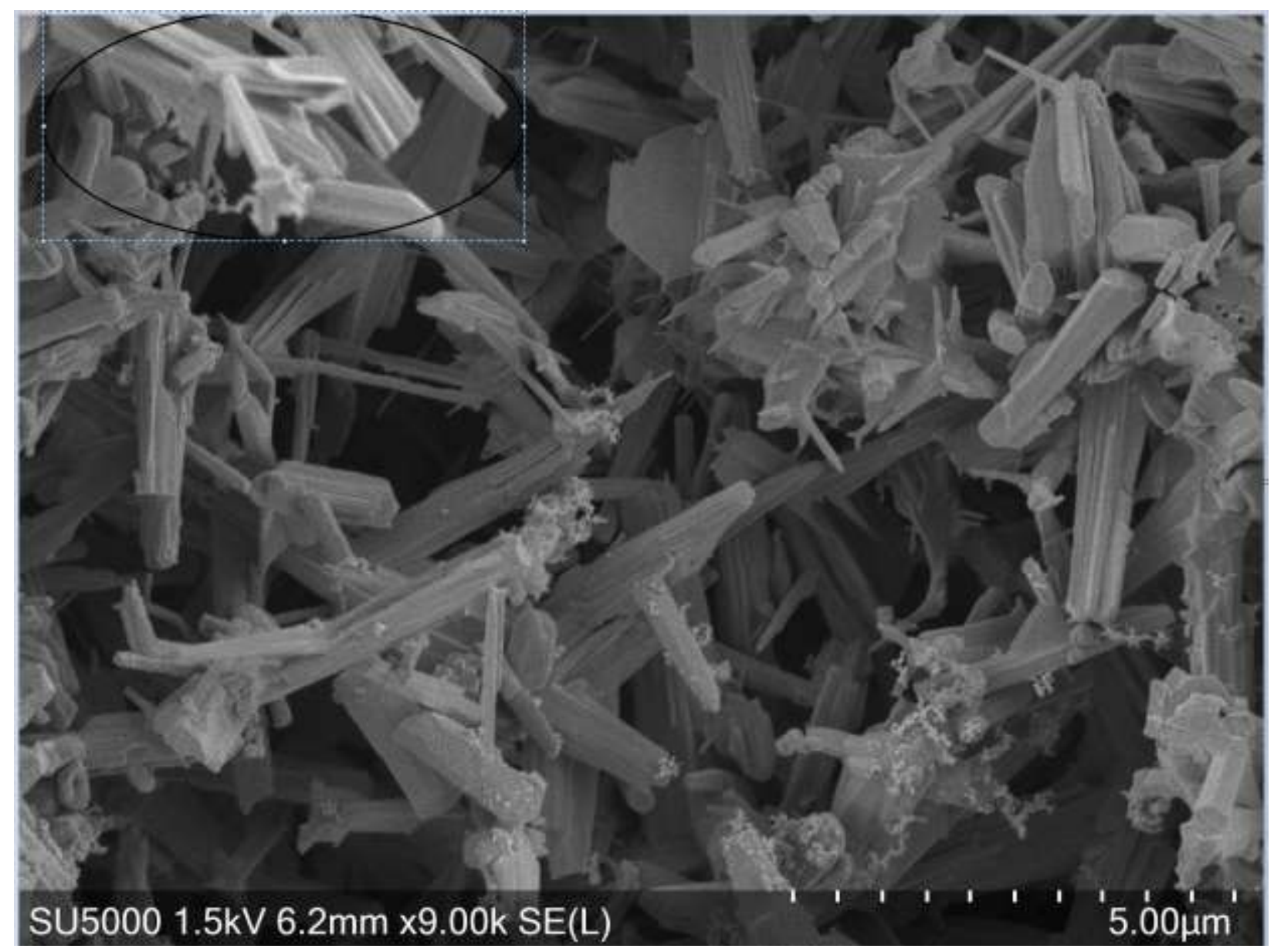

FIGURE 11 2.5-4-4 (Rupa Haldavnekar, 2018)

The above image was generated at $2.54 \mathrm{~mm} / \mathrm{sec}$ and the repetition rate of $4 \mathrm{MHz}$ as indicated in the figure name.Visually, here the rods are visible along with the small flakes which are the indication of the particles.In the figure 11 it is seen that the particular part is only bright whilethe rest of the image is all properly illuminated.Due to the light reflection or due to any other reason of experimental conditions this particular area is not clear. This can also be called as defects as there is no clarity in the surface finsih. 


\section{d Results}

\begin{tabular}{|c|c|c|c|c|c|c|}
\hline & Edit & \multirow{2}{*}{$\begin{array}{l}\text { Font } \\
\text { Mean }\end{array}$} & \multicolumn{2}{|l|}{ Results } & \multirow[b]{2}{*}{ Angle } & \multirow[b]{2}{*}{ Length } \\
\hline & Area & & Min & Max & & \\
\hline 1 & 18182.777 & 116.757 & 63.926 & 184.101 & 28.006 & 3312.521 \\
\hline 2 & 8144.682 & 135.483 & 95.199 & 187.847 & -12.184 & 1481.029 \\
\hline 3 & 10458.854 & 88.079 & 66.733 & 119.371 & -77.848 & 1899.656 \\
\hline 4 & 15387.739 & 100.952 & 44.380 & 145.658 & -97.195 & 2799.704 \\
\hline 5 & 19384.945 & 137.125 & 86.626 & 224.656 & -29.348 & 3531.432 \\
\hline 6 & 6551.811 & 96.133 & 75.330 & 151.169 & 20.772 & 1189.191 \\
\hline 7 & 5529.969 & 92.733 & 45.110 & 128.533 & -7.512 & 1002.769 \\
\hline 8 & 9917.879 & 118.220 & 77.848 & 165.476 & -39.828 & 1806.275 \\
\hline 9 & 6431.594 & 162.003 & 116.123 & 210.385 & -22.703 & 1166.167 \\
\hline 10 & 7723.924 & 181.738 & 109.526 & 254 & -66.537 & 1401.302 \\
\hline
\end{tabular}

FIGURE 12 RESULTS OF THE LENGTHS OF THE RODS OF 2.5_4_4

The above figure number 12, as explained earlier the results show the maximum length of the rods in the 3531.432nm among the rods in this image and the minimum rod length 1002. 769nm.And the corresponding areas are the maximum and minimum's respectively. 


\section{d Summary}

File Edit Font
\begin{tabular}{l|l|l|l|l|l|l} 
Slice & Count & Total Area & Average Size & $\%$ Area & Mean & \\
\hline 2.5-4-1.jpg & 2 & 786.074 & 393.037 & $6.572 \mathrm{E}-4$ & 255
\end{tabular}

In the above summary of the results of particle's distribution, it can be understood that the software detected 2 number of particles only even though the area was analysed is $786.074 \mathrm{~nm}$. This says that at this particular scanning speed and the repetition rate there is no precise results were generated which is not the same case in the previous figure. 


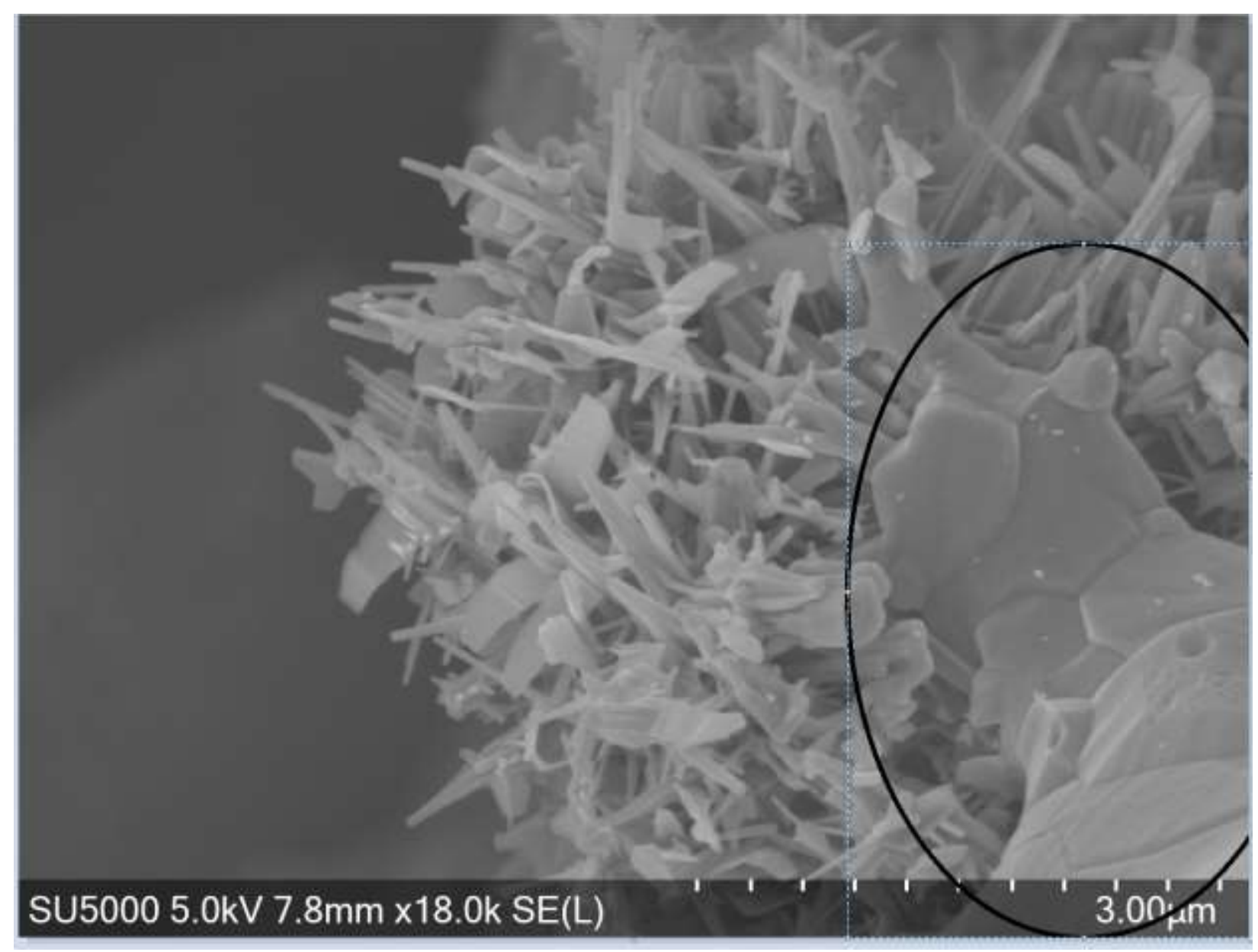

FIGURE 13 0-5-25-NITROGEN19 (Rupa Haldavnekar, 2018)

The above figure number 13 was generated at the scanning speed of $0.5 \mathrm{~mm} / \mathrm{s}$ and at the repetition rate of 25MhZ.Visually, the rods are more visible than the particles. In the figure 13 it can be seen there is pure distortion masking on the rods. It can be due to the scanning speed or due to any other obstruction. This a major defect. 


\section{d Results}

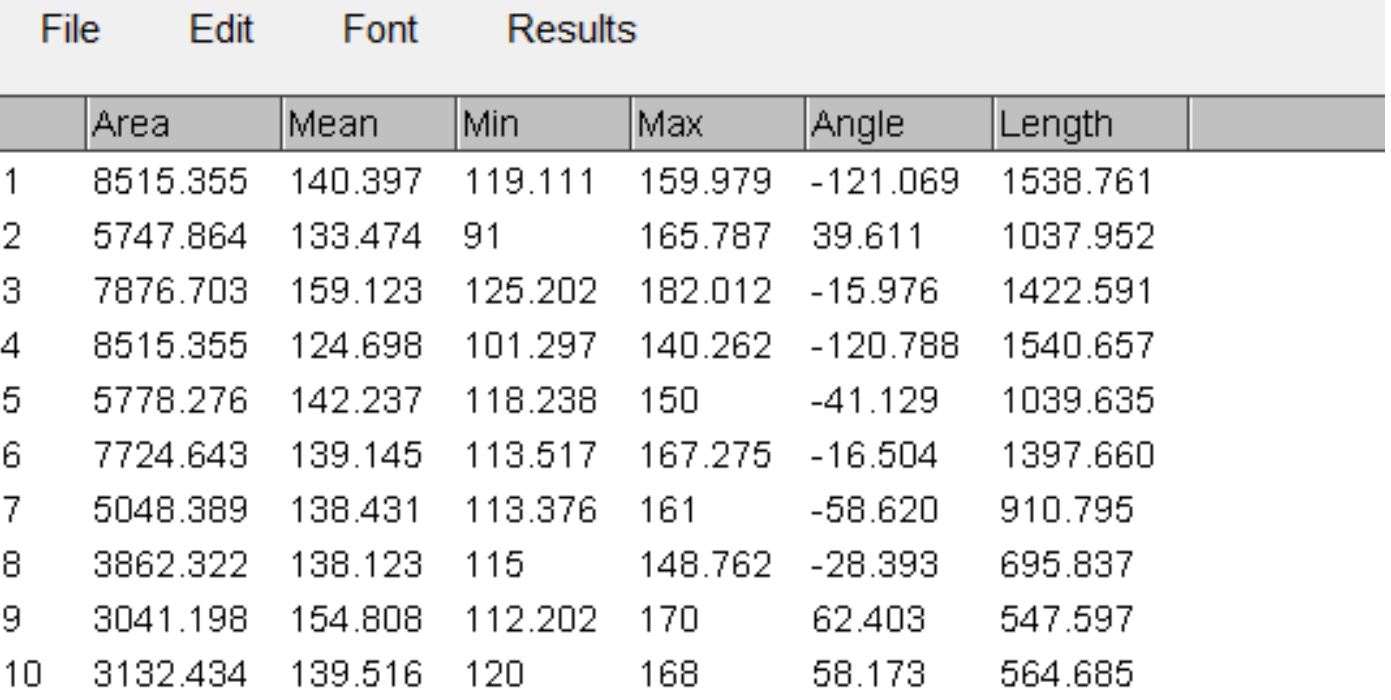

FIGURE 14 RESULTS OF THE LENGTHS OF THE RODS OF 0_5_25_NITROGEN 19

The above figure 14 shows the maximum length of the rod 1540nm and the minimum length of the rod is $547.597 \mathrm{~nm}$. The corresponding areas are maximum and minimum areas of the rods.

\section{Summary}

File Edit Font
\begin{tabular}{|l|l|l|l|l|l|l}
\hline Slice & Count & Total Area & Average Size & $\%$ Area & Mean & \\
\hline 0 -5-25-nitrogen19-2.tif & 209 & 2513032.189 & 12024.077 & 8.980 & 254.676
\end{tabular}


The above summary shows the particle count of 209 and the mean particle size is $254.676 \mathrm{~nm}$. The particle count is much higher than the previous case which indicates this experimental specification is suitable for exhibiting more morphological characteristics of $\mathrm{ZnO}$ material compared to the previous image with different experimental specifications.

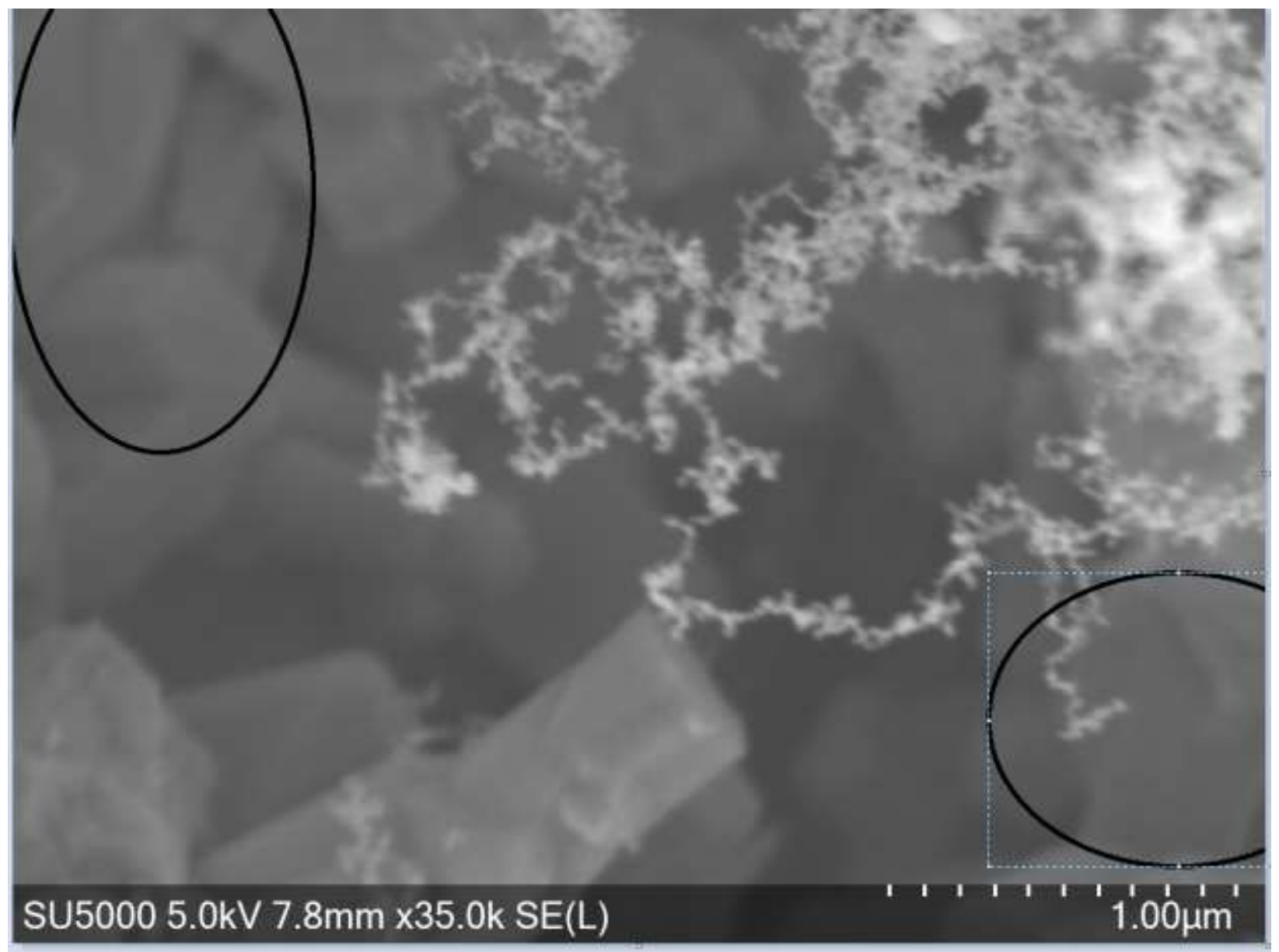

FIGURE 15 0-5-12-NITROGEN13 (Rupa Haldavnekar, 2018)

The above figure number 15 was generated at the scanning speed of $0.5 \mathrm{~mm} / \mathrm{s}$ and at the repetition rate of $12 \mathrm{MHz}$.Visually, both the rods and particles can be seen in different levels of layers. In the 
figure number 16 there is no clarity in rods alignment and start and end of the rods are not clearly visible. This is also an imperfection.

\section{d Results}

\begin{tabular}{|c|c|c|c|c|c|c|}
\hline & le & \multicolumn{3}{|c|}{ Results } & \multirow[b]{2}{*}{ Angle } & \multirow[b]{2}{*}{ Length } \\
\hline & Area & Mean & Min & Max & & \\
\hline 1 & 3517.173 & 122.186 & 52.575 & 255 & 40.323 & 1221.103 \\
\hline 2 & 2022.787 & 96.738 & 88.504 & 108.787 & 30.036 & 700.331 \\
\hline 3 & 2501.651 & 96.819 & 90.455 & 103.566 & -20.534 & 868.334 \\
\hline 4 & 2988.771 & 97.918 & 87 & 108.922 & 45.561 & 1038.290 \\
\hline 5 & 1560.436 & 98.216 & 83.253 & 106.717 & -98.259 & 540.049 \\
\hline 6 & 2402.576 & 94.905 & 90 & 100.800 & -16.244 & 832.014 \\
\hline 7 & 1362.285 & 103.897 & 98.658 & 111.415 & -57.475 & 470.286 \\
\hline 8 & 1659.511 & 103.199 & 89.592 & 113.312 & 18.344 & 575.170 \\
\hline 9 & 1989.762 & 107.014 & 98.691 & 114.053 & -22.510 & 690.495 \\
\hline 10 & 1420.079 & 106.231 & 101 & 113.858 & -37.875 & 491.422 \\
\hline
\end{tabular}

FIGURE16 RESULTS OF THE LENGTHS OF THE RODS 0_5_12_NITROGEN 13

The above figure 16 shows the maximum length of $1221.103 \mathrm{~nm}$ and the minimum length of the rod is $470.286 \mathrm{~nm}$. The corresponding areas are also maximum and minimum areas of the rods respectively. 


\section{Summary}

File Edit Font

\begin{tabular}{l|l|l|l|l|l|l}
\hline Slice & Count & Total Area & Average Size & $\%$ Area & Mean & \\
\hline 0-5-12-nitrogen13-1.tif & 1 & 40.353 & 40.353 & $6.314 \mathrm{E}-4$ & 255
\end{tabular}

In the above summary, the software could only detect only 1 particle. It can be understood that this sample has less number particles to detect.

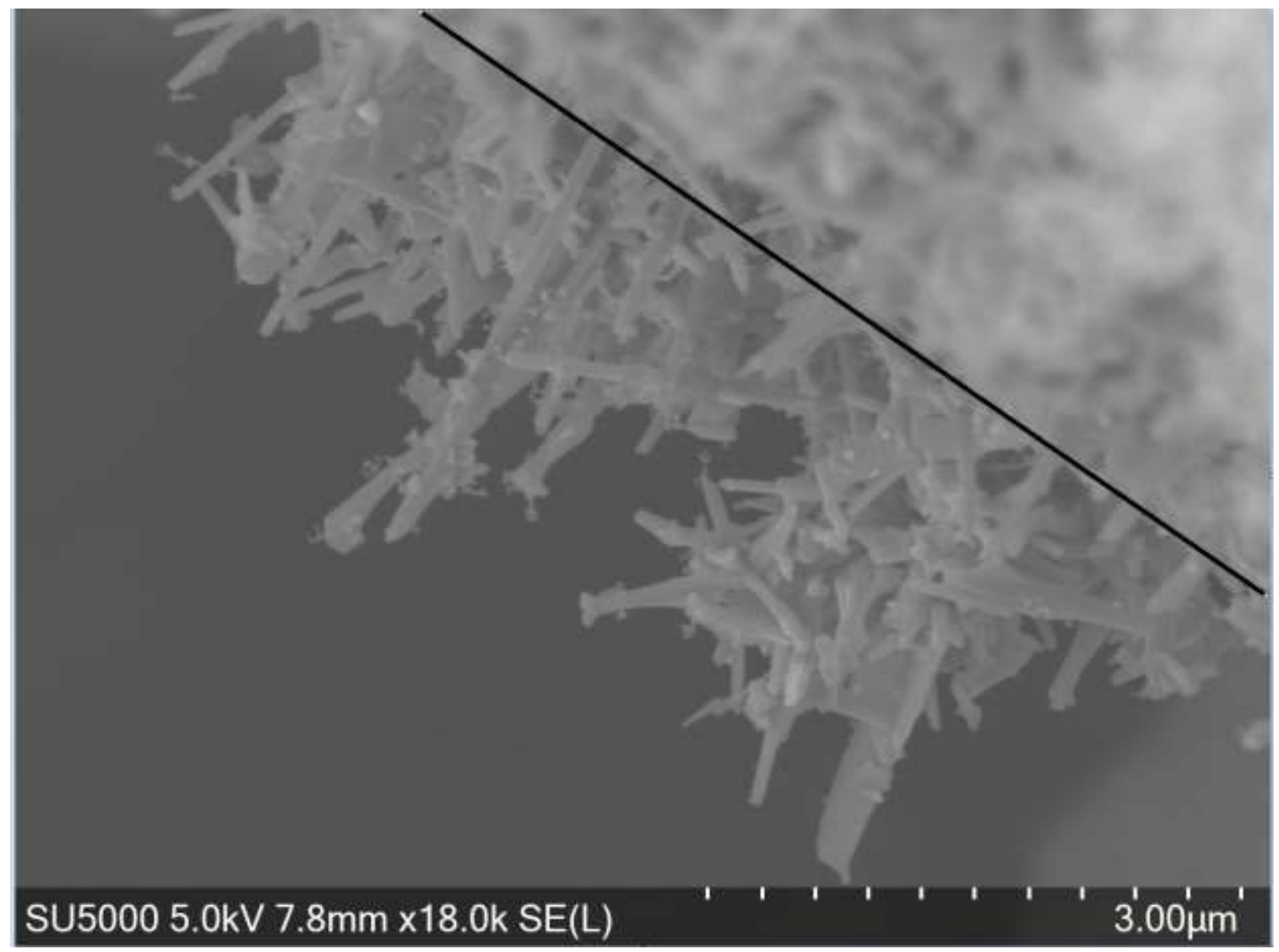


FIGURE.17 0-5-12-NITROGEN5 (Rupa Haldavnekar, 2018)

The above figure number 17, was generated at the scanning speed of $0.5 \mathrm{~mm} / \mathrm{sec}$ and at the repetition rate of $12 \mathrm{MHz}$.Visually, both the particles and the rods are visible in this image. In the figure 18 it is shown by drawing a line that the one side of the line is completely clear and other side is completely clouded due to different reasons. The reasons can be like obstructions or impact of repetition rate or the microscopy imperfection.

\begin{tabular}{|c|c|c|c|c|c|c|}
\hline File & Edit & Font & \multicolumn{2}{|c|}{ Results } & & \\
\hline & Area & Mean & Min & $\operatorname{Max}$ & Angle & Length \\
\hline 1 & 14975.349 & 129.377 & 114.695 & 144.599 & -117.726 & 2693.754 \\
\hline 2 & 7318.548 & 126.374 & 116.367 & 146 & 42.095 & 1315.262 \\
\hline 3 & 4428.029 & 125.719 & 114.980 & 143.042 & 49.834 & 790.957 \\
\hline 4 & 4428.029 & 125.719 & 114.980 & 143.042 & 49.834 & 790.957 \\
\hline 5 & 8517.806 & 124.831 & 91.138 & 151.603 & -12.124 & 1531.383 \\
\hline 6 & 8517.806 & 124.831 & 91.138 & 151.603 & -12.124 & 1531.383 \\
\hline 7 & 3382.522 & 127.320 & 86 & 137.596 & -103.782 & 605.224 \\
\hline 8 & 3382.522 & 127.320 & 86 & 137.596 & -103.782 & 605.224 \\
\hline 9 & 12115.580 & 127.141 & 108.740 & 150.085 & -6.582 & 2177.011 \\
\hline 10 & 9286.561 & 126.818 & 103.724 & 145.807 & -113.074 & 1669.610 \\
\hline 11 & 3259.521 & 139.262 & 131 & 152.303 & -23.629 & 581.066 \\
\hline 12 & 2244.765 & 129.847 & 89 & 138.530 & -101.155 & 401.296 \\
\hline 13 & 3136.521 & 113.839 & 98 & 126.299 & 34.946 & 561.500 \\
\hline
\end{tabular}

FIGURE 18 RESULTS OF THE LENGTHS OF THE RODS 0_5_12NITROGEN5

The figure 18 shows the maximum length of the rod is $2693.754 \mathrm{~nm}$ and the minimum length of the rod is $401.296 \mathrm{~nm}$. And the corresponding angles are angles oriented to the $\mathrm{x}$-axis. 


\section{d Summary}

\begin{tabular}{l|l|l|l|l|l|l}
\multicolumn{1}{c}{ File Edit Font } \\
\hline Slice & Count & Total Area & Average Size & $\%$ Area & Mean & \\
\hline $0-5-12-$ nitrogen5-1.tif & 835 & 1123496.352 & 1345.505 & 3.680 & 254.984
\end{tabular}

The above summary shows the 835 particles. The figure number 18 also can been seen clearly that there are many particles located on that phase.

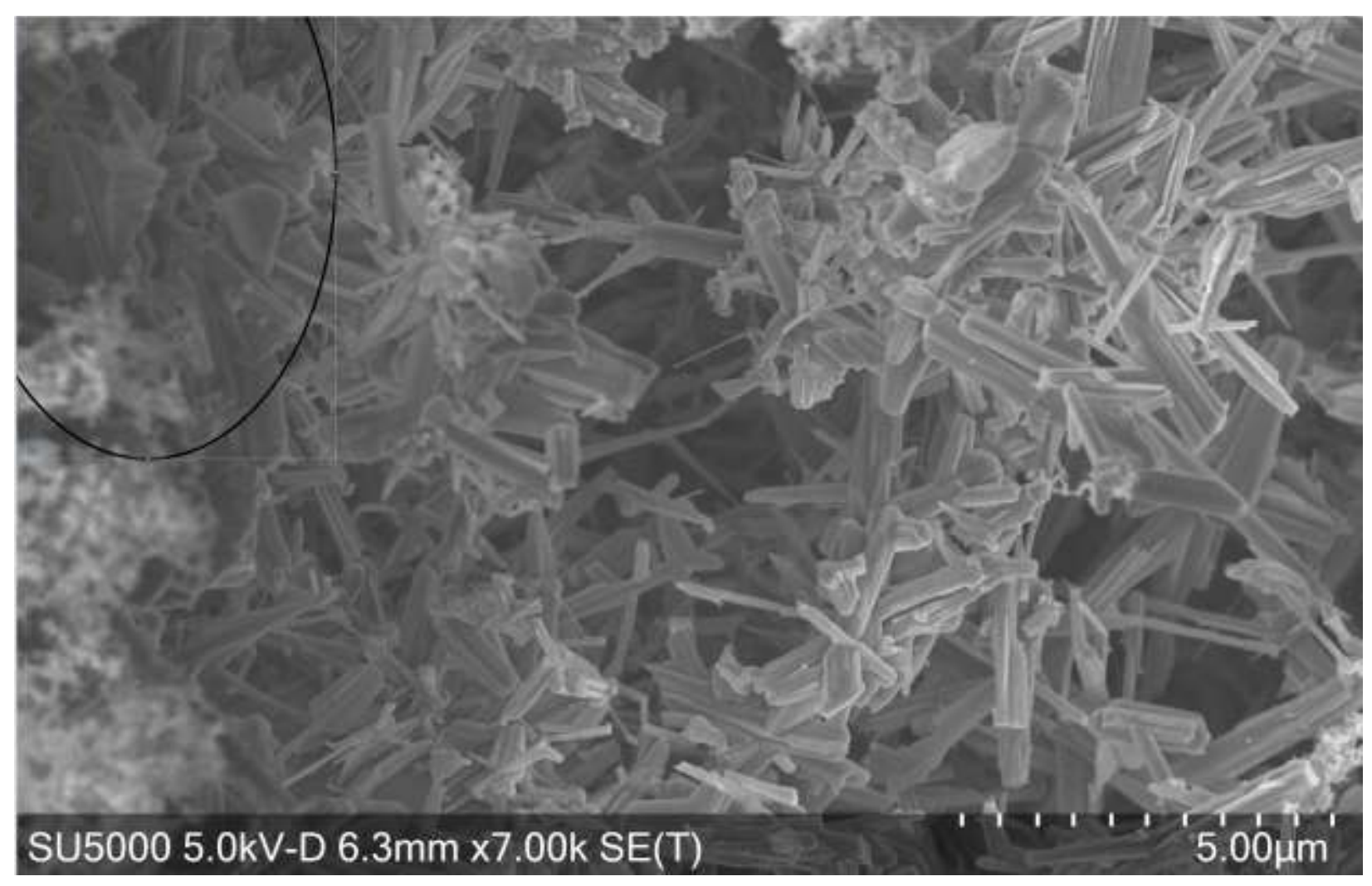

FIGURE 19 2.5-4-6 (Rupa Haldavnekar, 2018) 
The above figure 19 was generated at the $2.5 \mathrm{~mm} / \mathrm{sec}$ scanning speed and the $46 \mathrm{MHz}$ repetition. Visually it is can be understood that there is no clarity in the left top corner indicated by circle there is a dim area where the rods are not clear. This can also be called as defect.

\begin{tabular}{|c|c|c|c|c|c|c|}
\hline File & \multirow[t]{2}{*}{ Edit } & \multirow{2}{*}{$\begin{array}{l}\text { Font } \\
\text { Mean }\end{array}$} & \multicolumn{2}{|l|}{ Results } & \multirow[b]{2}{*}{ Angle } & \multirow[b]{2}{*}{ Length } \\
\hline & & & Min & $\operatorname{Max}$ & & \\
\hline 1 & 10734.346 & 125.721 & 107.063 & 170 & -24.624 & 1502.887 \\
\hline 2 & 15392.648 & 99.808 & 84.823 & 157.135 & -32.747 & 2155.388 \\
\hline 3 & 14633.142 & 99.657 & 82.702 & 127.825 & 24.246 & 2050.957 \\
\hline 4 & 14734.409 & 151.338 & 124.983 & 187.730 & -66.178 & 2064.409 \\
\hline 5 & 13468.567 & 139.936 & 118.519 & 164.314 & -36.091 & 1888.257 \\
\hline 6 & 14734.409 & 97.583 & 76.401 & 120.521 & -52.021 & 2061.179 \\
\hline 7 & 25721.924 & 102.997 & 78 & 129.315 & -7.602 & 3608.164 \\
\hline 8 & 12810.328 & 133.875 & 108.473 & 181.942 & -30.535 & 1794.771 \\
\hline 9 & 13367.299 & 112.893 & 91.055 & 155.247 & 77.022 & 1868.850 \\
\hline 10 & 17417.996 & 127.242 & 94.139 & 165.850 & 27.309 & 2444.152 \\
\hline
\end{tabular}

\section{FIGURE 20 RESULTS OF THE LENGTHS OF THE RODS 2.5_4_6}

The figure number 21 shows the maximum length of the rod is $3608 \mathrm{~nm}$ and the minimum length of the rod $1502.887 \mathrm{~nm}$. And the corresponding areas of the rods are $25721.924 \mathrm{~nm}$ and the 10734.346nm. 


\section{Summary}

\begin{tabular}{l|l|l|l|l|l|l}
\multicolumn{1}{c}{ File } & Edit & \\
\hline Slice & Count & Total Area & Average Size & $\%$ Area & Mean & \\
\hline 2.5-4-1.jpg & 153 & 6805411.407 & 44479.813 & 2.961 & 253.833 &
\end{tabular}

In the above summary, the particle count is 153 and the area analysed is also high. The mean particle size for this result is 253 . $833 \mathrm{~nm}$.From all the above summary, it can be seen that the figure number 18 has the greater number of particles were detected and when the area which was analysed is also proportion to every other image in FESEM was analysed.

\begin{tabular}{|l|l|l|}
\hline Image Name & Average of Area (sq. & Average of Length (nm) \\
$\mathbf{n m})$ & 1049.067 & \\
\hline $0-5-4-n i t r o g e n 25$ & 2583.538 & 528.6796 \\
\hline $0-5-4-$ nitrogen26 & 10771.4174 & 1959.0046 \\
\hline $2.5-4-4$ & 5924.2539 & 1069.617 \\
\hline $0-5-25-$ nitrogen19 & 2142.5031 & 742.7494 \\
\hline $0-5-12-$ nitrogen13 & 6537.966077 & 1173.432846 \\
\hline $0-5-12-n i t r o g e n 5$ & 15301.5068 & 2143.9014 \\
\hline $2.5-4-6$ & & \\
\hline
\end{tabular}

TABLE 6 SUMMARY OF THE AVERAGES OF AREA AND LENGTHS OF THE RODS 
The table number 6 summarizes the average of areas and average of lengths of the rods in each image analysed in FESEM when at different repetitions and scanning speeds. These results are matched with the literature review lengths of the rods, it can be concluded that the lengths of the rods are within the range of the values mentioned in the papers.

FESEM is analysed using the IMAGE J like the analysing of the SEM images. These exhibits the morphology of the material which are like particles sizes and the rods structure with the skews and $\mathrm{x}$ and $\mathrm{y}$ coordinates of the particles being selected using the software.

These can further be used for the doping the material for the optimising the properties according to the industry demands. (Wang, 2004)

\begin{tabular}{|l|l|l|}
\hline Image Name & Particle Count & Mean particle size (nm) \\
\hline $0-5-4-$ nitrogen25 & 11 & 255 \\
\hline $0-5-4-$ nitrogen26 & 711 & 252.822 \\
\hline $2.5-4-4$ & 2 & 255 \\
\hline $0-5-25-$ nitrogen19 & 209 & 254.676 \\
\hline $0-5-12-$ nitrogen13 & 1 & 255 \\
\hline $0-5-12-$ nitrogen5 & 835 & 254.984 \\
\hline $2.5-4-6$ & 153 & 253.833 \\
\hline
\end{tabular}

\section{TABLE 7 SUMMARY OF PARTICLE COUNT AND MEAN PARTICLE SIZE}

The above table 7 summarizes the mean particle size and the particle count derived from the software for all the images. 


\subsection{SEM}

The following are the SEM images which can also be use for the particle size analysis.

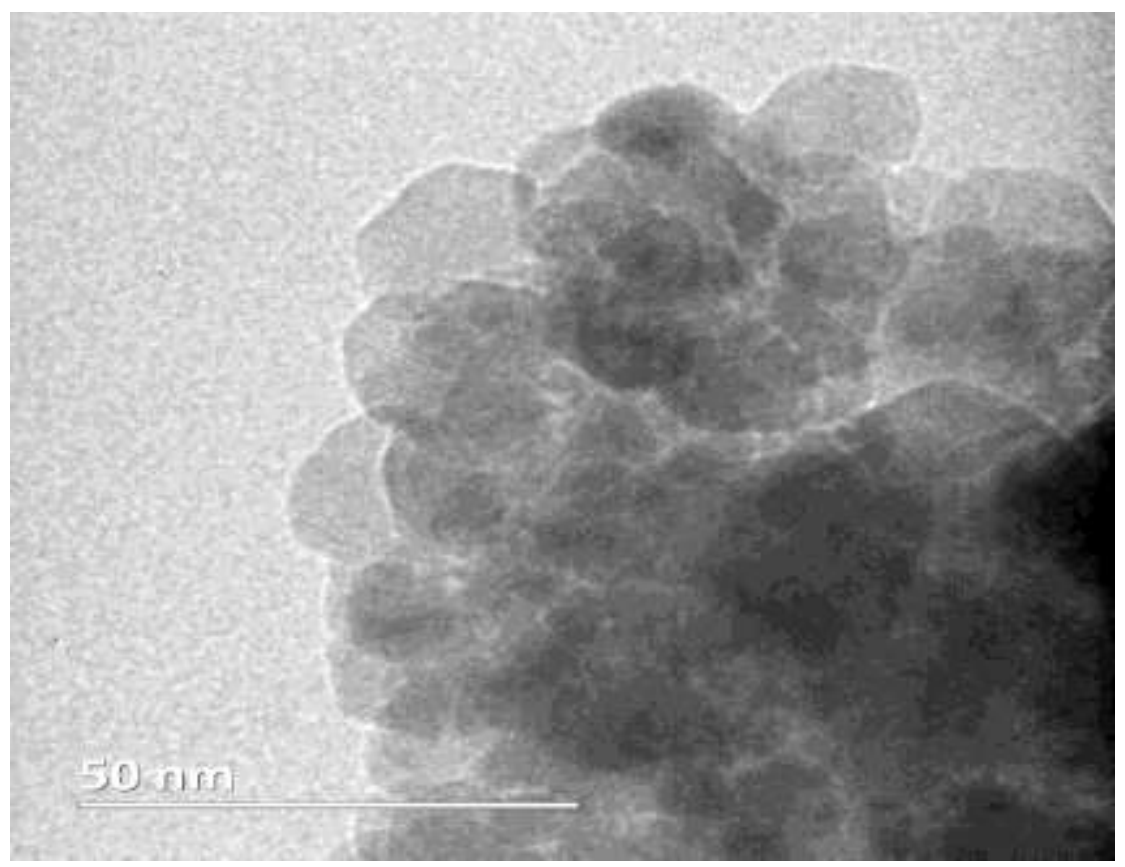

FIGURE 21 0_5_12_0006 (Rupa Haldavnekar, 2018)

The same steps were followed from the above case to give the nanoparticle size distribution using the Image J. But the difference is that these pictures does not include any rods. So, its much better to analyse the particles. 


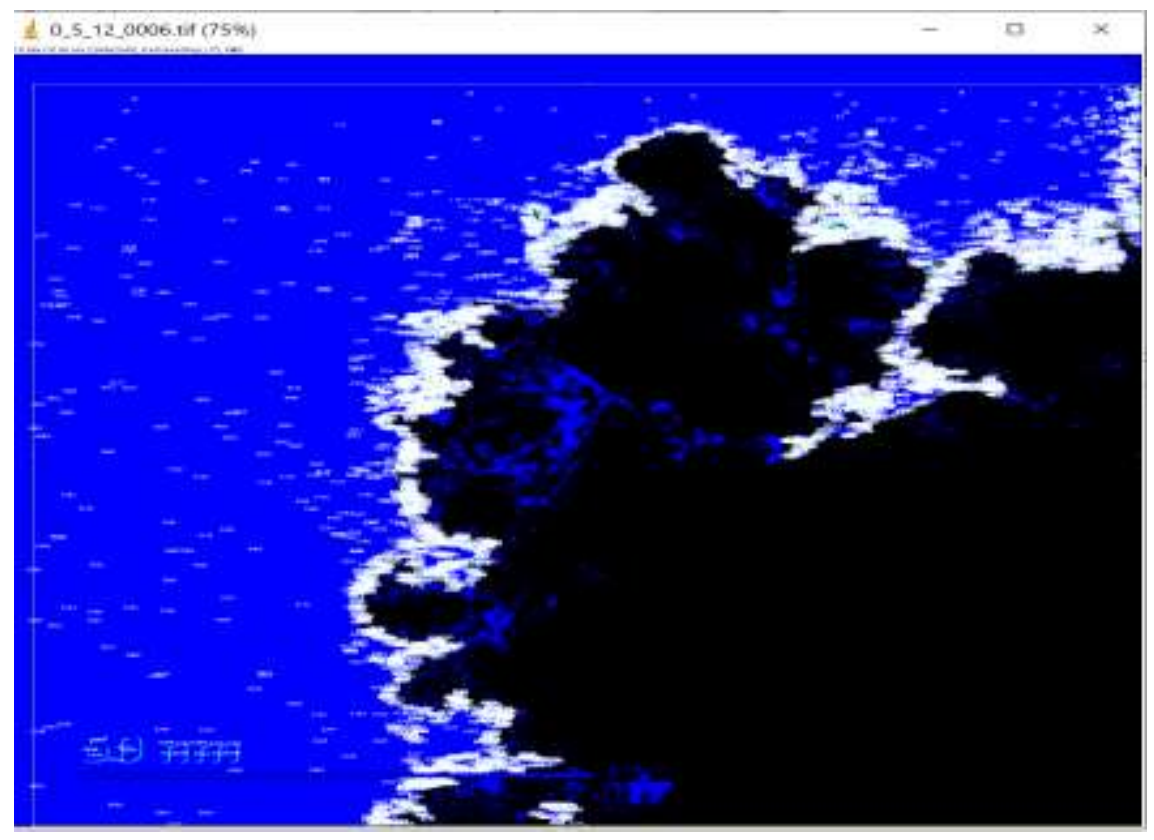

FIGURE 22 THRESHOLD APPLIED TO ILLUMINATE FOR THE IMAGE CLARITY

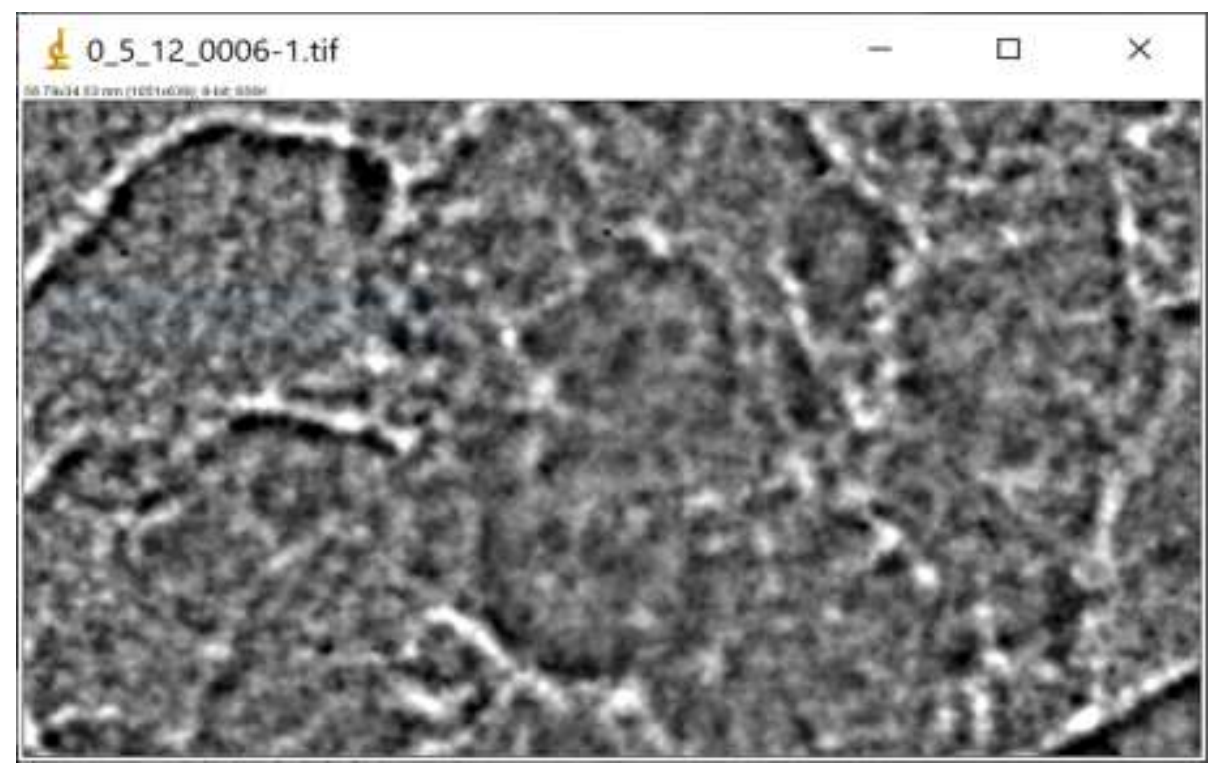

\section{FIGURE 23 ILLUMINATED IMAGE WITH THE BANDPASS FILTER}

The figure number 22 and 23 shows the threshold applied to illuminate area and then the filters were applied in the images respectively as said before. It was much easier to find the patches to analyse the particle after using those. 


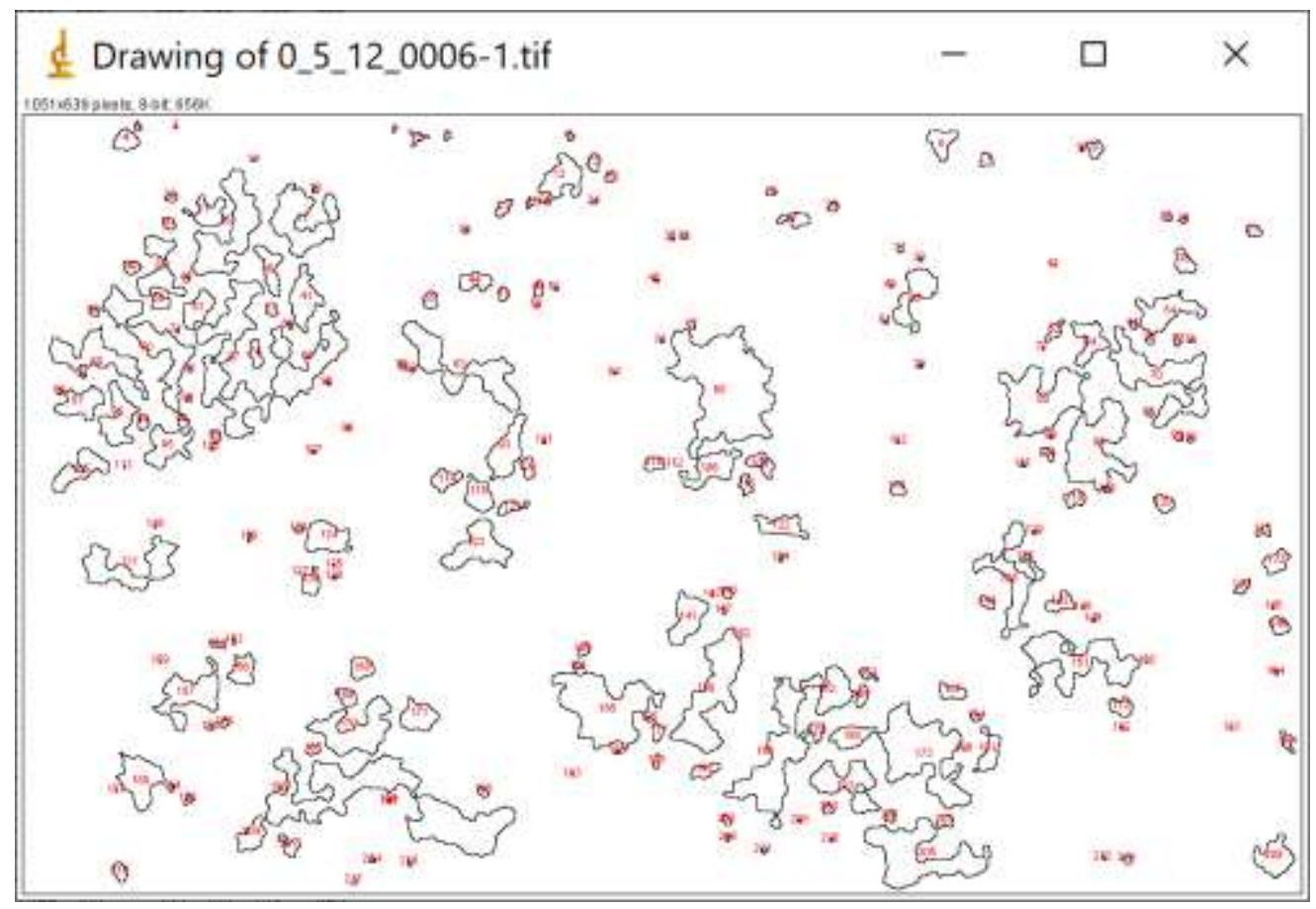

FIGURE 24 PARTICLES INDICATED FOR THE ANALYSIS

The above figure 25 shows the indication of different particles after the image was completely cleared from clutter which are not mandatory of analysis. The numbers in red are the counts of particles so that the frequency of the particles available can be noted, this image was generated for all the image in particle size analysis due to page constraint. The image is shown in single example.

\section{d Summary}

File Edit Font
\begin{tabular}{l|l|l|l|l|l|l} 
Slice & Count & Total Area & Average Size & \%Area & Mean & \\
\hline 0_5_12_0006.tif & 6758 & 76.516 & 0.011 & 0.661 & 254.398
\end{tabular}


The above summary shows that the particles identifies through the figure number 21 has the particle count of 6758. The image number 21 which is different from figures of FESEM reveals many particles than the FESEM so it can be said that these images reveal better morphology of particles compared to the FESEM images even when the same proportion area was analysed.

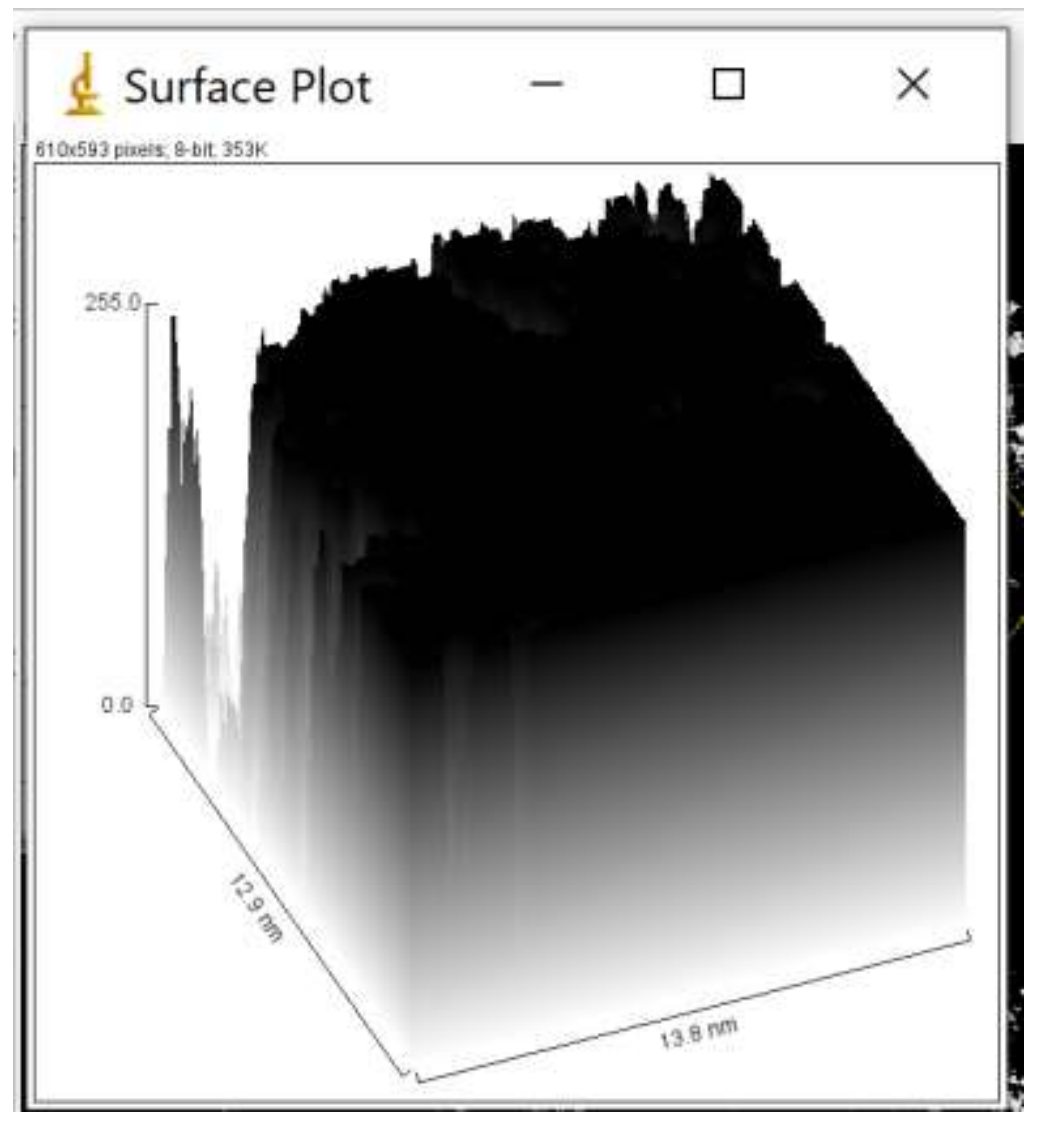

FIGURE 25 SURFACE PLOT OF THE SEM IMAGE

The figure number 25 shows the 3D surface plot of the particles with the two length of axis and the mean of the particle sizes. 


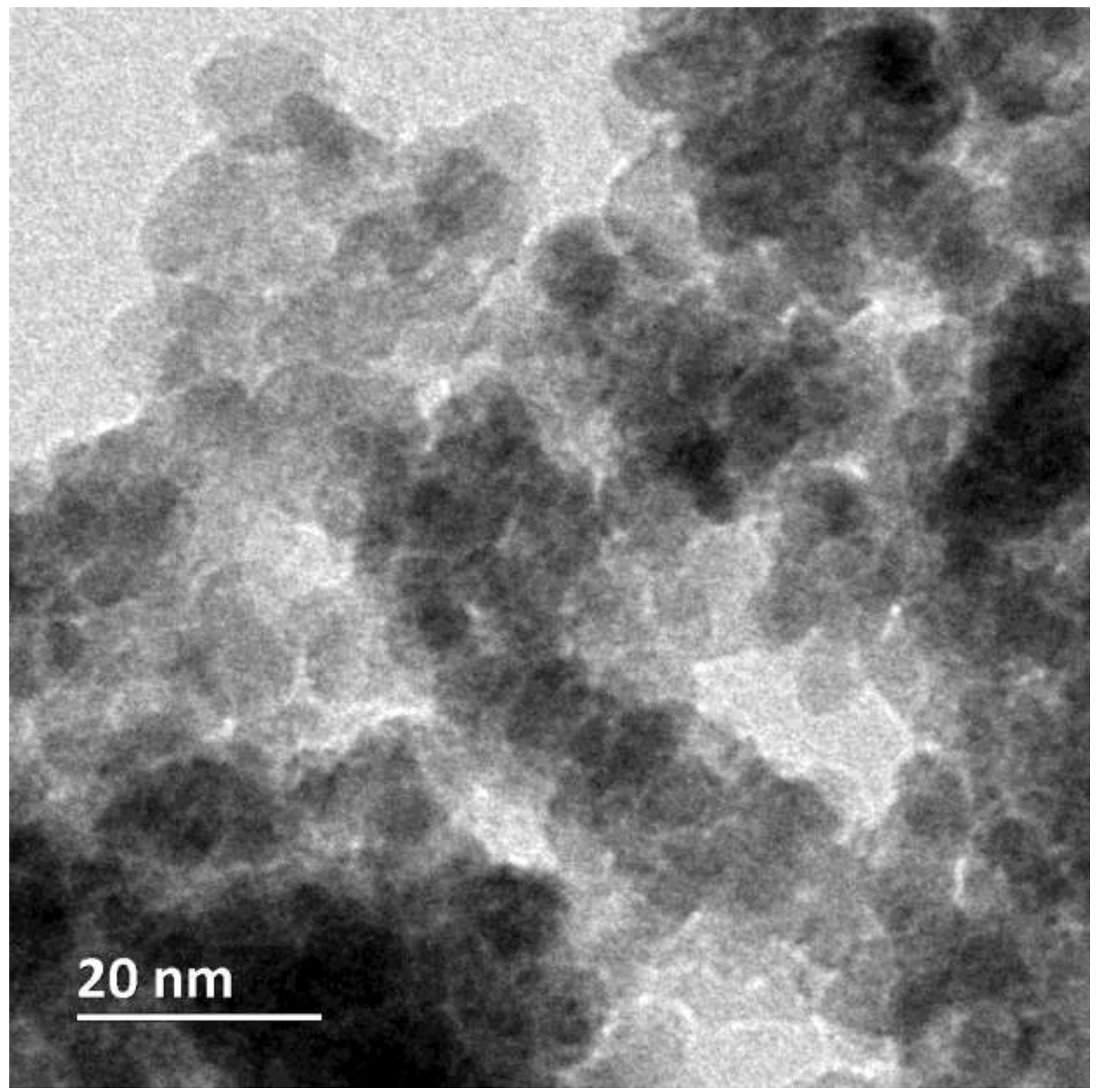

FIGURE 26 0_5_4_N2_0005 (Rupa Haldavnekar, 2018)

The figure number 26 was obtained at the scanning speed of $0.5 \mathrm{~mm} / \mathrm{sec}$ and the repetition rate of $4 \mathrm{MHz}$ and $\mathrm{n} 2$ is the nitrogen 2 at 0005 series. 


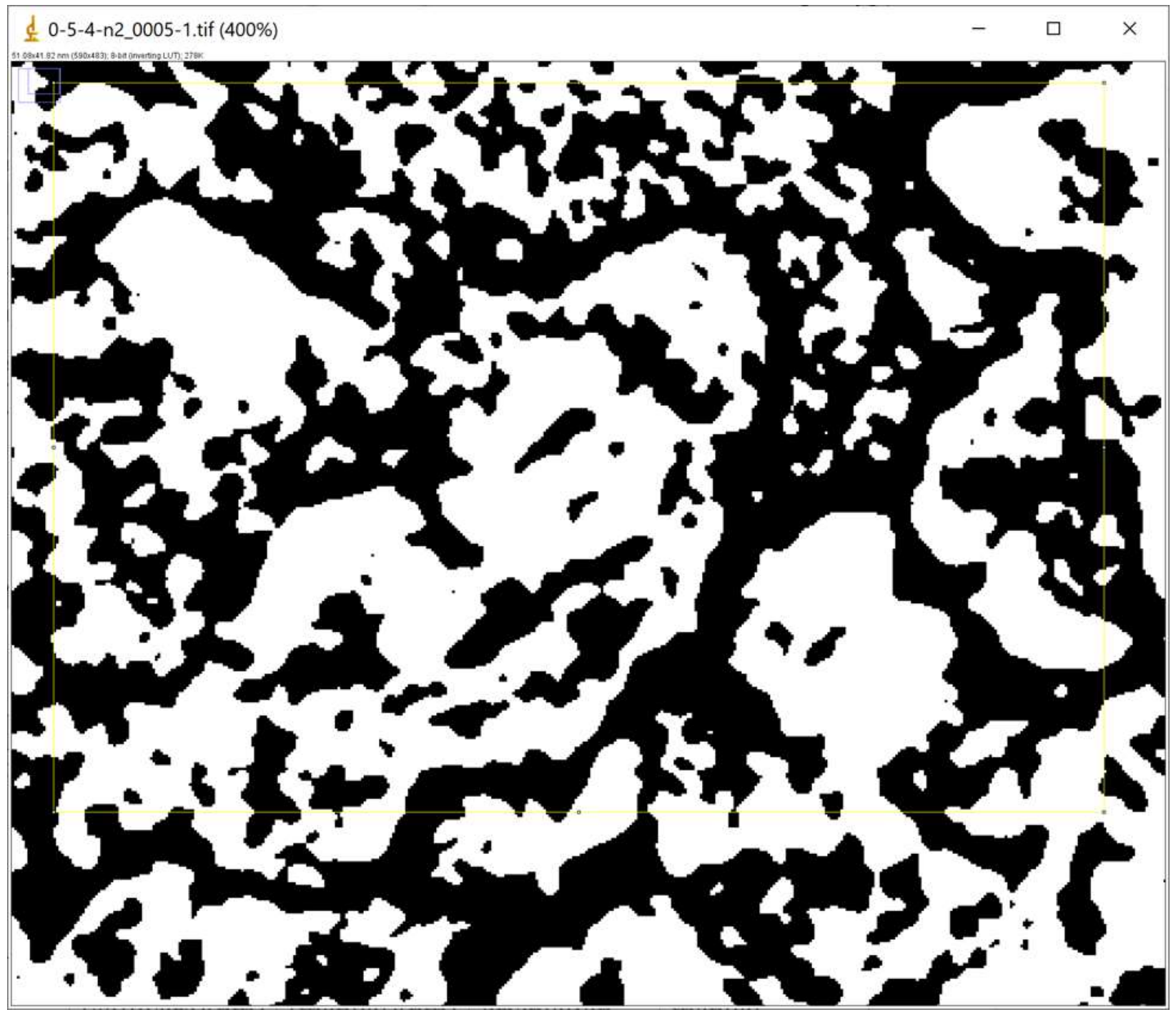

FIGURE 27 ILLUMINATED IMAGE WITH THE BANDPASS FILTER

The figure number 27 image was generated when the bandpass filter was used after neglecting the major turbulence and clutter. The clarity was achieved by increasing the circularity. 
Summary

\begin{tabular}{l|l|l|l|l|l|l}
\multicolumn{1}{c}{ File Edit } & Font \\
\hline Slice & Count & Total Area & Average Size & $\%$ Area & Mean & \\
\hline J-5-4-n2_0005-1.tif & 42 & 49.968 & 1.190 & 5.907 & 255
\end{tabular}

The above summary shows the 42 count of particles and in approximately $50 \mathrm{~nm}$ area which more or less close to the area which was analysed in the previous image and the count of particles was so huge 6758 when compared to present case which is 42 . So, it can be concluded that the image which is being generated in different experimental conditions depends on the clarity of the image.

\begin{tabular}{|l|l|l|}
\hline Image Name & Particle Count & Mean particle size (nm) \\
\hline 0_5_12_0006 & 6758 & 254.398 \\
\hline 0_5-4_n2_0005 & 42 & 255 \\
\hline
\end{tabular}

\section{TABLE 8 SUMMARY OF THE SEM NANO PARTICLE DISTRIBUTION}

The above table 8 summarizes the particle count and the mean particle size derived from the software for the SEM images. 


\subsection{HRTEM ANALYSIS:}

High resolution transmission electron microscopy refers to imaging in which lattice fringes are observed or atomic resolution is achieved. Unlike BF, DF or TEM, HRTEM images are formed from number of diffracted images, this process is called phase contrast imaging which is also a multi beam approach. This process is mandatory to construct an image of crystal lattice.

It also imparts access to more information than basic microscopy about the sample like analysing crystalline defects and interfaces at atomic scales or nanoscales and observing and verifying devices and multi layers and nanocrystals and nanostructures. The technique typically requires very thin TEM specimens free of preparation artefacts. Moreover, correct interpretation of images depends on image simulation such as possible with the JEMS software.

In this project, the images of fringes obtained from the HRTEM, when its been analysed through the GATAN software.

Using the following steps, importing the image to the software and matching the scale of the image correctly by measuring option followed by selecting a proper single layered area of the image to analyse better. And then using the FFT option to get the particles highlighted in that particular area of the image. Now use spot masking option to mask the spots in dark color to get the high resolution. Following with the inverse FFT to get the Nano scaled resolution and then any draw a line using line profile to show the IFFT of FFT. And now measuring the distance between two similar peaks of height and then dividing the value by the number of spaces between each peak 
between the same two peaks gives the lattice spacing. After finding the $d$ spacing the lattice orientation is obtained through literature review.

So, these are the values for the images generated through HRTEM. Each lattice orientation is discussed.

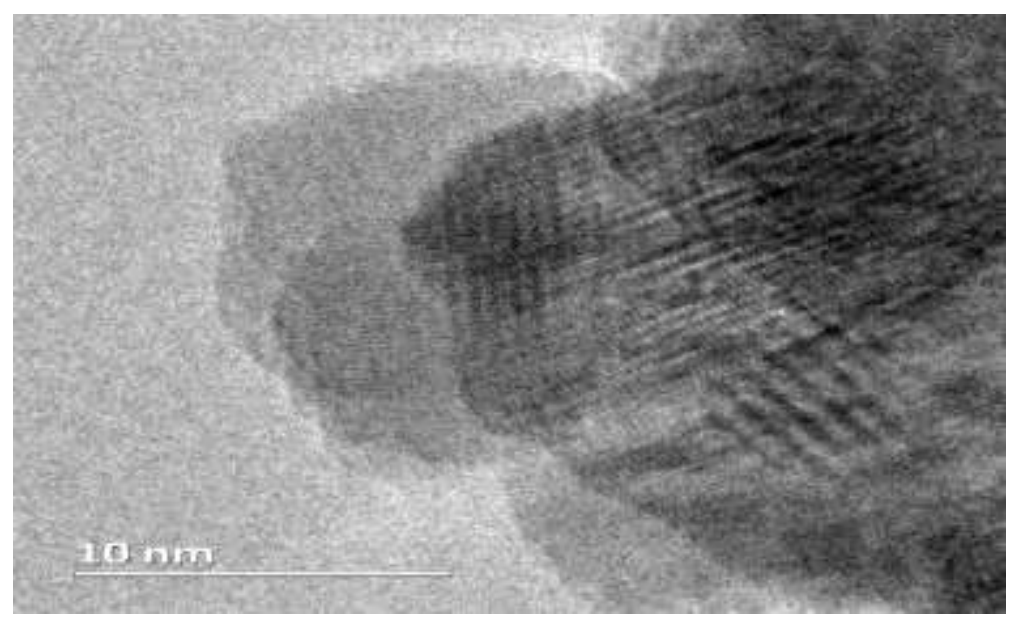

FIGURE 28 0_5_25_0010 (Rupa Haldavnekar, 2018)

As mentioned in the previous method, the first two digits indicates the scanning speed, the figure number 28 has $0.5 \mathrm{~mm} / \mathrm{sec}$ and the next two digits indicates the repetition rate of $25 \mathrm{MHz}$, and the last four digits indicate just the first series that particular repetition and scanning speed. 


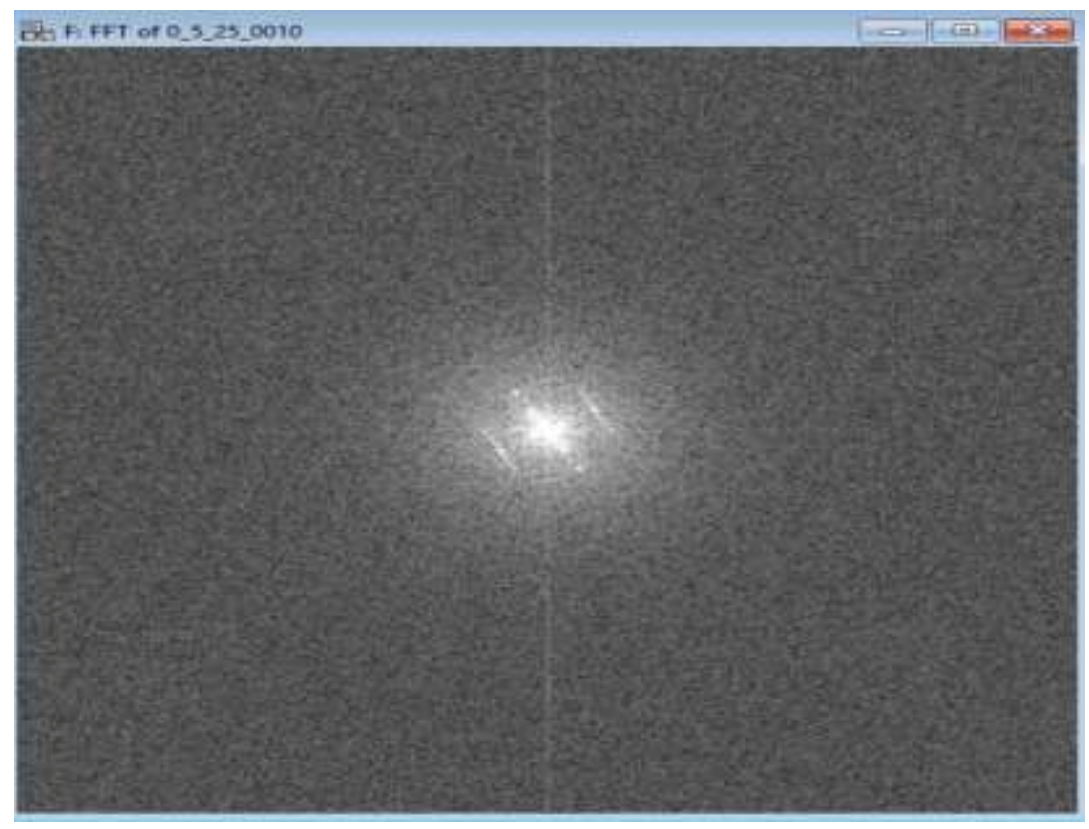

FIGURE 29 FFT PROFILE OF THE HRTEM IMAGE

In the above figure number 29 , the bright spots are the hexagonal lattice structure and from these after selecting two opposite lattice cells and then later masking tool was used. Later the inverse FFT the d spacing was calculated from the profile generated. 


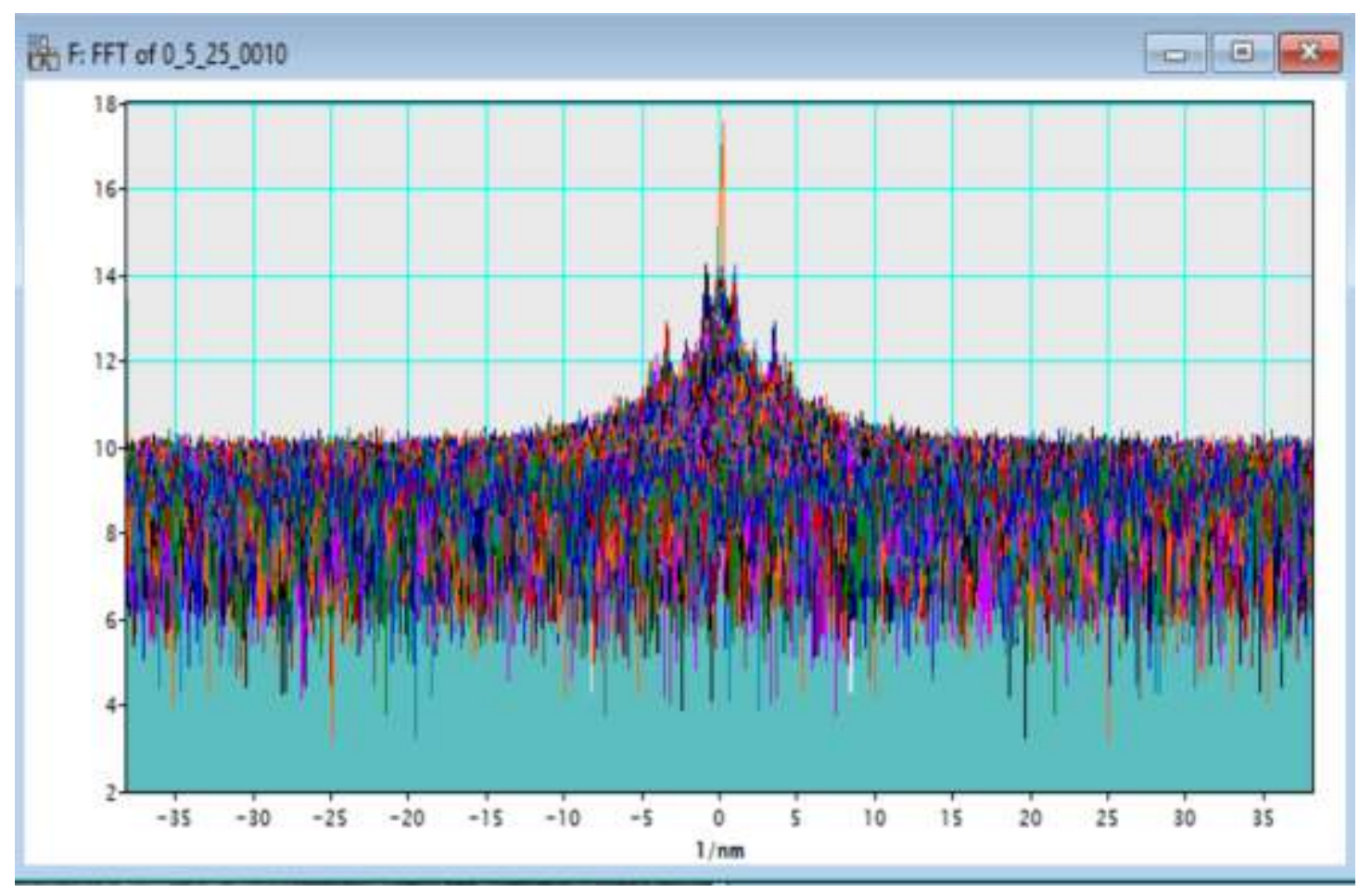

FIGURE 30 FFT SURFACE PROFILE OF HRTEM IMAGE

The above figure number 30 shows the surface plot of the HRTEM image in the scale and the depth of the fringes in the y axis.

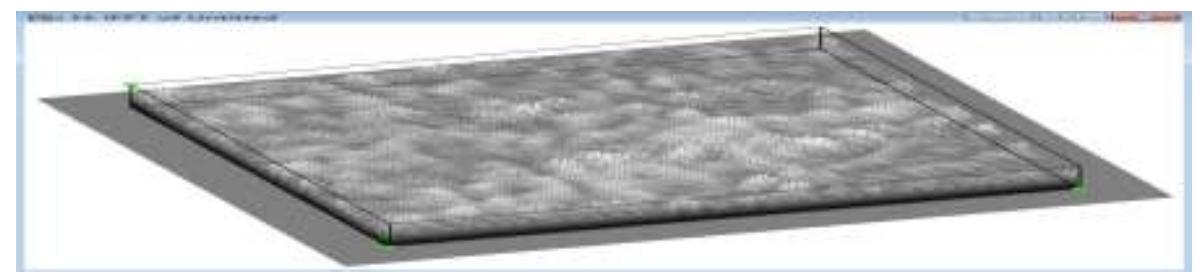

FIGURE 31 SURFACE PROFILE IN 3D

The figure 31 shows the surface profile in $3 \mathrm{D}$ view how the material is visible in the far view. 


\begin{tabular}{|c|c|c|c|c|c|c|}
\hline \multicolumn{4}{|c|}{ B. F: FFT of 0_5_25_0010 } & \multicolumn{3}{|c|}{$\square$ 口 $x$} \\
\hline & $C 16$ & $C_{17}$ & $\mathrm{C} 1 \mathrm{~s}$ & $C 19$ & $C 20$ & 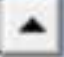 \\
\hline$R 12$ & $\begin{array}{l}4510.0791+ \\
-1111.3425\end{array}$ & $\begin{array}{l}5111.7993+ \\
5834.2397 i \\
\end{array}$ & $\begin{array}{l}7496.4458+ \\
4302.457 i^{+}\end{array}$ & $\begin{array}{l}4908.3477+ \\
-2816.3232\end{array}$ & $\begin{array}{l}-307 . \\
4593 . i\end{array}$ & \\
\hline$R 13$ & $\begin{array}{l}9605.6846+ \\
10178.804 i\end{array}$ & $\begin{array}{l}-3818.856+ \\
6765.9463 i \\
\end{array}$ & $\begin{array}{l}-5669.73+ \\
-7391.2163 \\
\end{array}$ & $\begin{array}{l}9068.6436 \\
-14568.549\end{array}$ & $\begin{array}{r}14700 \\
-7037 \\
\end{array}$ & \\
\hline$R 14$ & $\begin{array}{l}-13822.117 \\
-2018.609\end{array}$ & $\begin{array}{l}12842.501{ }^{-15196.697}\end{array}$ & $\begin{array}{l}-2153.8911 \\
6758.3535 \text { i }\end{array}$ & $\begin{array}{l}-1224.8984 \\
-6018.7993\end{array}$ & $\begin{array}{l}600 \cdot 61 \\
-7810\end{array}$ & \\
\hline$R 15$ & $\begin{array}{l}-3832.7959 \\
-7119.0596 \\
\end{array}$ & $\begin{array}{l}4527.3564+ \\
1818.939 i^{4}\end{array}$ & $\begin{array}{l}-1697.4053 \\
5199.7085\end{array}$ & $\begin{array}{l}-153.74187 \\
2198.1621 \mathrm{i}\end{array}$ & $\begin{array}{l}2635 \\
-6030 \\
\end{array}$ & \\
\hline$R 16$ & $\begin{array}{l}191.53448+ \\
-10282.629\end{array}$ & $\begin{array}{l}-14142.937 \\
5709.5913 \quad i\end{array}$ & $\begin{array}{l}-11354.011 \\
9582.3877_{i}\end{array}$ & $\begin{array}{l}2078.1978+ \\
-3349.2947\end{array}$ & $\begin{array}{l}-2710 \\
5283.1\end{array}$ & \\
\hline$R 17$ & $\begin{array}{l}-1169.9199 \\
-9208.2666 \\
\end{array}$ & $\begin{array}{l}475.39969+ \\
-5061.8311\end{array}$ & $\begin{array}{l}-2243.4453 \\
-4314.394 i\end{array}$ & $\begin{array}{l}15428.783+ \\
2059.9893 i\end{array}$ & $\begin{array}{l}-3331 \\
15533 \\
\end{array}$ & \\
\hline$R 18$ & $\begin{array}{l}-1980.8782 \\
7192.7285\end{array}$ & $\begin{array}{l}768.63782+ \\
8628.6855 i\end{array}$ & $\begin{array}{l}-6124.3027 \\
1738.3086 \quad i\end{array}$ & $\begin{array}{l}8335.8584+ \\
-2302.6438\end{array}$ & $\begin{array}{l}4836.1 \\
3861 . !\end{array}$ & \\
\hline$R 19$ & $\begin{array}{l}5131.4751+ \\
-2991.5 i\end{array}$ & $\begin{array}{l}-6558.6948 \\
-1909.7543 \\
\end{array}$ & $\begin{array}{l}-4013.293+ \\
2027.7819 i \\
\end{array}$ & $\begin{array}{l}-250.43147 \\
-14947.561 \\
\end{array}$ & $\begin{array}{l}-7393 \\
11352 \\
\end{array}$ & \\
\hline$R 20$ & $\begin{array}{l}-17654.859 \\
-6270.6123 \\
\end{array}$ & $\begin{array}{r}-2838.585+ \\
3575.7632 \quad i \\
\end{array}$ & $\begin{array}{l}-7681.8623 \\
-4810.9277 \\
\end{array}$ & $\begin{array}{l}4278.5747+ \\
5569.0342 \quad i \\
\end{array}$ & $\begin{array}{l}340.5 \\
2257 .\end{array}$ & \\
\hline$R 21$ & $\begin{array}{l}13365.293+ \\
8357.9561 i\end{array}$ & $\begin{array}{l}5187.9331+ \\
5583.1699 i \\
\end{array}$ & $\begin{array}{l}2663.1079+ \\
-681.93646\end{array}$ & $\begin{array}{l}3110.2537+ \\
6367.9819 i \\
\end{array}$ & $\begin{array}{l}-1430 ! \\
3345\end{array}$ & \\
\hline 1 & $a n a n-a n$ & $m a n$ & 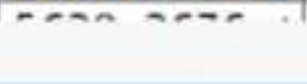 & $a$ nana. & 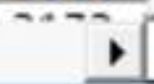 & \\
\hline
\end{tabular}

FIGURE 32 FFT MATRIX VALUES OF THE HRTEM ANALYSIS FOR THE D-

\section{SPACING CALCULATION}

The above figure 32 shows the matrix indications of the software analysis carried out to calculate the d-spacing. 


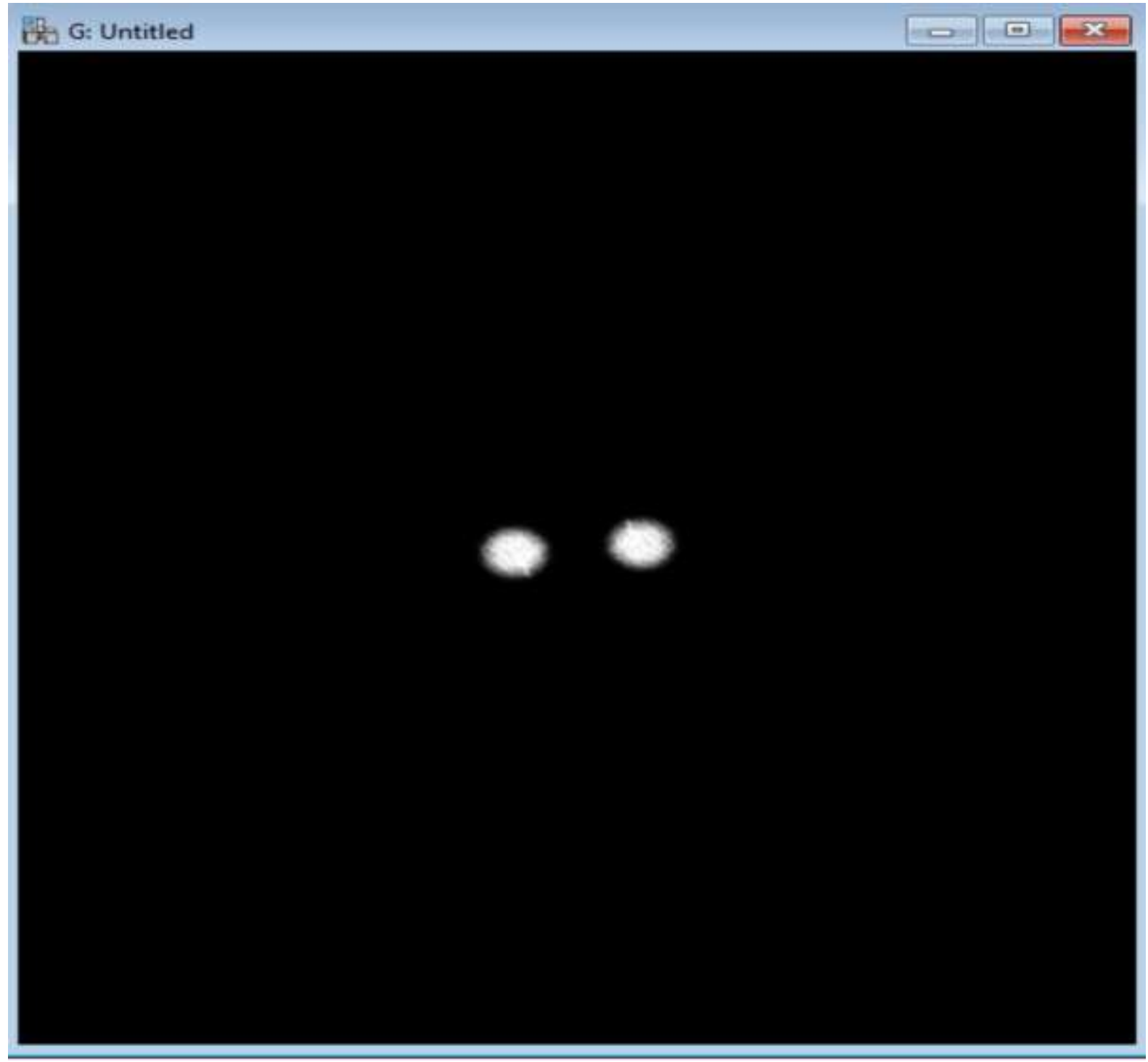

FIGURE 33: HIGHLIGHTED PARTICLES IN THE USAGE OF MASKING TOOL

The figure number 33 is generated after the masking tool was used which clearly shows the lattice cells to show the fringes in the zoomed view to calculate the number of spaces and number of fringes for d-spacing. 


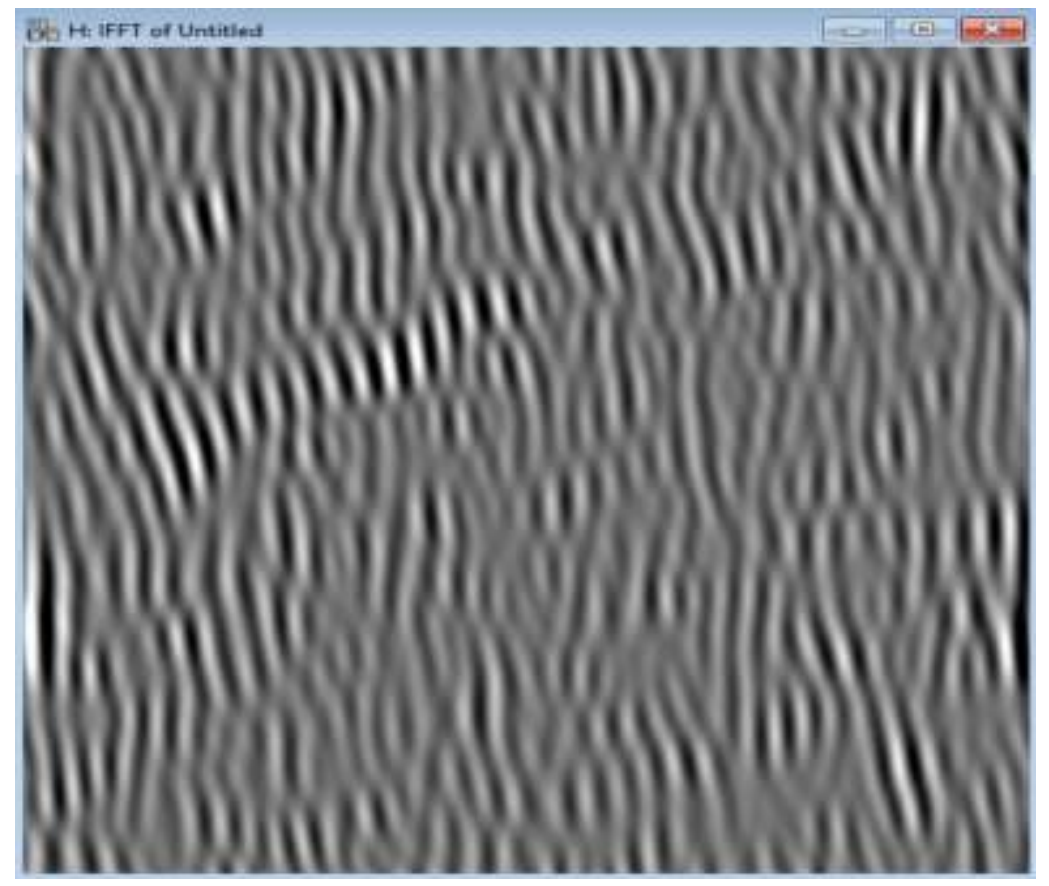

FIGURE 34 HIGH RESOLUTION IMAGE OF THE FRINGES TO CALCULATE THE D-SPACING MANUALLY

In the figure number 34, the fringes shown clearly in the zoomed angle to calculate the number of dark rings and spaces manually and to calculate the values. 


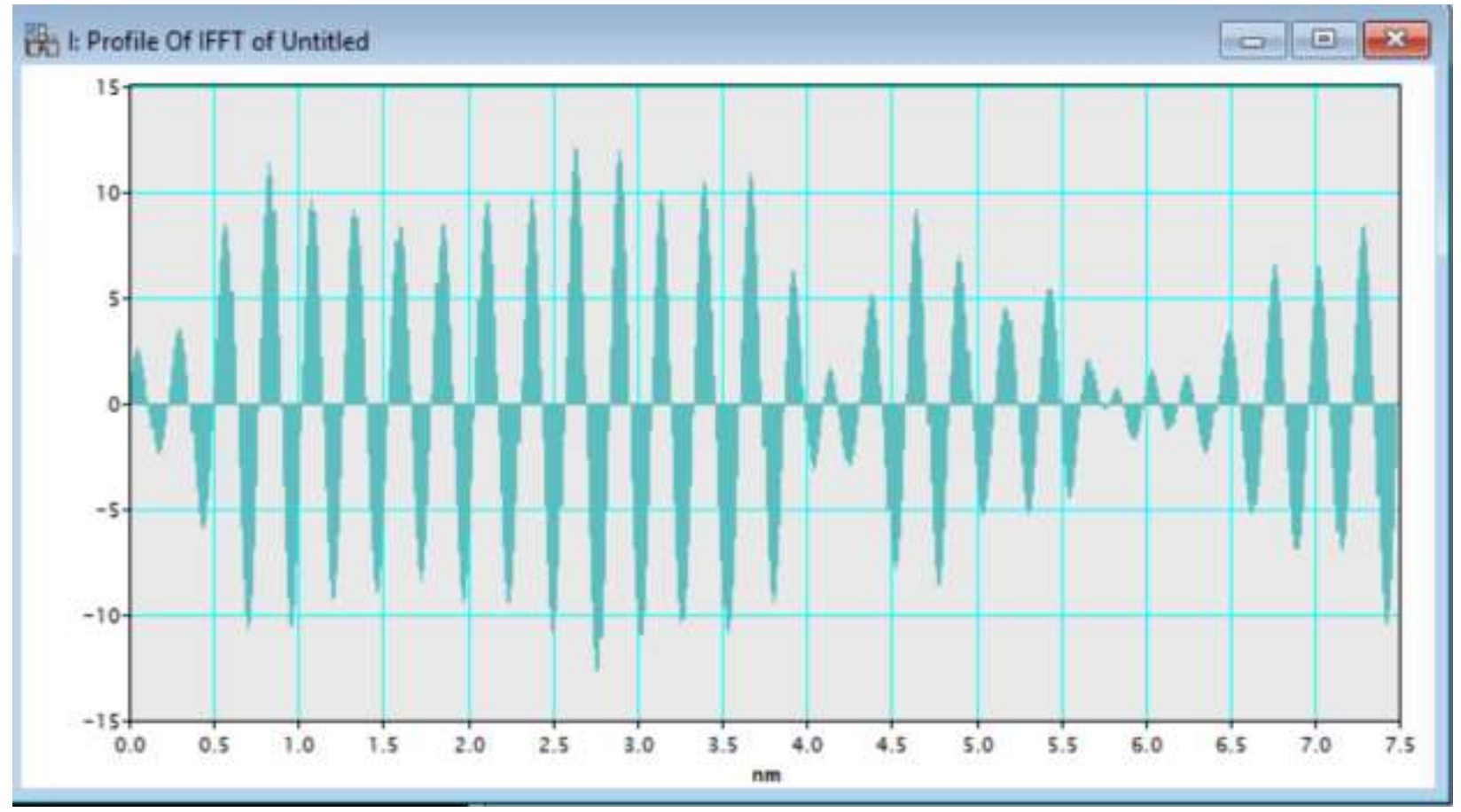

\section{FIGURE 35 PROFILE OF IFFT}

The above figure 35 is used to calculate the distance between 2 similar peaks. Similar kind of profile is obtained for every other image to calculate the d-spacing. The distance between 2 similar height peaks -2. 676.Number of spaces between the peaks-10. D spacing- $2.676 / 10=0.2676 \mathrm{~nm}$.

From the literature review it can be said that the $0.2676 \mathrm{~nm}$ which is 2.676 Angstroms corresponds to the 002 planar orientation. This orientation is desirable for the application of crystallographic anisotropy. The applications of UV diodes and piezoelectric surface acoustic waves or acoustic optic devices corresponds in enhancing the qualities of 002 planar orientation. When inferred from a paper the miller index which is corresponding to the 2.676Angstroms value is having1120 miller 
index and the plane name which corresponds to this is "a" (https://application.wileyvch.de/books/sample/3527408134_c01.pdf, 2009)

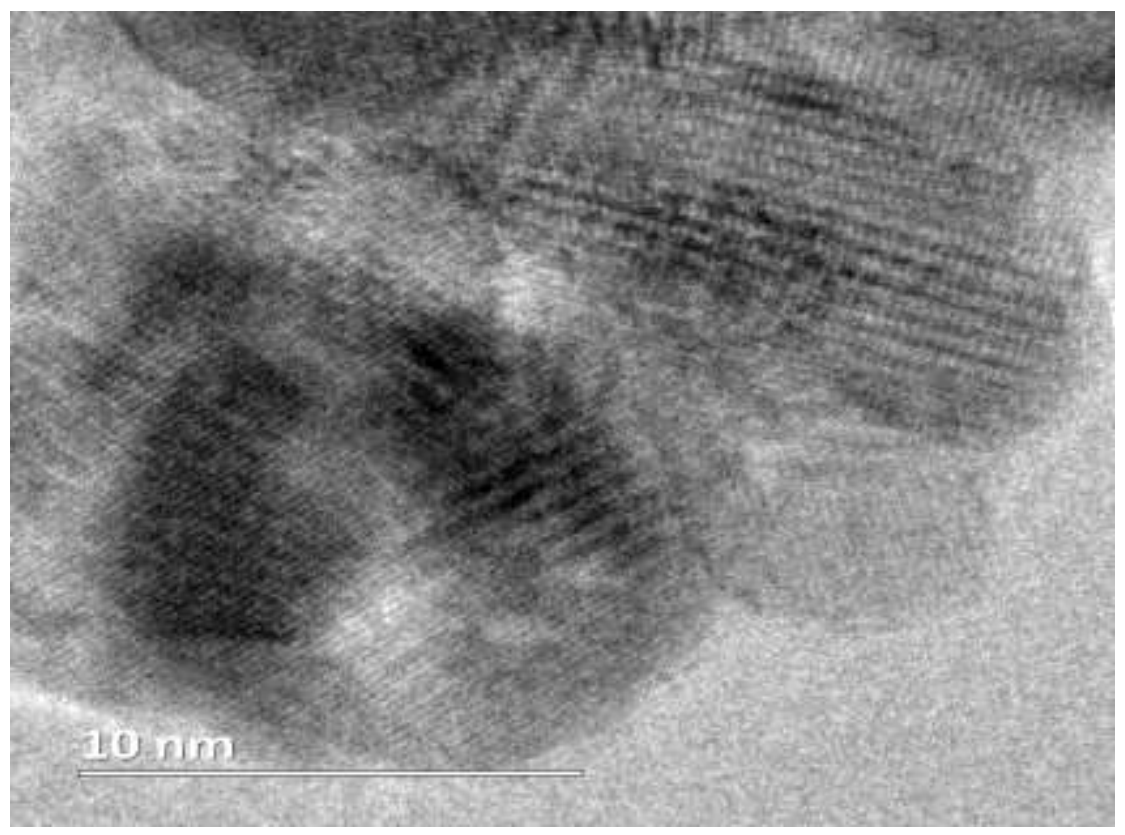

FIGURE 36 0_5_25_0013 (Rupa Haldavnekar, 2018)

The distance between 2 similar height peaks- 0.617 for figure 36 . Number of spaces between the peaks-3. $D$ spacing- $0.617 / 3=0$. 2056nm. This result corresponds to the 101 planar orientation. This corresponds to 1011 miller index from the paper and with the plane name of "s". (https://application.wiley-vch.de/books/sample/3527408134_c01.pdf, 2009) 


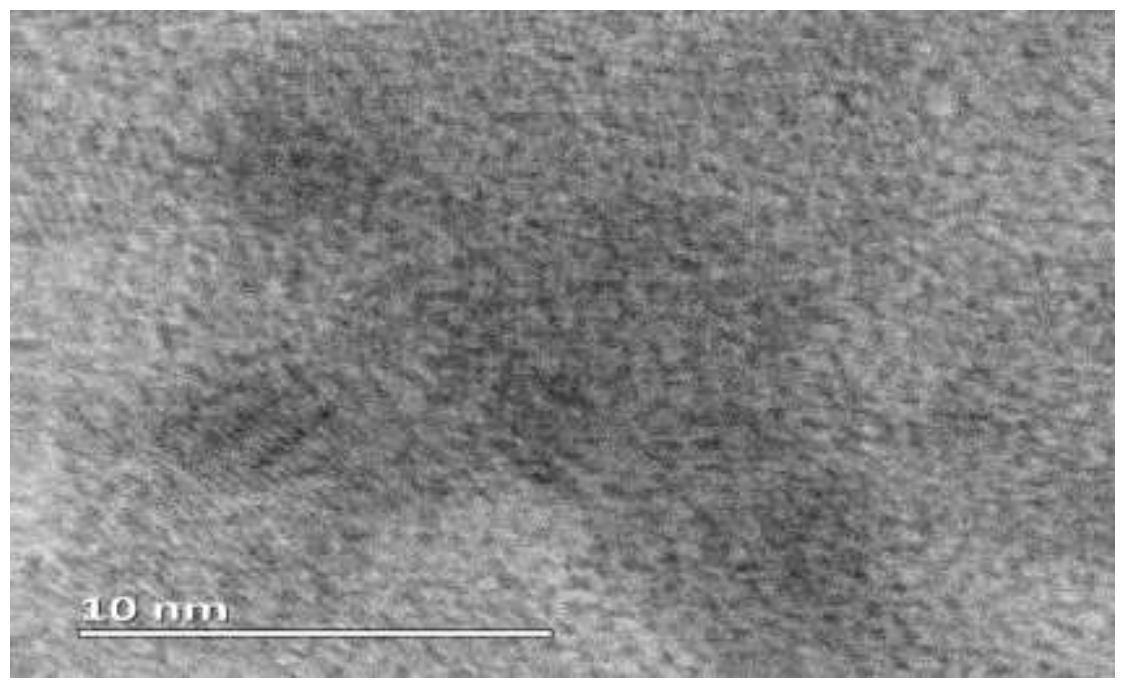

FIGURE 37 0_5_4_NIT_0003 (Rupa Haldavnekar, 2018)

The distance between 2 similar height peaks-3.084 for figure 37. Number of spaces between the peaks-10. D spacing- 3.084/10=0. 3084nm. This corresponds to 111 planes. This d-spacing again corresponds to the 1101 miller index and which refers to the plane name "b" (https://application.wiley-vch.de/books/sample/3527408134_c01.pdf, 2009)

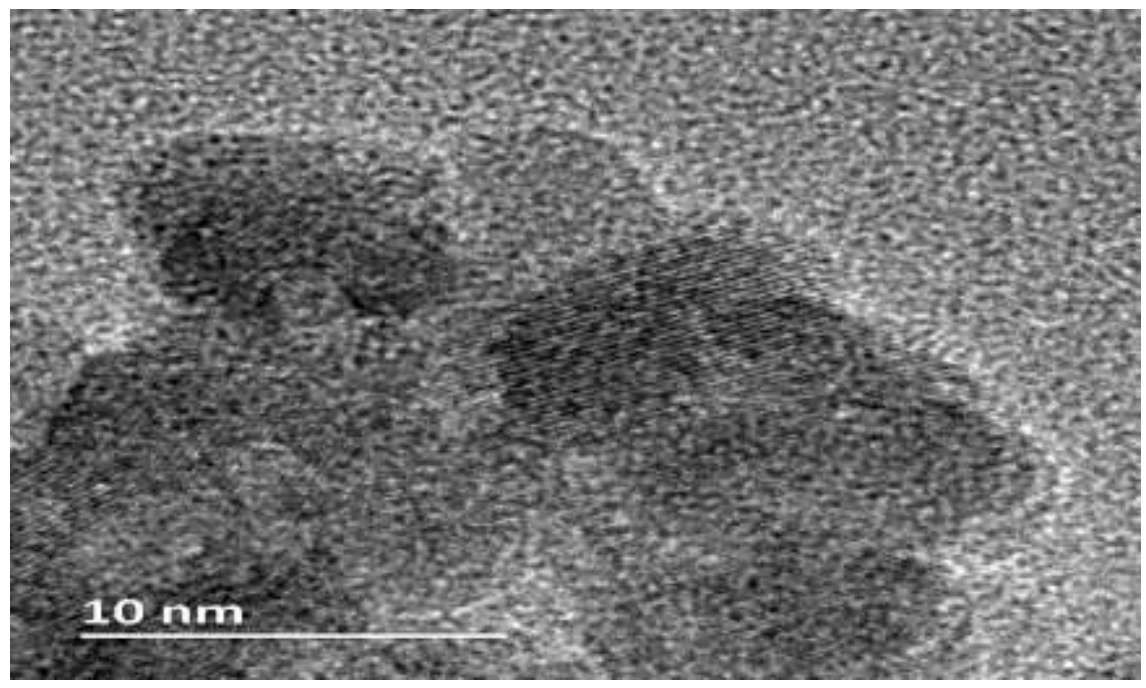

FIGURE 38 0_5_12_N2_0005 (Rupa Haldavnekar, 2018) 
The distance between 2 similar height peaks-1.255 for figure 38. Number of spaces between the peaks-4. D spacing- $1.255 / 4=0.31375 \mathrm{~nm}$. This corresponds to 111 planar orientation. Like the previous this also refers to the plane " $\mathrm{b}$ " in the paper and the 1101 miller index. (https://application.wiley-vch.de/books/sample/3527408134_c01.pdf, 2009)

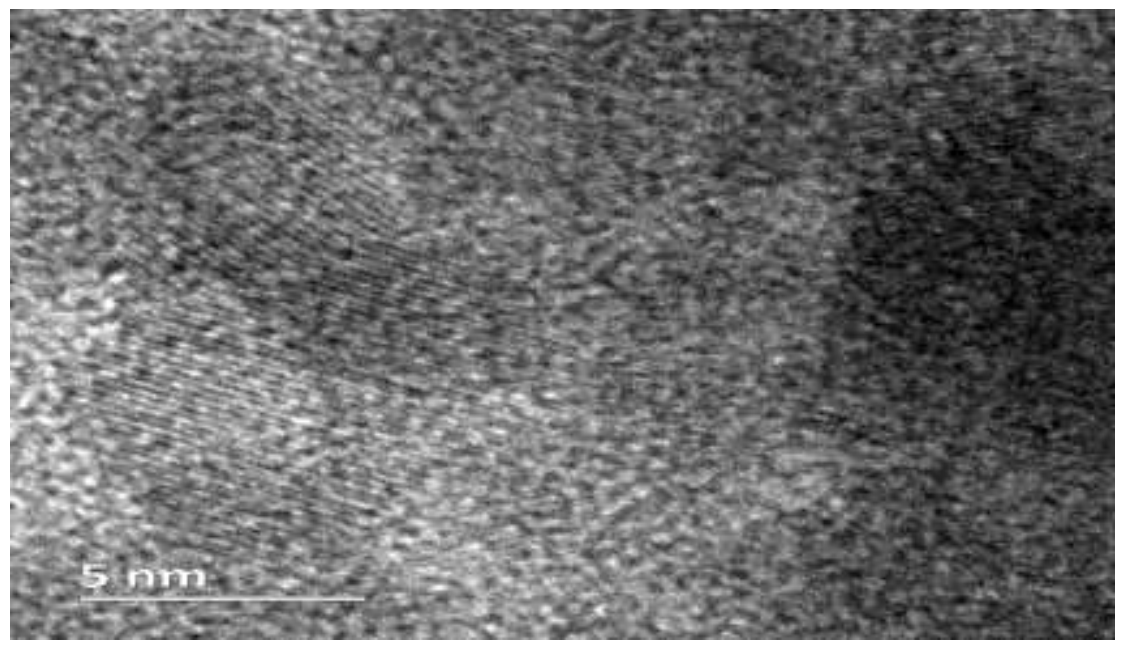

FIGURE 39 0_5_12_N2_0010 (Rupa Haldavnekar, 2018)

The distance between 2 similar height peaks-0.231 for figure 39. Number of spaces between the peaks-1. D spacing- $0.231 / 1=0$. $231 \mathrm{~nm}$. This corresponds to 100 planar orientation. This corresponds to 1120 miller index and surface "a". (https://application.wileyvch.de/books/sample/3527408134_c01.pdf, 2009) 


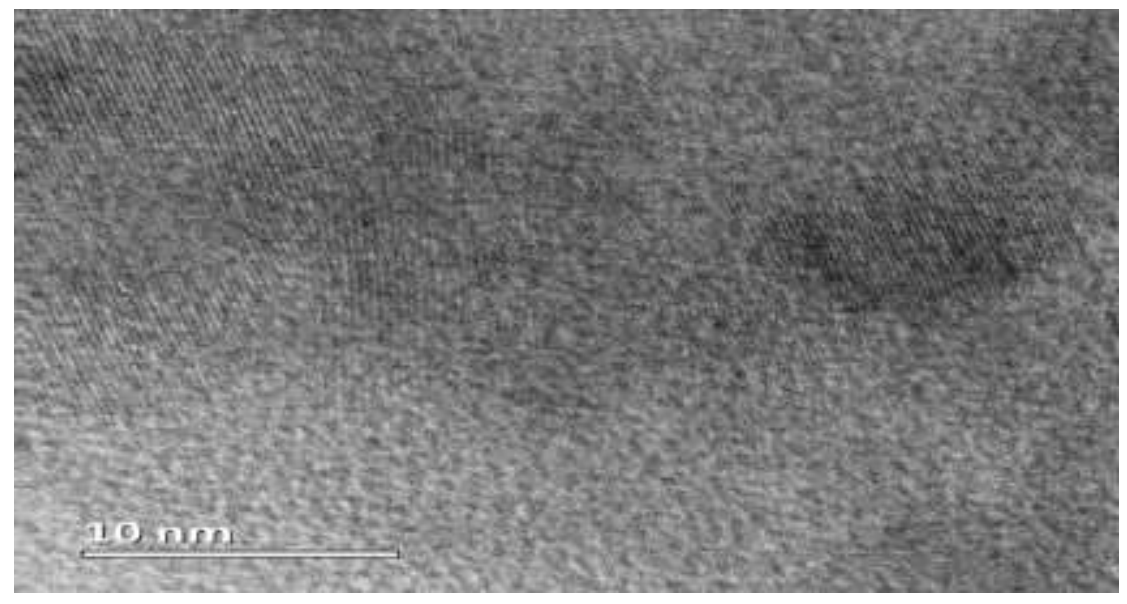

FIGURE 40 0_5_25_NIT_0018 (Rupa Haldavnekar, 2018)

The distance between 2 similar height peaks-4.505 for figure 40 . Number of spaces between the peaks-17. D spacing- 4.505/17=0. 265nm. This again corresponds to 002 orientation. This corresponds to 1120 miller index and plane name "a". (https://application.wileyvch.de/books/sample/3527408134_c01.pdf, 2009).

According to the planar orientation, d-spacing values it can be concluded that the structure of the material is wurtzite structure. 


\begin{tabular}{|l|l|l|l|l|}
\hline Image Name & $\begin{array}{l}\text { d-spacing } \\
\text { (software)(nm) }\end{array}$ & $\begin{array}{l}\text { d-spacing } \\
\text { (reference)(nm) }\end{array}$ & $\begin{array}{l}\text { Planar } \\
\text { orientation }\end{array}$ & Difference \\
\hline 0_5_25_0010 & 0.2676 & 0.2567 & 002 & 0.0424 \\
\hline 0_5_25_0013 & 0.2056 & 0.1986 & 101 & 0.0352 \\
\hline 0_5_4_nit_003 & 0.3084 & 0.2988 & 111 & 0.0321 \\
\hline 0_5_12_n2_0005 & 0.31375 & 0.3126 & 111 & 0.0036 \\
\hline 0_5_12_n2_0010 & 0.231 & 0.2456 & 100 & 0.0632 \\
\hline 0_5_25_nit_0018 & 0.265 & 0.2432 & 002 & 0.0896 \\
\hline
\end{tabular}

TABLE 9 D-SPACING VALUES FROM HRTEM IMAGES.

The above table 9 summarizes the d-spacing values calculated manually and the values from software and the corresponding planar orientation and the similarity between the values of manually calculated and the values from the software.

\subsection{SAED}

It was used in order to find the d-spacing of the crystal planes, the radius of the spots that observed in the SAED pattern from the bright center. Then the spacing angle was used to calculate the $d$ spacing.

SAED was used to find if the sample is amorphous or crystalline. The crystalline (bright spots), poly nanocrystalline (small spots making up a ring, each spot arising from Bragg reflection from an individual crystallite). Initially, the diameter, $2 \mathrm{R}$ was measured of each ring using GATAN 
processing software. Then the $\mathrm{R}$ value was calculated. The d-value (each of which correspond to a certain set of hkl indices) with the diffraction data from literature was compared.

From the software the different spots from the different was selected using the pointing tool and diffpack tool to compare the source image with standard image to get the 111planethen the spacing angle tool was used to do the SAED indexing which gives the brightest intense spot among the spots selected.

After the d-spacing of each spot in each ring is calculated the Pearson crystal database is used to check the d-spacing according to the material in this case it is zinc oxide the value is compared to the closest value in the d-spacing listed in results. That particular value will be the most intense spot among the ones selected in examination.

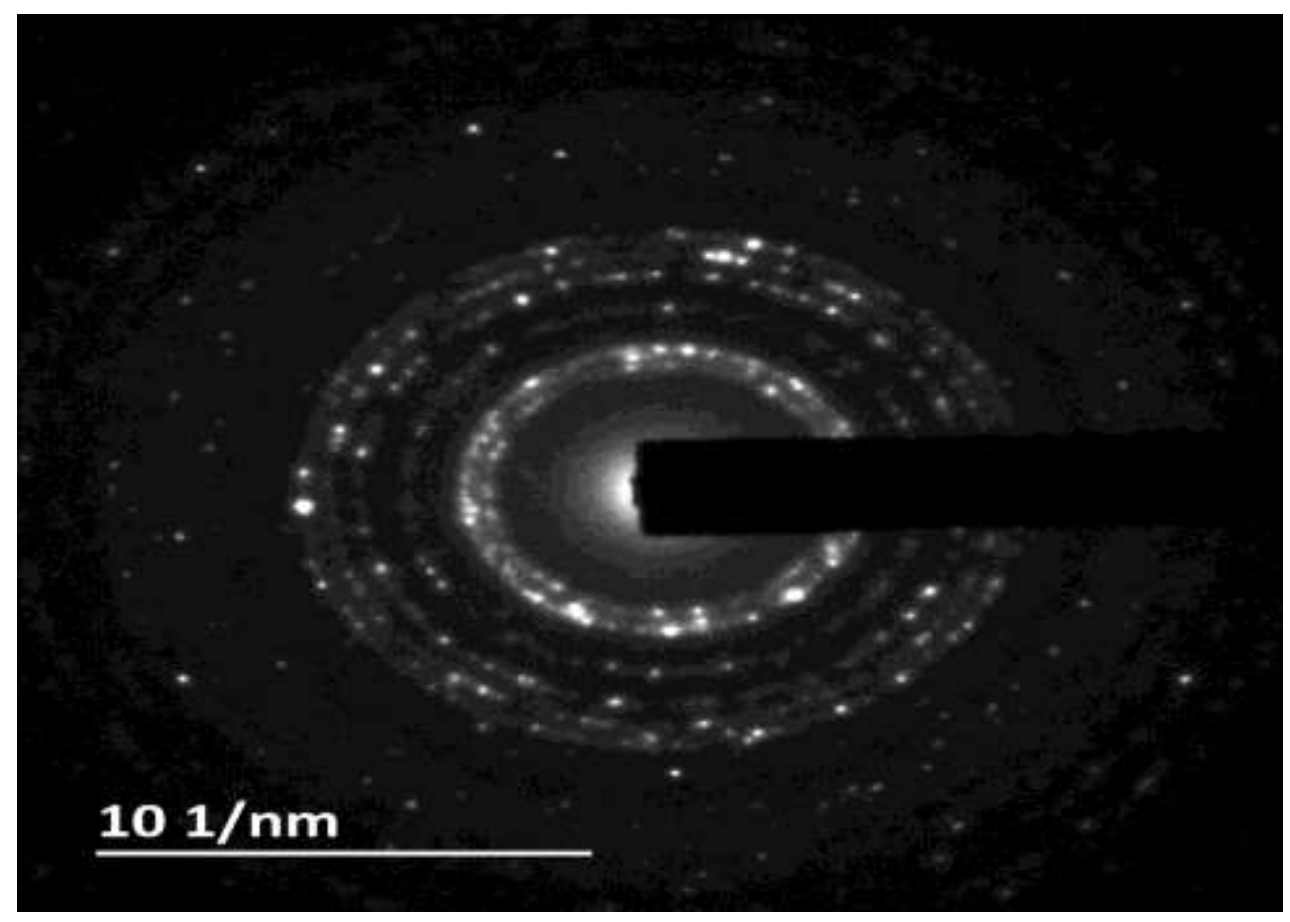

FIGURE 41 0_5_12_0016 (Rupa Haldavnekar, 2018) 
The figure 41 shows that it was generated at $0.5 \mathrm{~mm} / \mathrm{sec}$ scanning speed and $12 \mathrm{MHz}$ repetition rate and series of 0016. Series is the just the count of the images taken in same specification just for the record purpose.

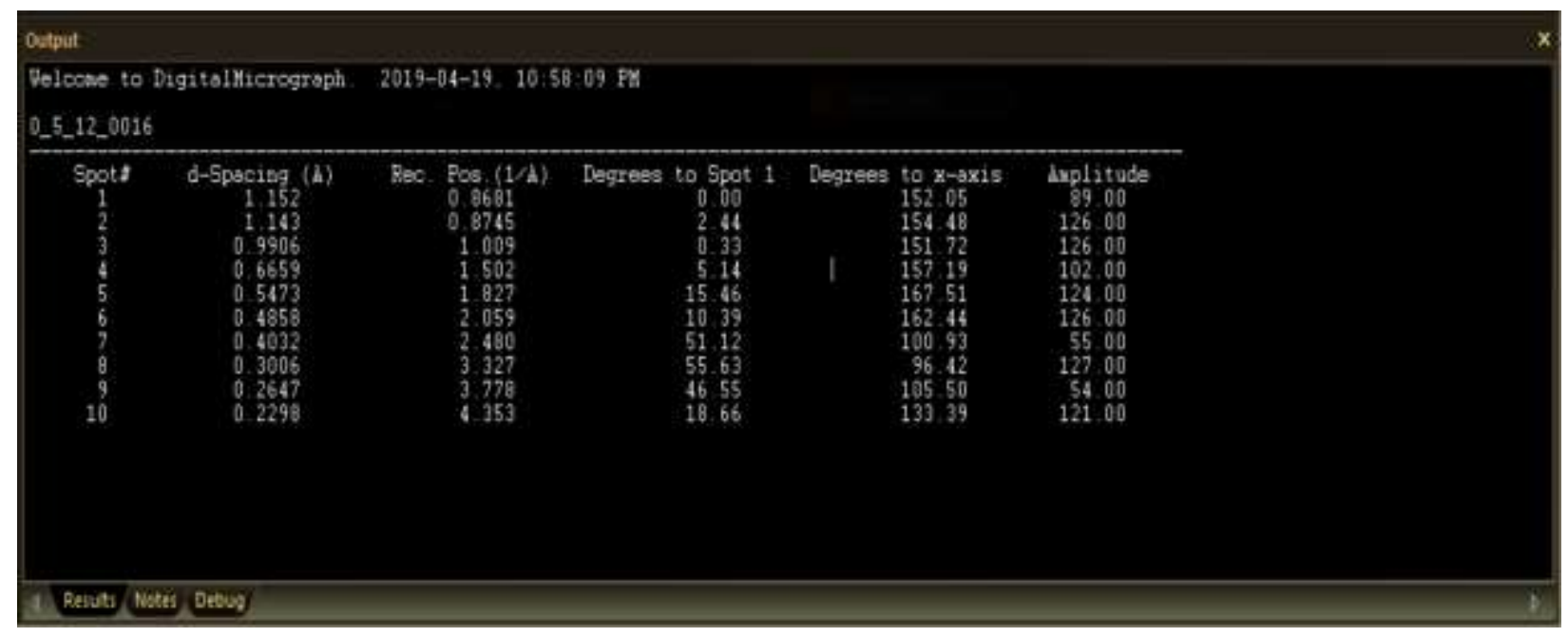

FIGURE 42 RESULTS OF THE SAED INDEXING OF 0_5_12_0016

In the above figure 42 the intense spot was $8^{\text {th }}$ spot which has the $\mathrm{d}$-spacing value of $0.4858 \mathrm{~nm}$. The $3^{\text {rd }}$ column indicates the position of the miller plane which is reciprocal of $\mathrm{d}$-spacing. The degrees measured to the current spot from the spot 1. The degrees of the spot aligned in polycrystalline structure to the $\mathrm{x}$-axis. The amplitude of the brightness of the spot. The amplitude of brightest spot is $127 \mathrm{~nm}$. 


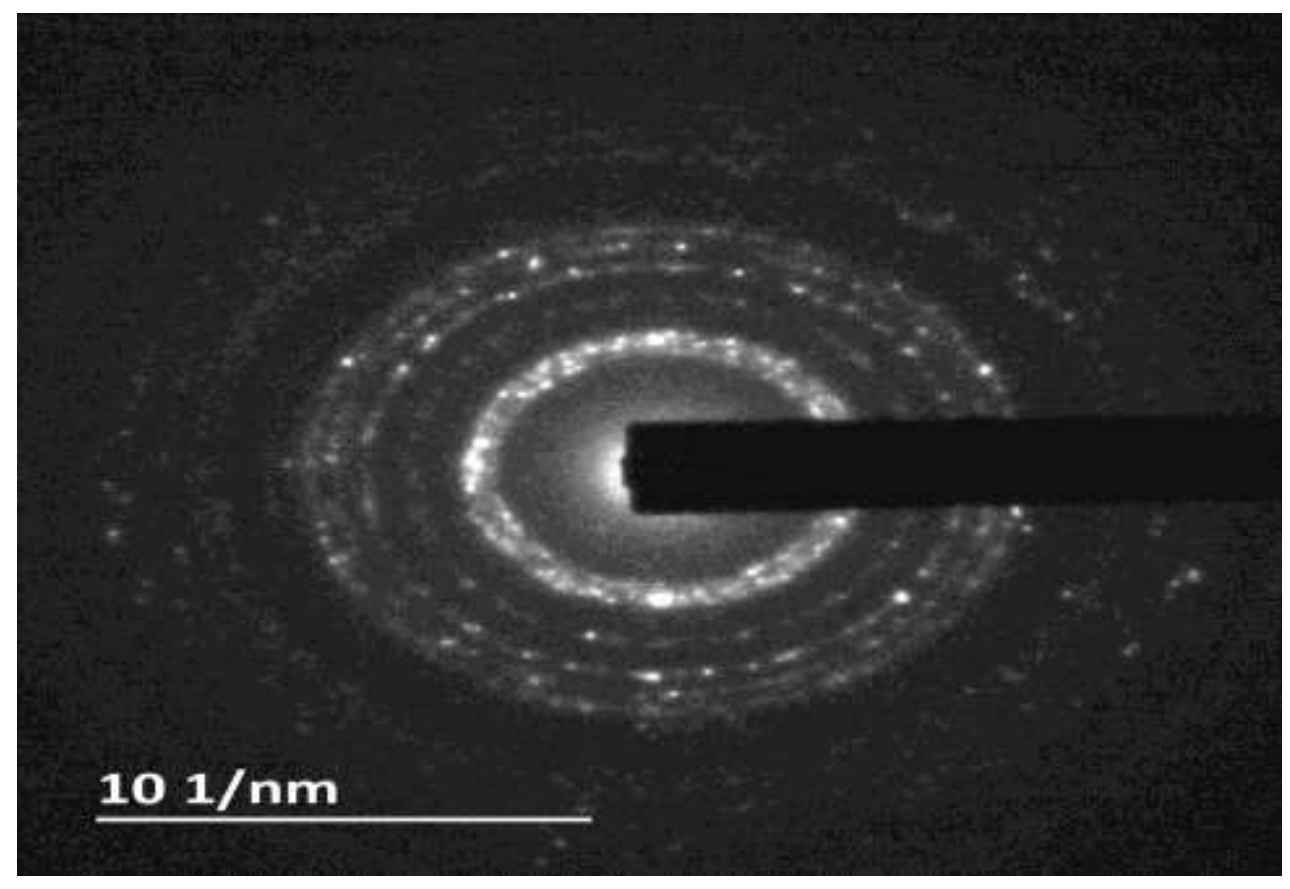

FIGURE 43 0_5_25_0009 (Rupa Haldavnekar, 2018)

\begin{tabular}{|c|c|c|c|c|c|c|}
\hline \multicolumn{6}{|l|}{ Output } & $x$ \\
\hline \multicolumn{6}{|c|}{$\begin{array}{l}\text { Welcone to DigitalWicrograph. 2019-04-16, 1:31:00 All } \\
\text { 0_5_25_0009 }\end{array}$} & \\
\hline $\begin{array}{c}\text { Spot: } \\
1 \\
2 \\
3 \\
4 \\
5 \\
6 \\
7 \\
8 \\
9 \\
10 \\
11 \\
12 \\
13 \\
14 \\
15\end{array}$ & $\begin{array}{c}\text { d-Spacing (m) } \\
1.200 \\
1.008 \\
0.7864 \\
0.6716 \\
0.6207 \\
0.5772 \\
0.4502 \\
0.3611 \\
0.3487 \\
0.3183 \\
0.3178 \\
0.3178 \\
0.3178 \\
0.3178 \\
0.4218\end{array}$ & $\begin{array}{c}\text { Pec. Pos. }(1 / \mathrm{ma}) \\
0.8332 \\
0.9923 \\
1.272 \\
1.489 \\
1.611 \\
1.733 \\
2.221 \\
2.624 \\
2.868 \\
3.142 \\
3.147 \\
3.147 \\
3.147 \\
3.147 \\
2.371\end{array}$ & $\begin{array}{c}\text { Degrees to Spot } 1 \\
0.00 \\
1.49 \\
1.86 \\
2.77 \\
0.57 \\
1.25 \\
5.94 \\
5.48 \\
1.36 \\
81.54 \\
81.68 \\
81.68 \\
81.68 \\
81.68 \\
11.58\end{array}$ & $\begin{array}{c}\text { Degrees to } z \text {-axis } \\
141.66 \\
140.18 \\
139.81 \\
144.44 \\
141.09 \\
140.41 \\
147.60 \\
147.14 \\
140.30 \\
60.13 \\
59.98 \\
59.98 \\
59.98 \\
59.98 \\
130.08\end{array}$ & $\begin{array}{c}\text { Alsplitude } \\
127.00 \\
126.00 \\
87.00 \\
-1.00 \\
127.00 \\
115.00 \\
66.00 \\
71.00 \\
83.00 \\
59.00 \\
56.00 \\
56.00 \\
56.00 \\
56.00 \\
71.00\end{array}$ & \\
\hline
\end{tabular}

FIGURE 44 RESULTS OF SAED INDEXING OF 0_5_25_0009 
In this case, the figure 44 shows the high intense spot is $2^{\text {nd }}$ spot which has d-spacing value of 1. $008 \mathrm{~nm}$. The brightest spot amplitude is $126 \mathrm{~nm}$.

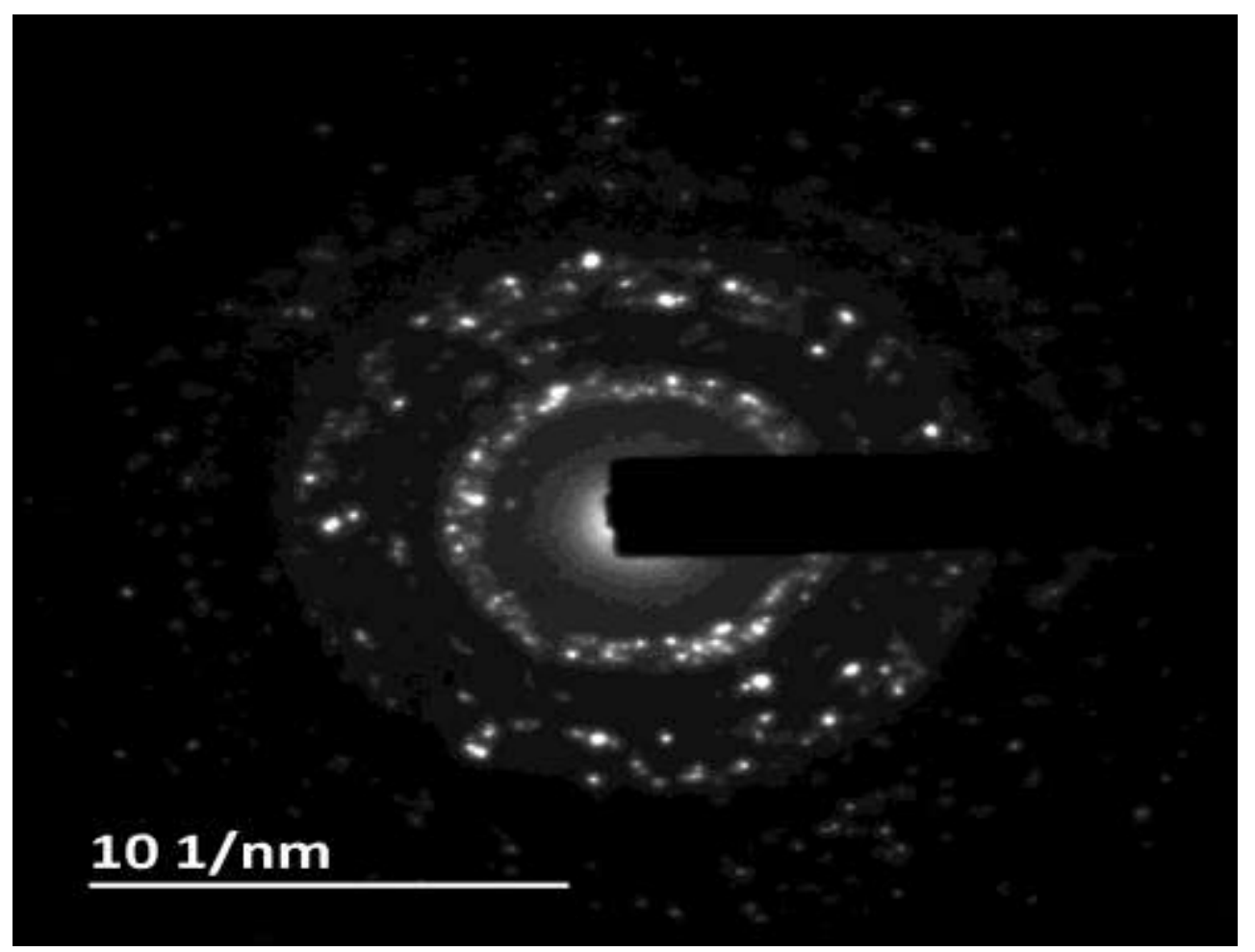

FIGURE 45 0_5_4_A_0001 (Rupa Haldavnekar, 2018) 


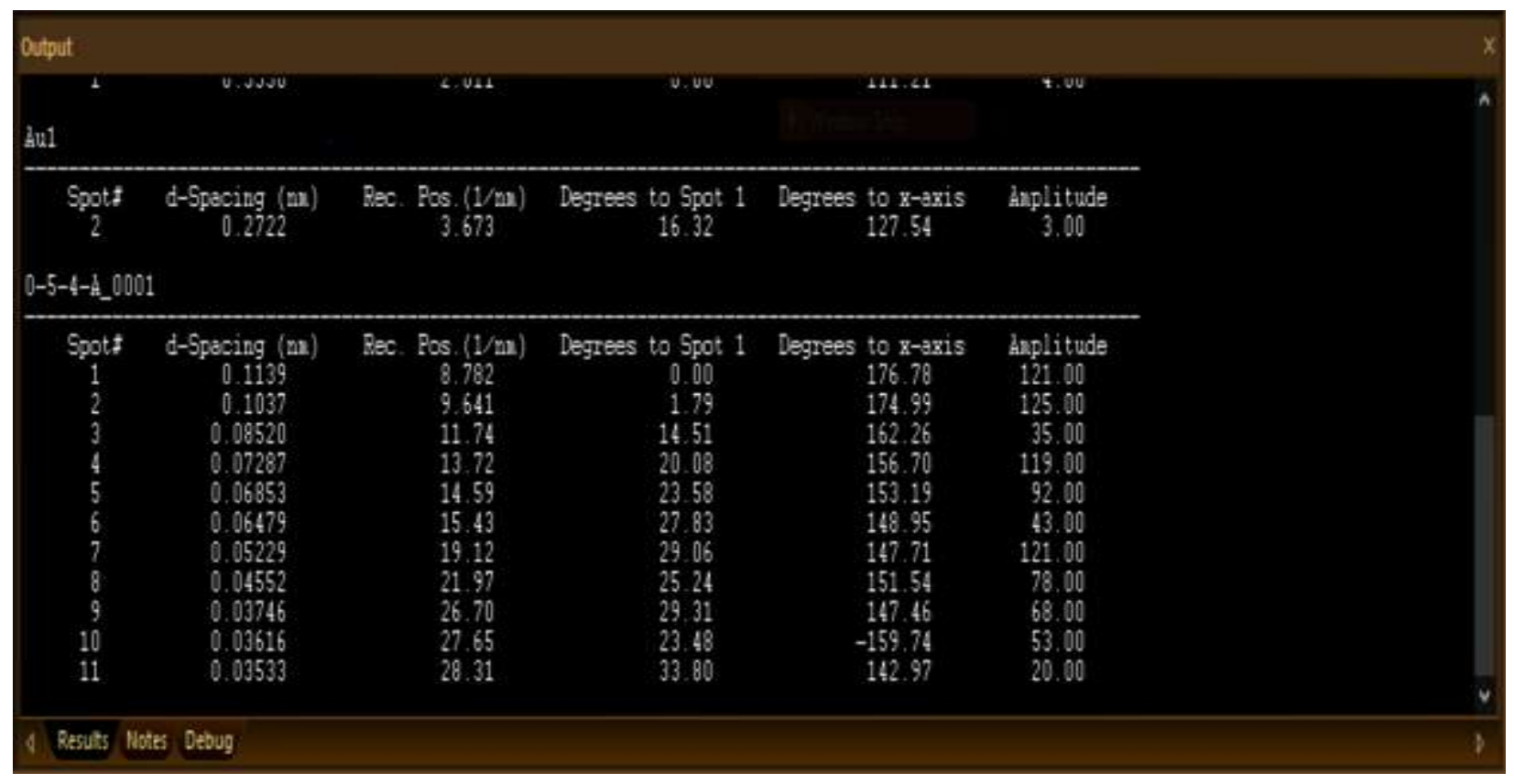

FIGURE 46 RESULTS OF SAED INDEXING OF 0_5_4_A_0001

The brightest spot in the above figure 46 was identified to be the $7^{\text {th }}$ spot with the $d$-spacing value of $0.05229 \mathrm{~nm}$. The brightest spot amplitude is $121 \mathrm{~nm}$. 


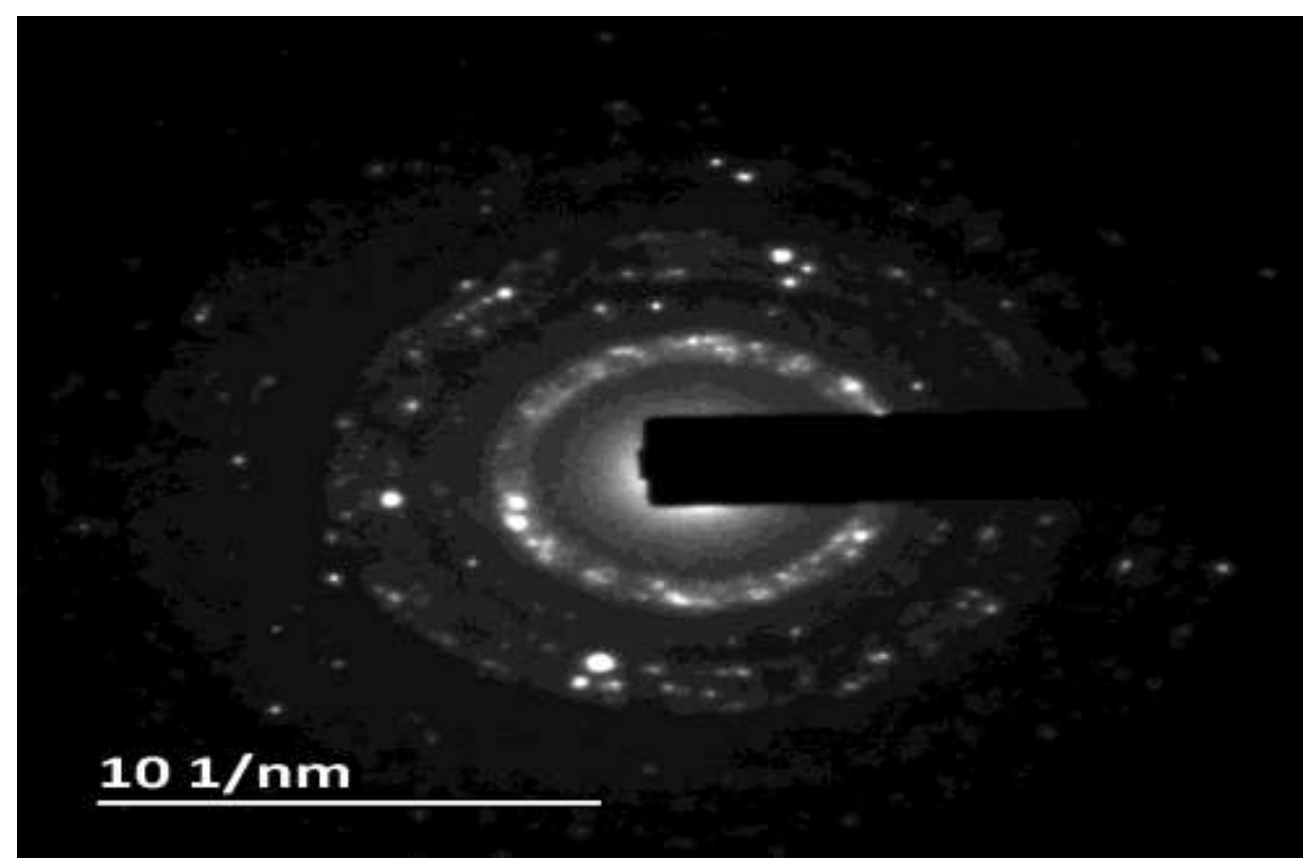

FIGURE 47 0_5_4_N2_0002 (Rupa Haldavnekar, 2018)

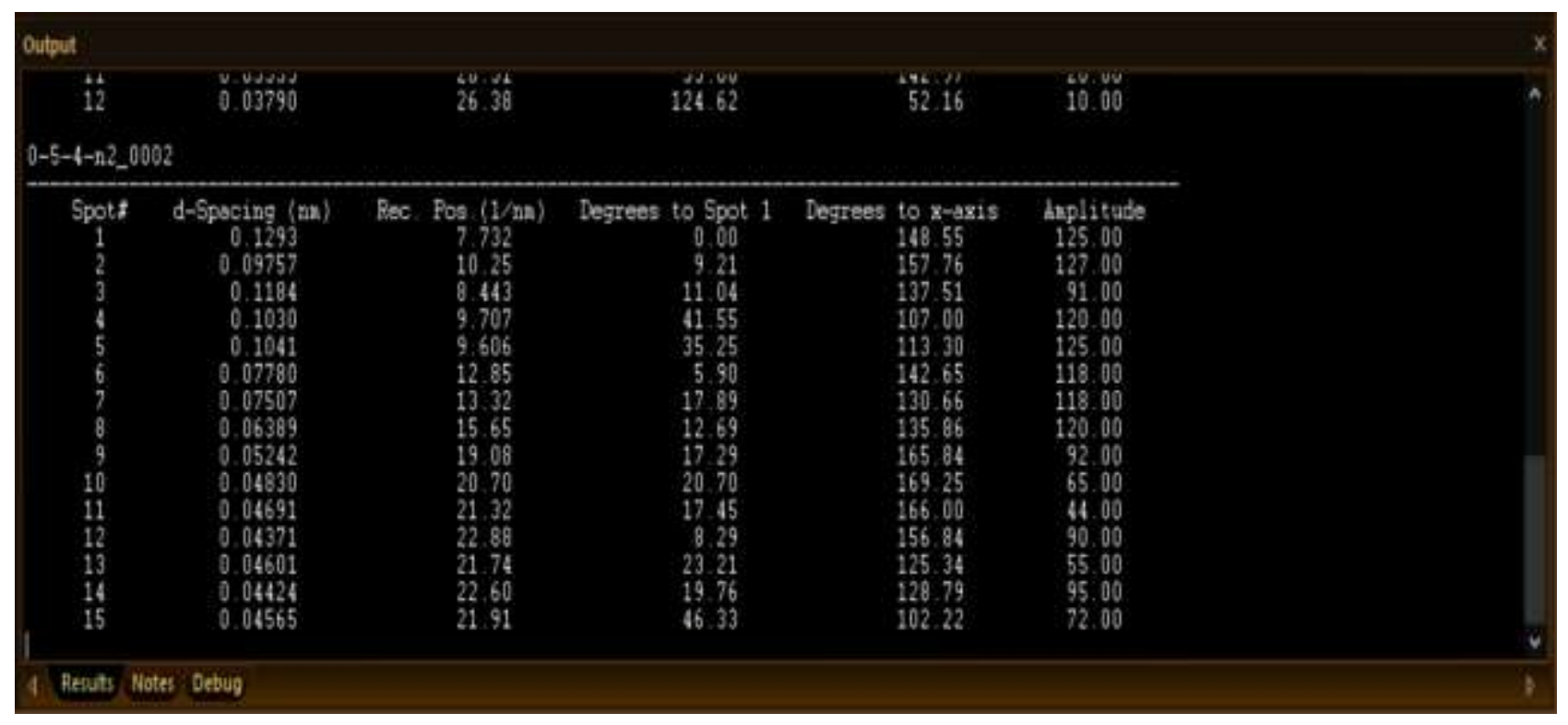

\section{FIGURE 48 RESULTS OF SAED INDEXING OF 0_5_4_N2_0002}

The brightest spot was identified as the $2^{\text {nd }}$ spot in the figure 48 and the spot has the $d$-spacing value as the $0.0975 \mathrm{~nm}$. The brightest spot amplitude is $127 \mathrm{~nm}$. 


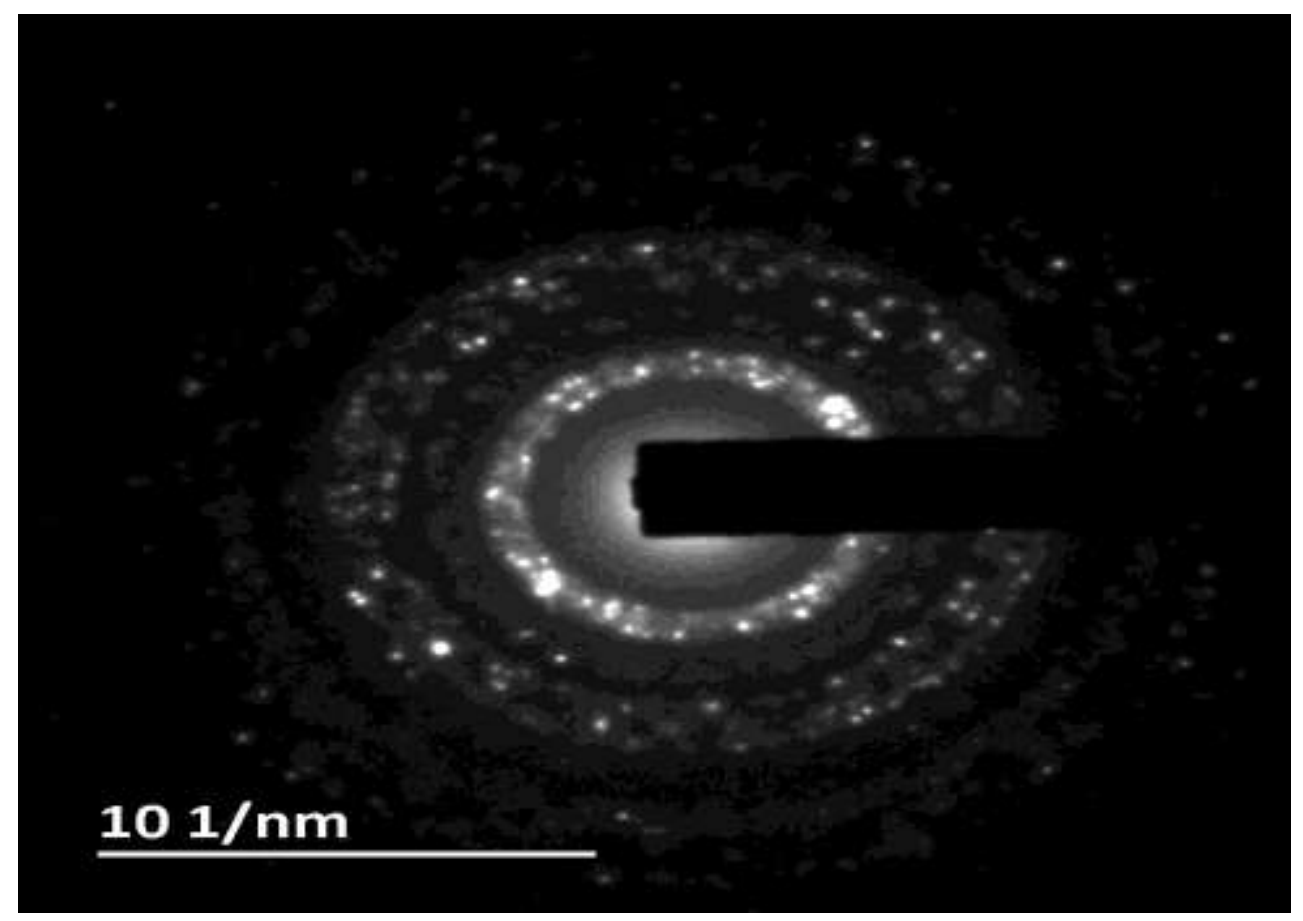

FIGURE 49 0_5_4_N2_0003 (Rupa Haldavnekar, 2018)

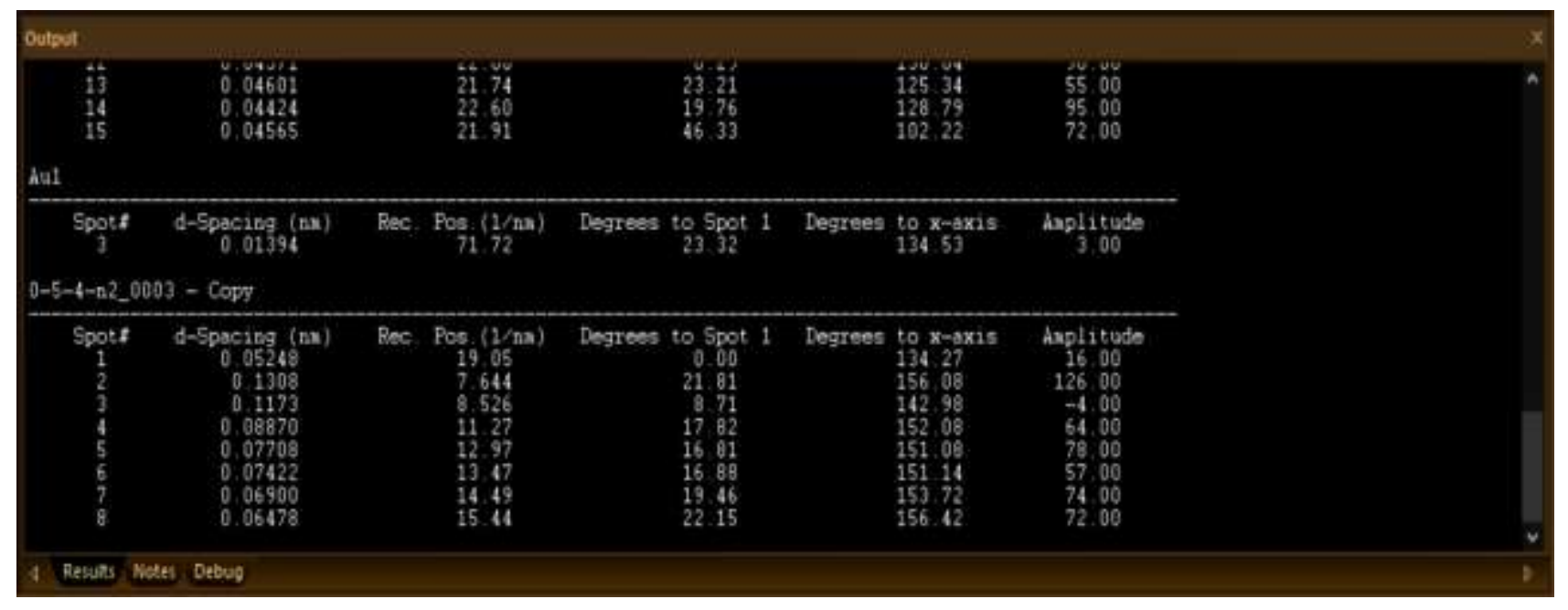

FIGURE 50 RESULTS OF SAED INDEXING OF THE 0_5_4_N2_0003 
The figure number 50 shows the brightest spot was identified to be the $2^{\text {nd }}$ spot and it has the dspacing value of $0.1308 \mathrm{~nm}$. The brightest spot amplitude is $126 \mathrm{~nm}$.

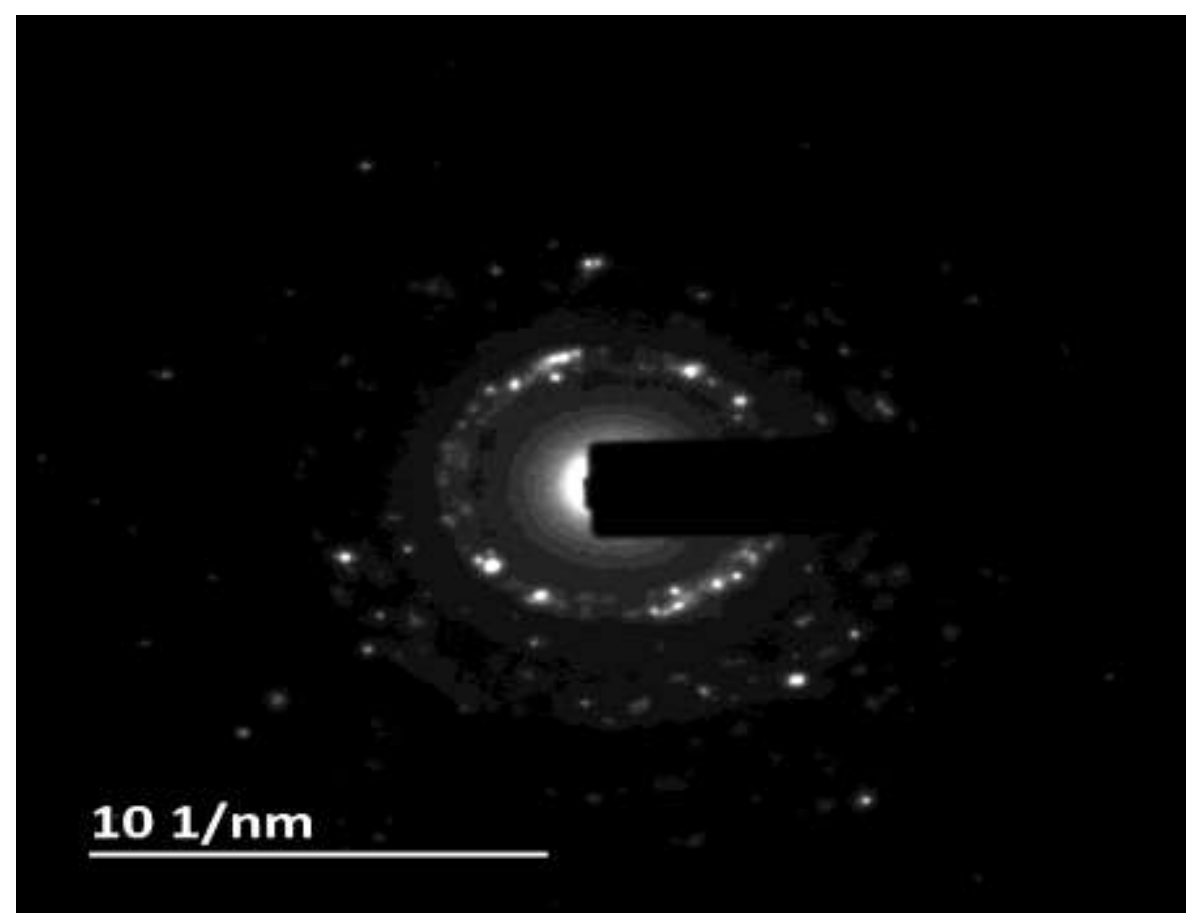

FIGURE 51 0_5_12_N2_0001 (Rupa Haldavnekar, 2018) 


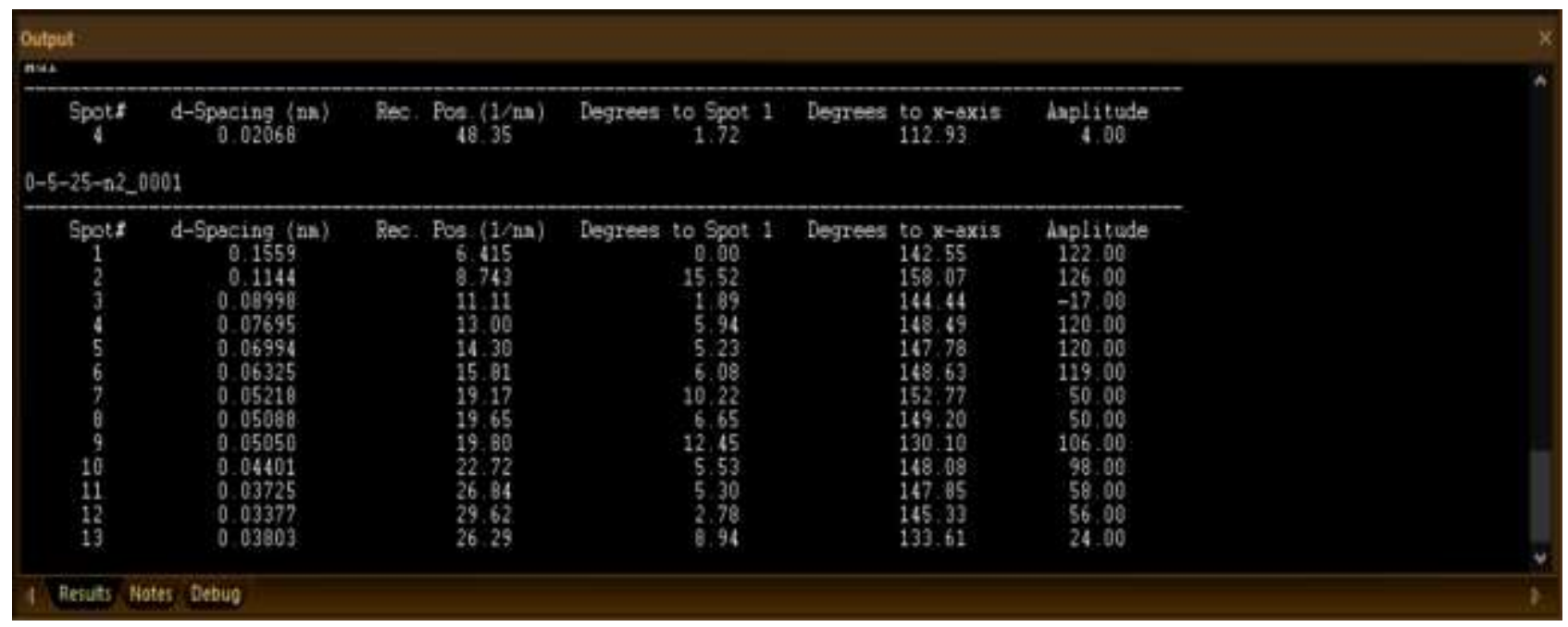

FIGURE 52 RESULTS OF SAED INDEXING OF 0_5_12_N2_0001

The high intense spot among the spots selected in the above figure 51 is shown in figure $52,1^{\text {st }}$ spot which has a d-spacing value of $0.1559 \mathrm{~nm}$. The brightest spot amplitude is $122 \mathrm{~nm}$.

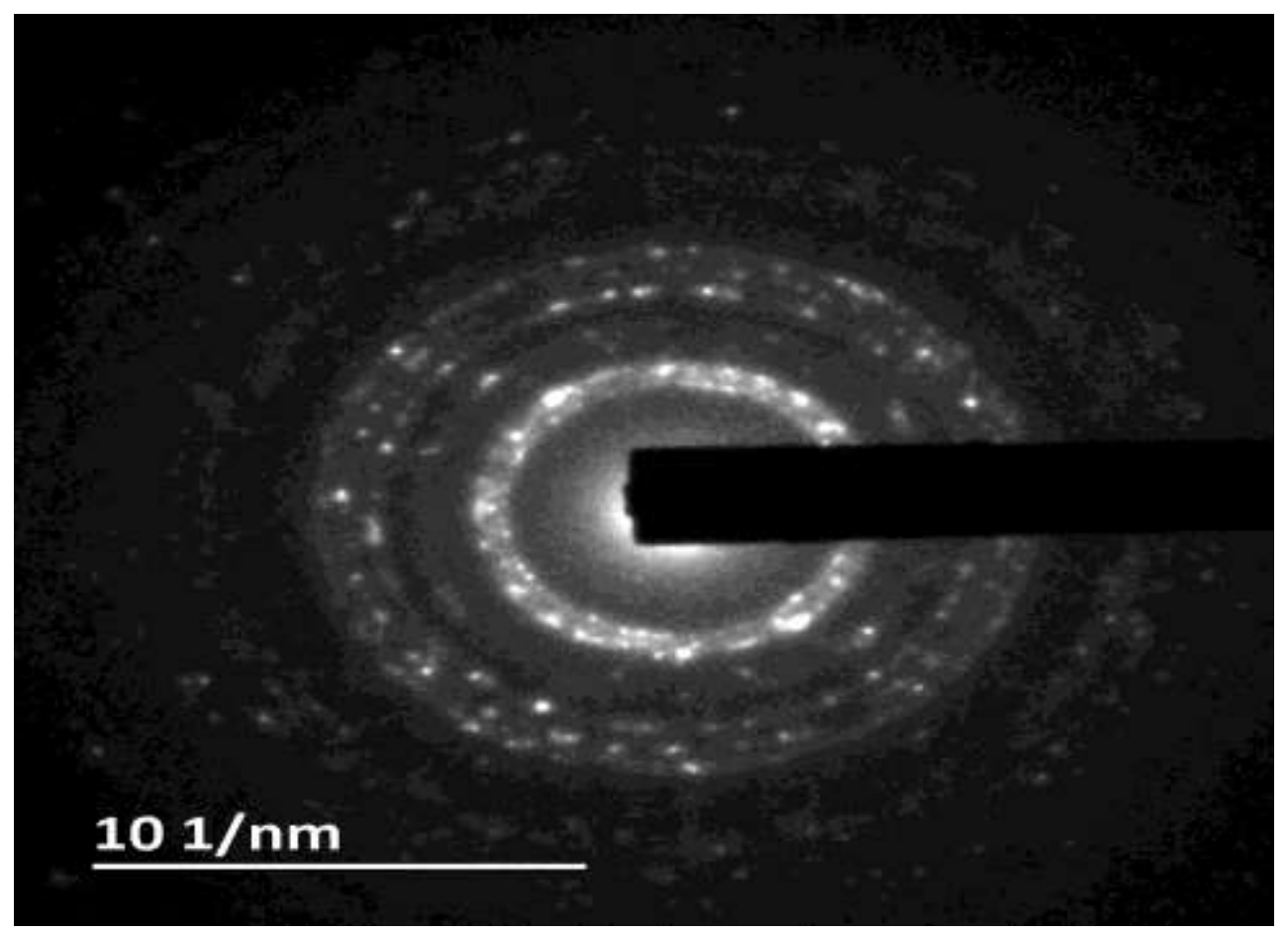

FIGURE 53 0_5_25_N2_0001 (Rupa Haldavnekar, 2018) 


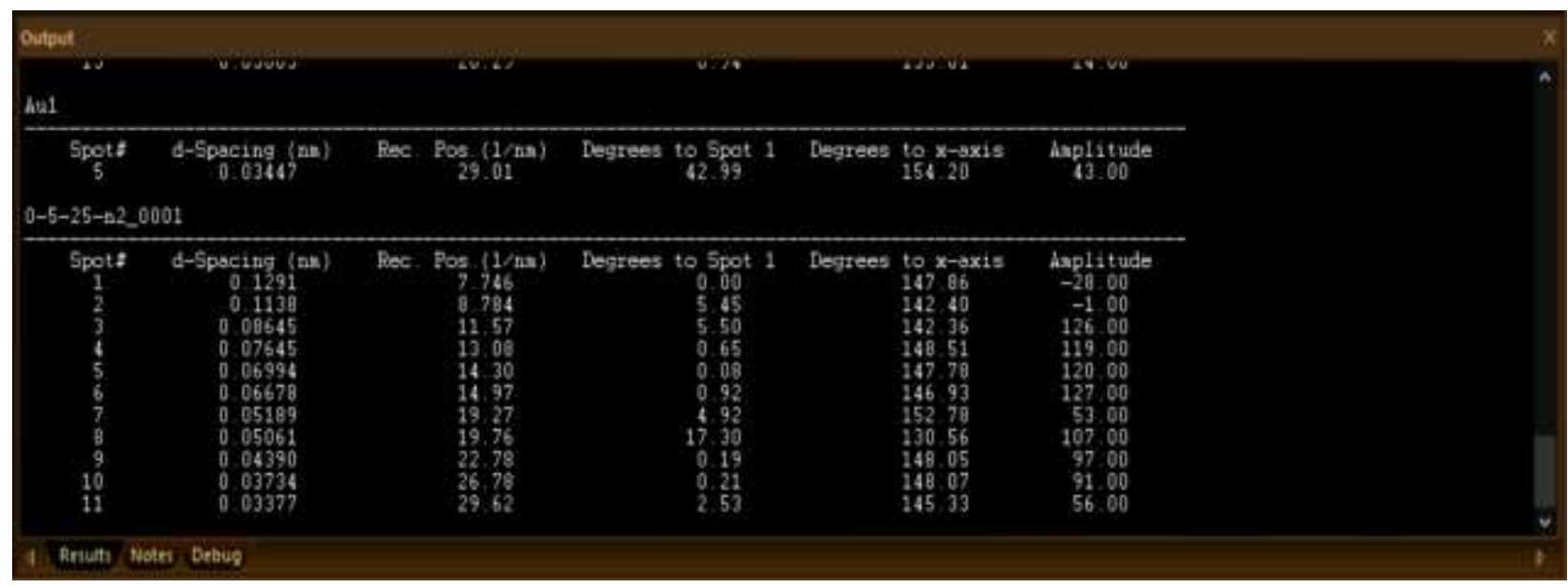

FIGURE 54 RESULTS OF SAED INDEXING OF 0_5_25_N2_0001

The figure 54 shows the brightest spot in this result was derived to be $6^{\text {th }}$ one and the $d$-spacing for this is $0.06678 \mathrm{~nm}$. The brightest spot amplitude is $127 \mathrm{~nm}$.

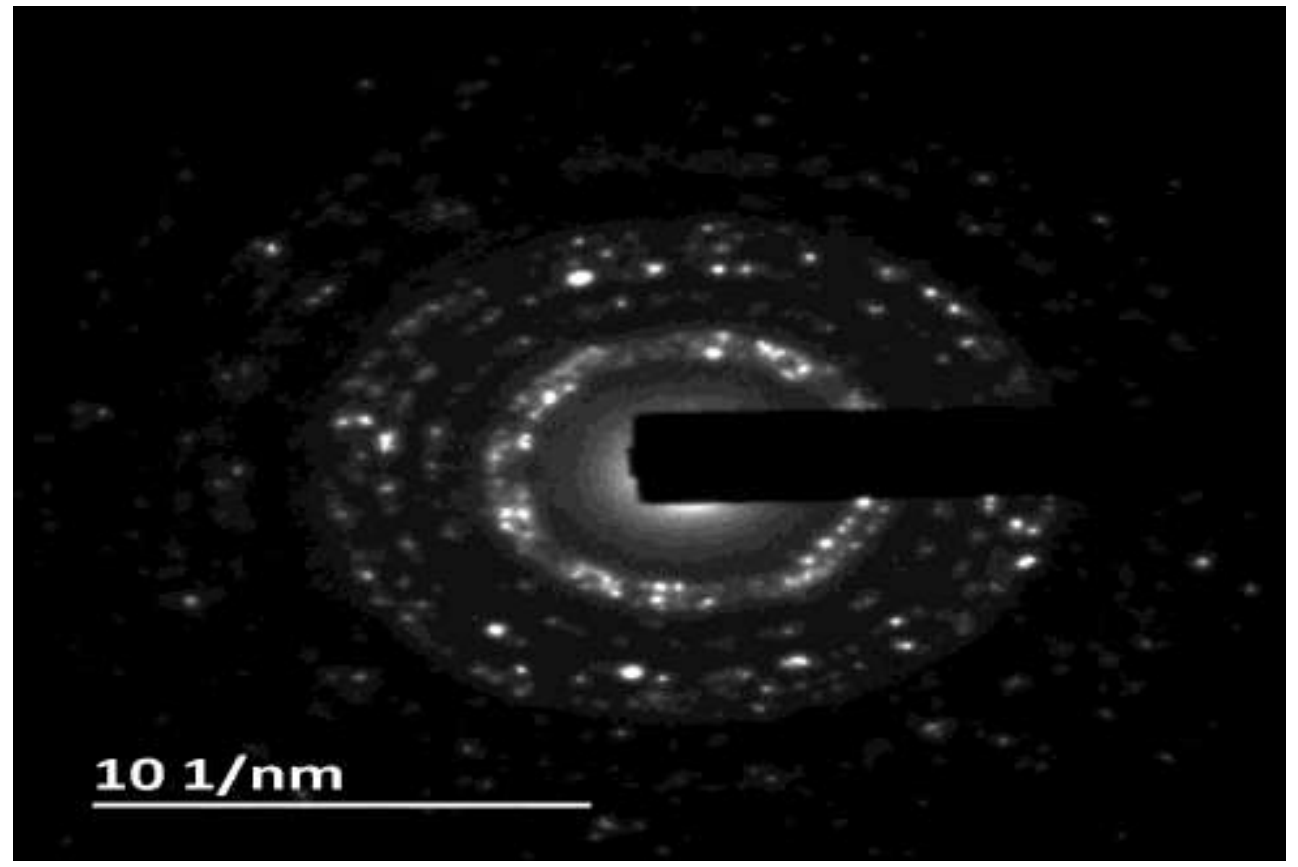

FIGURE 55 0_5_25_N2_0002 (Rupa Haldavnekar, 2018) 


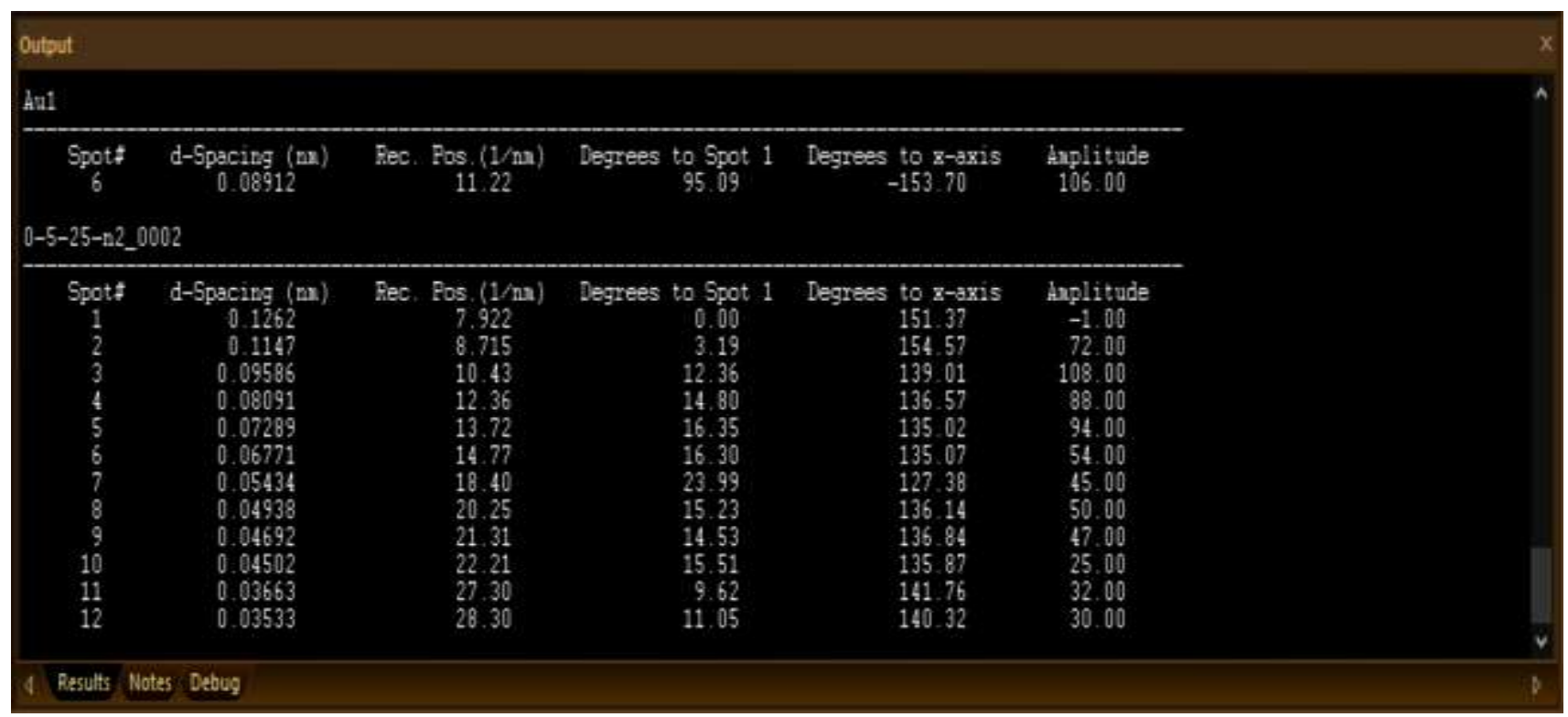

FIGURE 56 RESULTS OF THE SAED INDEXING OF 0_5_25_N2_0002

The figure 56 shows the brightest spot in the above was found to be $4^{\text {th }}$ spot $0.09586 \mathrm{~nm}$ with the amplitude $108 \mathrm{~nm}$. 


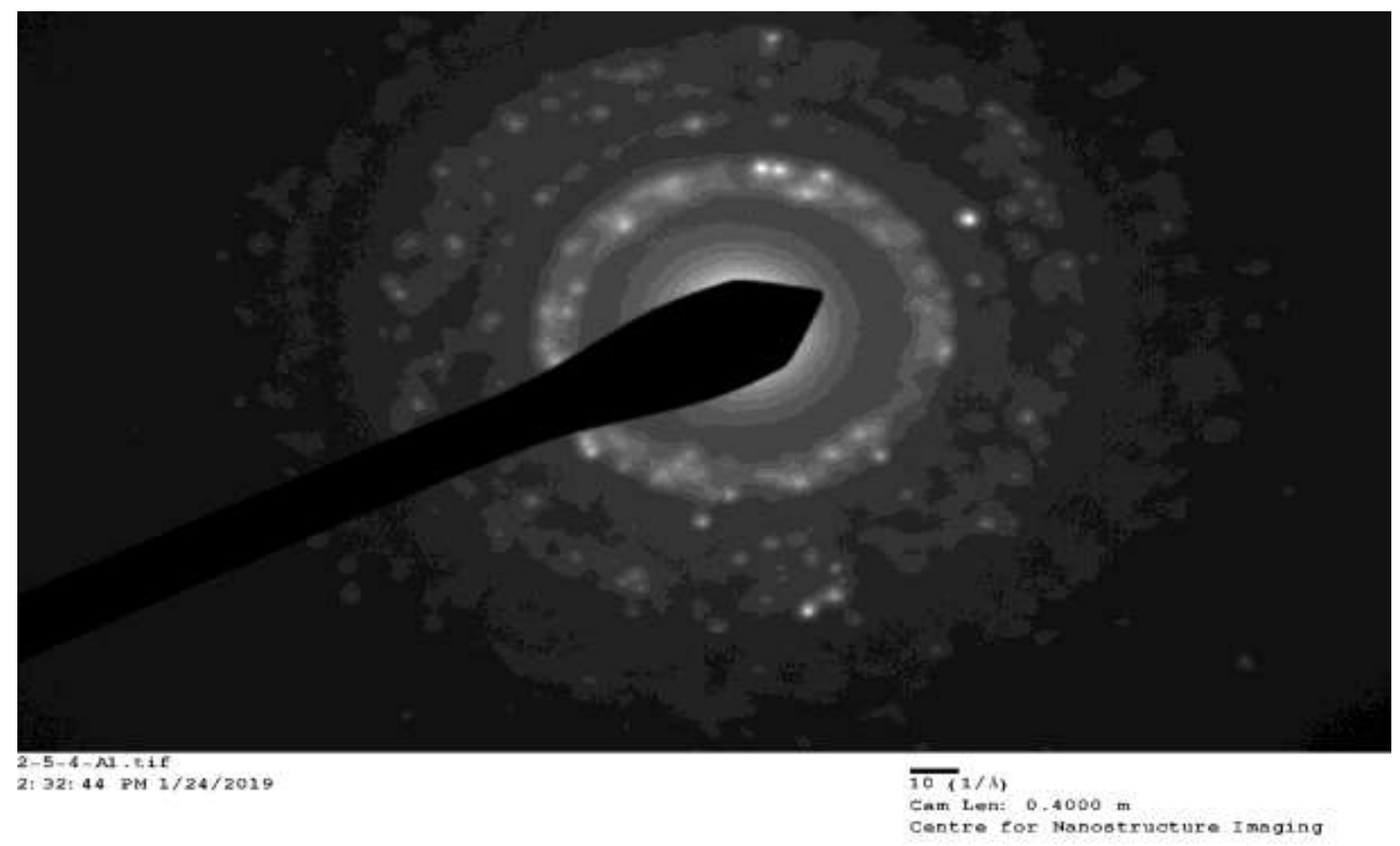

FIGURE 57 2_5_4_A1 (Rupa Haldavnekar, 2018)

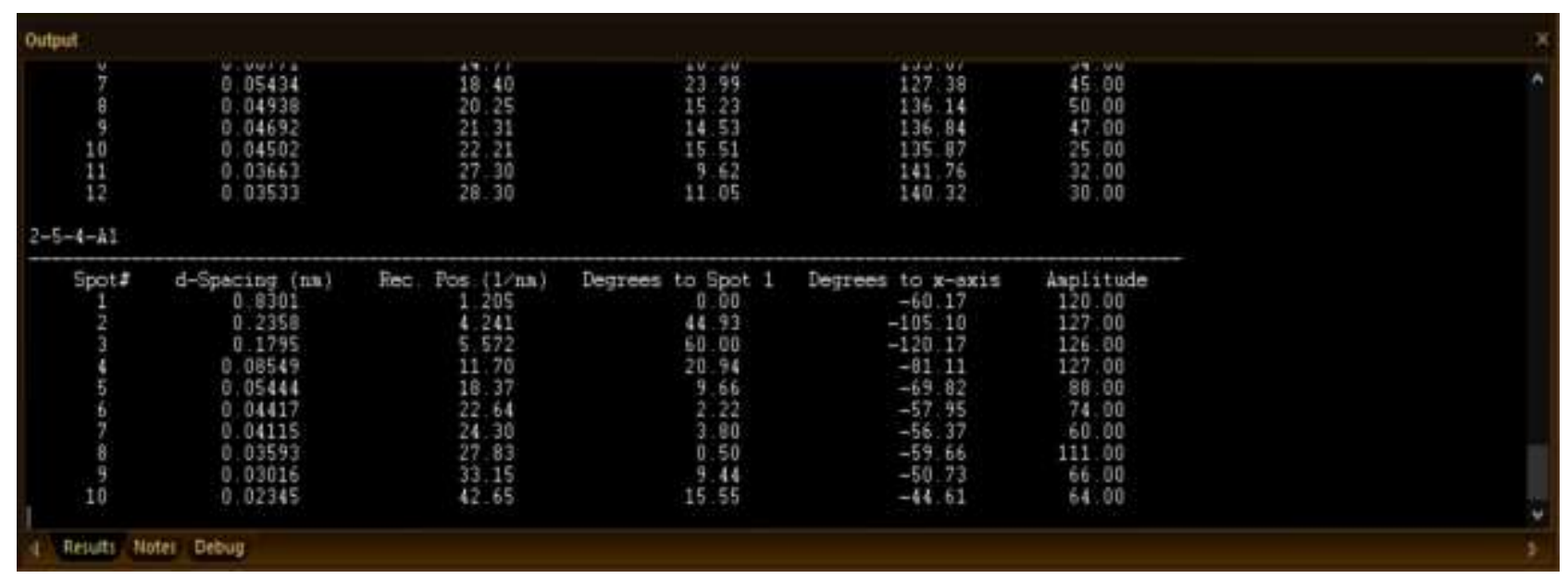

FIGURE 58 RESULTS OF SAED INDEXING OF THE 2_5_4_A1

The figure 58 shows the brightest spot in the above result was found to be $4^{\text {th }}$ spot which has the $\mathrm{d}$-spacing value of $0.08549 \mathrm{~nm}$. The brightest spot amplitude is $127 \mathrm{~nm}$. 


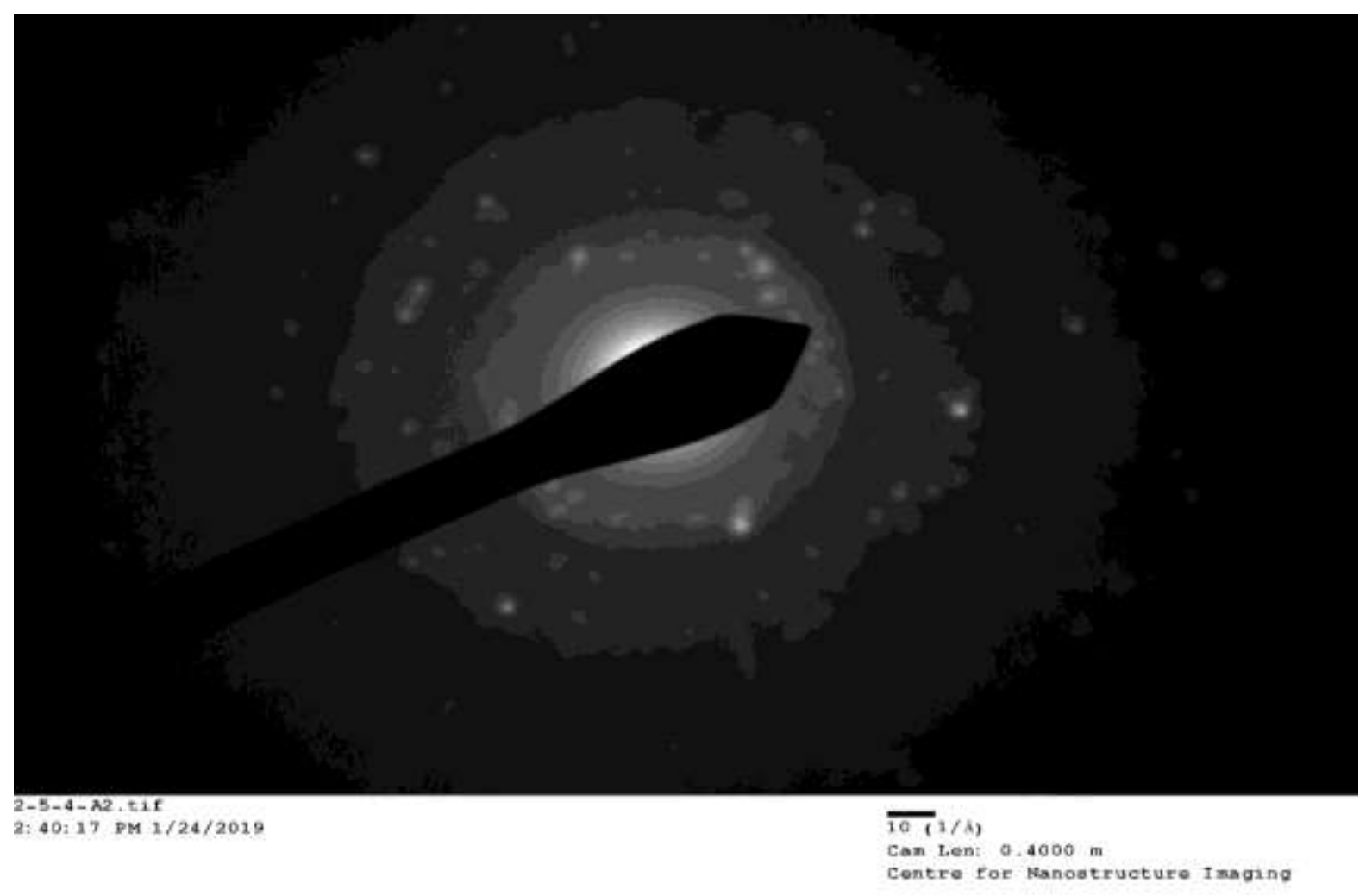

FIGURE 59 2_5_4_A2 (Rupa Haldavnekar, 2018) 


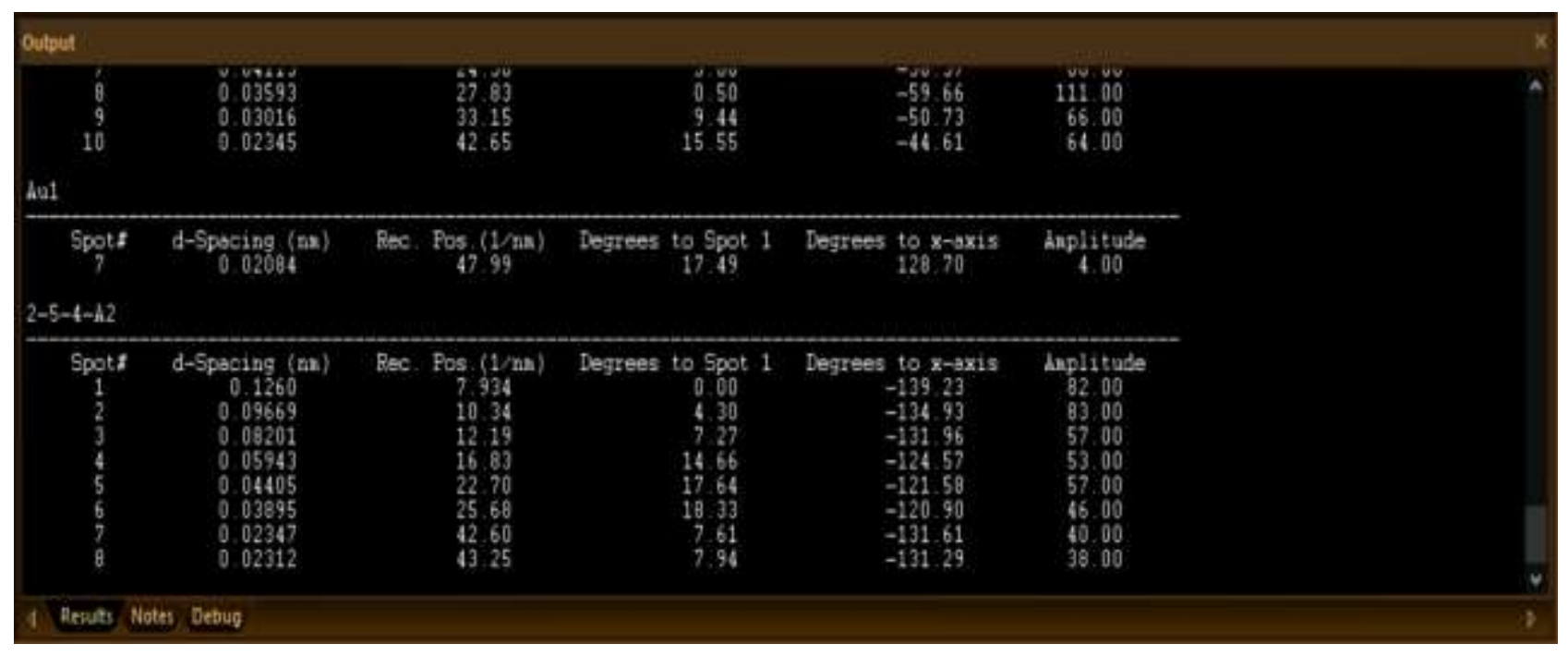

FIGURE 60 RESULTS OF SAED INDEXING OF 2_5_4_A2

The above figure 60 shows the brightest spot with d-spacing $0.09669 \mathrm{~nm}$ which is $2^{\text {nd }}$ spot from the centre of the rings. The brightest spot amplitude is $83 \mathrm{~nm}$. The SAED is a complementary to the TEM results. These can give the lattice $\mathrm{d}$ spacing for the above polycrystalline results. The tables show the $\mathrm{d}$ spacing along with the highest intense spot can be determined by indexing process. It can be obtained by using spacing angle by determining the centre of the polycrystalline plot using diffpack options auto find centre and then transferring the Calibration from standard AURAM (gold) polycrystalline plot image. Using the spacing angle tool each ring is been selected from the centre until the last ring to the find the highest intense plane (111) plane with the help of the spots selected. 


\begin{tabular}{|l|l|l|}
\hline Image Name & $\begin{array}{l}\text { d-spacing of the brightest } \\
\text { spot } \\
(\mathbf{n m})\end{array}$ & $\begin{array}{l}\text { Amplitude of the brightest } \\
\text { spot (nm) }\end{array}$ \\
\hline 0_5_12_0016 & 0.4858 & 127 \\
\hline 0_5_25_0009 & 1.008 & 126 \\
\hline 0_5_4_A_0001 & 0.05229 & 121 \\
\hline 0_5_4_n2_0002 & 0.0975 & 127 \\
\hline 0_5_4_n2_0003 & 0.1308 & 126 \\
\hline 0_5_12_n2_0001 & 0.1559 & 122 \\
\hline 0_5_25_n2_0001 & 0.06678 & 127 \\
\hline 0_5_25_n2_0002 & 0.09586 & 108 \\
\hline 2_5_4_A1 & 0.08549 & 127 \\
\hline 2_5_4_A2 & 0.09669 & 83 \\
\hline
\end{tabular}

TABLE 10 SUMMARY OF SAED RESULT WITH AMPLITUDES OF BRIGHTEST SPOTS

From the above table number 10 it can be understood that the amplitudes ranges from 83 to $127 \mathrm{~nm}$. The maximum bright spots are in the series of 120's. The amplitude helps in understanding the energy of the particles which can be related to the structural properties of the material, isoelectric properties and also sonochemical effects of the material . 


\subsection{FTIR RESULTS:}

These curves were analysed using the spectragryph software. The .csv files with the absorbance values and the wavenumber values are imported to the software to get the plot. And to analyse the curve peaks properly the absorbance plot is reversed which exhibits the transmittance plot.

The curves were smoothed and normalised and baselines were adjusted to see only the major transformations.

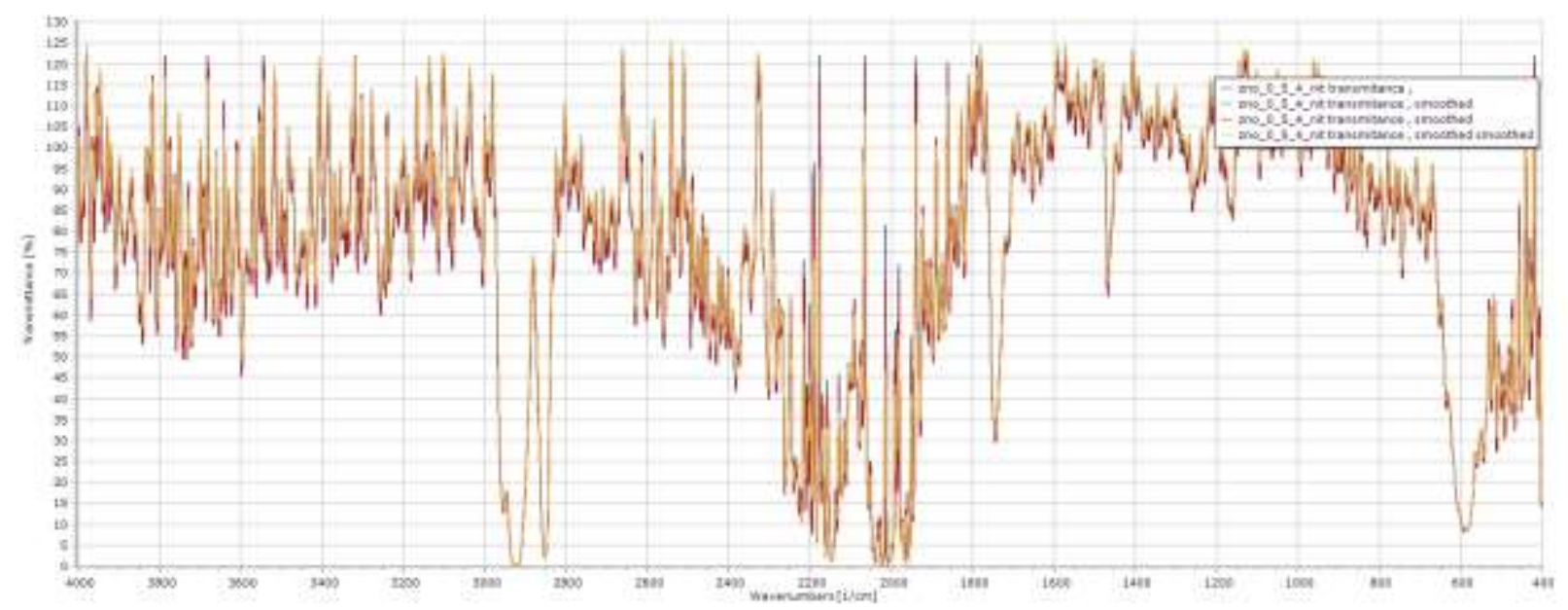

\section{PLOT 1 SPECTROGRAPH ANALYSIS OF 0_5_4 ZnO MATERIAL.}

The above plot 1 shows that there are two deep peaks in between 2800 and 3000 1/cm. These deep peaks indicate the stretching vibrations. In between the 400 and $6001 / \mathrm{cm}$ there are continuous fluctuations this area represents the prepared nanoparticles. This plot is for the repetition rate of $4 \mathrm{MHz}$ at $0.5 \mathrm{~mm} / \mathrm{s}$ scanning speed. 


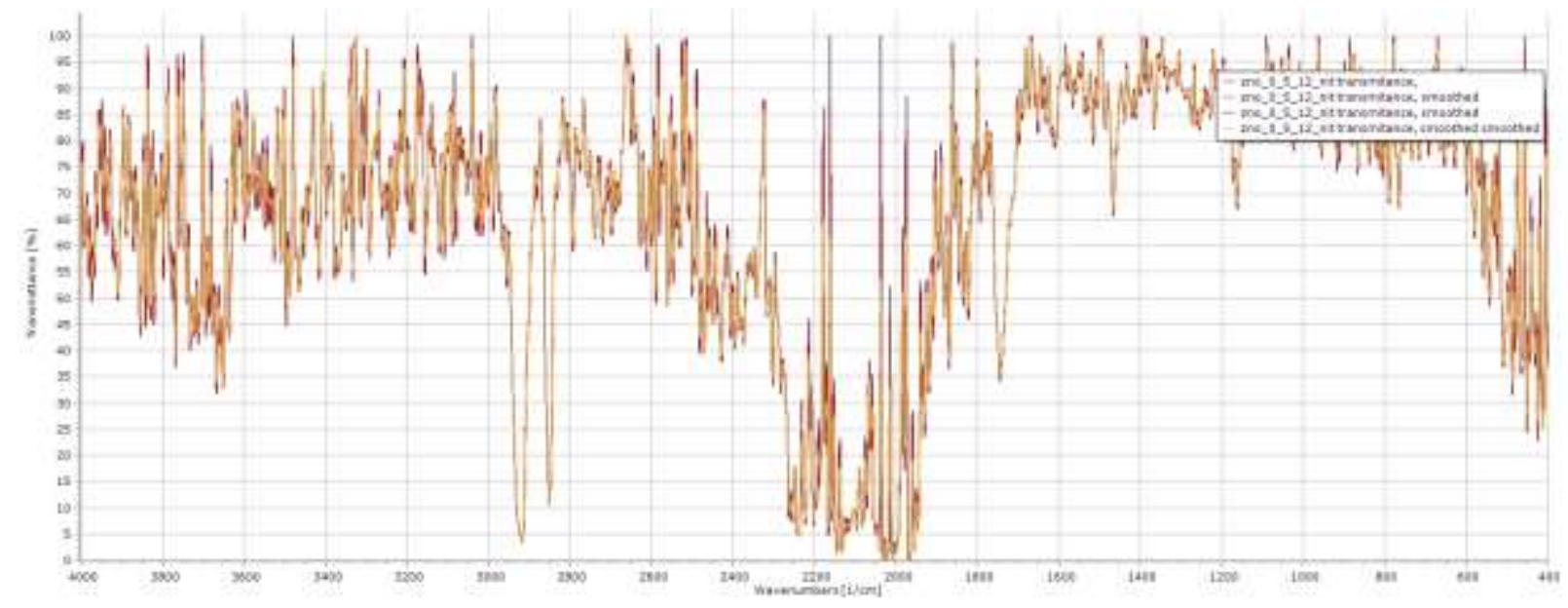

\section{PLOT 2 SPECTRAGRAPH ANALYSIS OF 0_5_12}

The above plot 2 shows the similar results to the previous the major difference is that the fluctuations in peaks in between the wavenumbers are bit raised up by the \% levels of transmittance from $10 \%$ to $30 \%$.

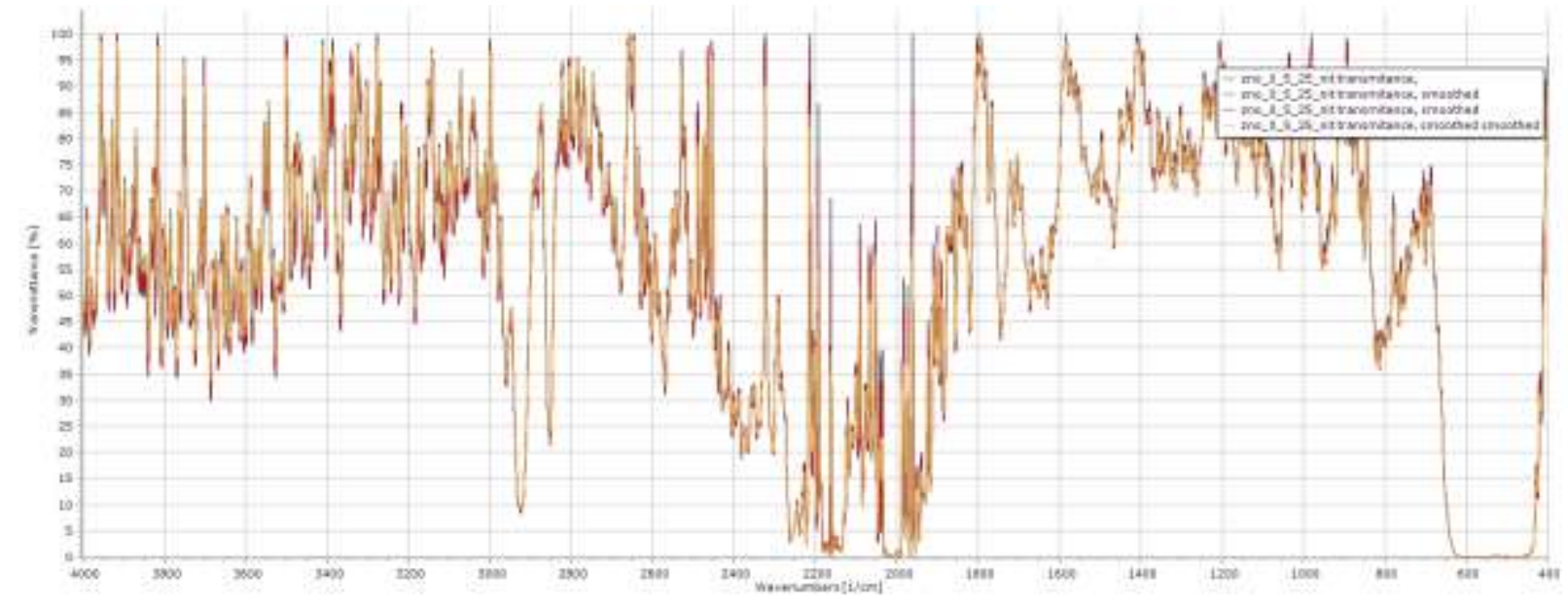

PLOT 3 SPECTRAGRYPH RESULTS OF 0_5_25 ZnO MATERIAL 
The third plot number 3 shows the results at repetition rate of $5 \mathrm{MHz}$ at same scanning speed of $0.5 \mathrm{~mm} / \mathrm{sec}$ here the major difference is in between the 400 and $6001 / \mathrm{cm}$ of wavenumbers that the percentage of transmittance levels completely goes down which indicates that prepared nanoparticles has lost its all transmittance power at this repetition rate of $25 \mathrm{MHz}$.

The plots 1, 2 and 3 shows the same results except the difference in the fluctuations in 400 to 600 nm. The IR modes in all the above 3 plots show, at 400 to 600 wavenumbers contributes to prepared nanoparticles. The IR mode at 600 wavenumbers as it's the deep curve it must be the substitutional hydrogen at oxygen $\mathrm{H}_{0}$ bound to the lattice zinc site. This oxygen might act as a shallow donor in the $\mathrm{ZnO}$.

There is no special doping in all the samples as there is no passivation of curves as from the reference material, so this doesn't assert any substitution of different material in the place of $\mathrm{O}$ in $\mathrm{ZnO}$ lattice.

The broader peaks contribute to the bending mode of hydroxyl group again.

The modes between the wavenumbers 2800 and 3000 for all samples are observed these are usually assigned to the $\mathrm{O}-\mathrm{C}=\mathrm{O}$ symmetric and asymmetric stretching vibrations and $\mathrm{C}-\mathrm{O}$ bond vibrations due to ambient conditions. There is substantial difference between the 3 plots in between the wavenumbers of 800 to $4001 / \mathrm{nm}$ in $25 \mathrm{MHz}$ repetition the curves completely flattens out, in $12 \mathrm{MHz}$ repetition the fluctuations in curves gradually decreases and in the $4 \mathrm{MHz}$ repetition there is sudden drop and then there are fluctuations rise. 


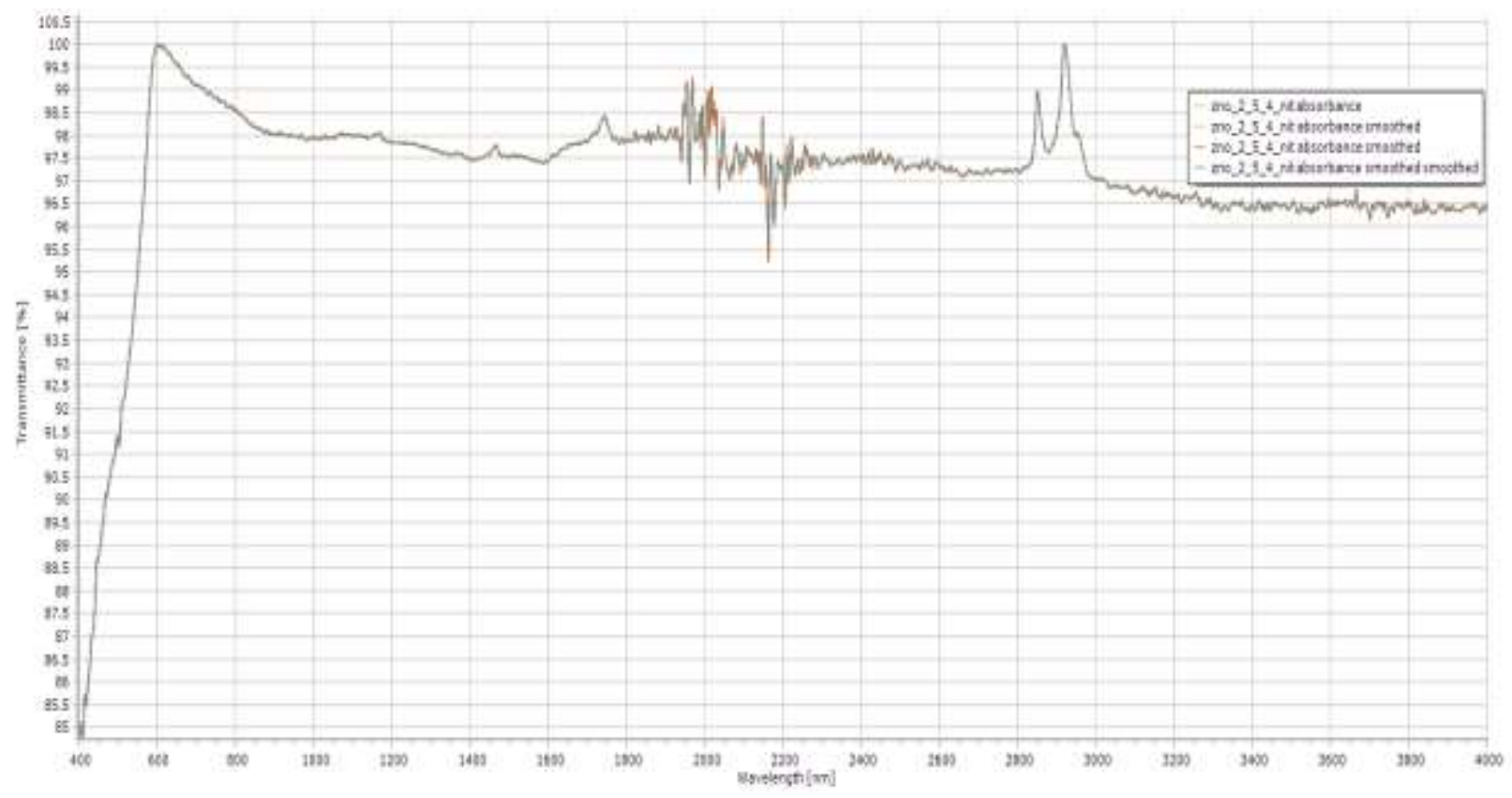

\section{PLOT 4 SPECTRAGRYPH RESULTS OF 2_5_4 ZnO MATERIAL}

The above plot 4 shows there is sharp peak and substantial rise in the $\%$ transmittance in between the wavelength of 400 and $600 \mathrm{~nm}$. Which indicates that the specimen has high receptivity during this phase and has the high transmissibility power in this phase. These parameters correspond to the electrical properties of the material. And then there is the gradual decrease and there are continuous fluctuations in the transmittance from $1800 \mathrm{~nm}$ to $2200 \mathrm{~nm}$ this indicates the unstable chemical bonds transmissibility that on the whole leads to weak electrical properties and optical properties. In the similar wavelengths of 2800 to $3000 \mathrm{~nm}$ there are 2 peaks there are 2 peaks like previous 3 plots which indicates the symmetric and asymmetric vibrations due to ambient conditions. These all corresponds to the better structural properties, which are being used in nanorods where the aircraft outer structures are being coated in present industry. 


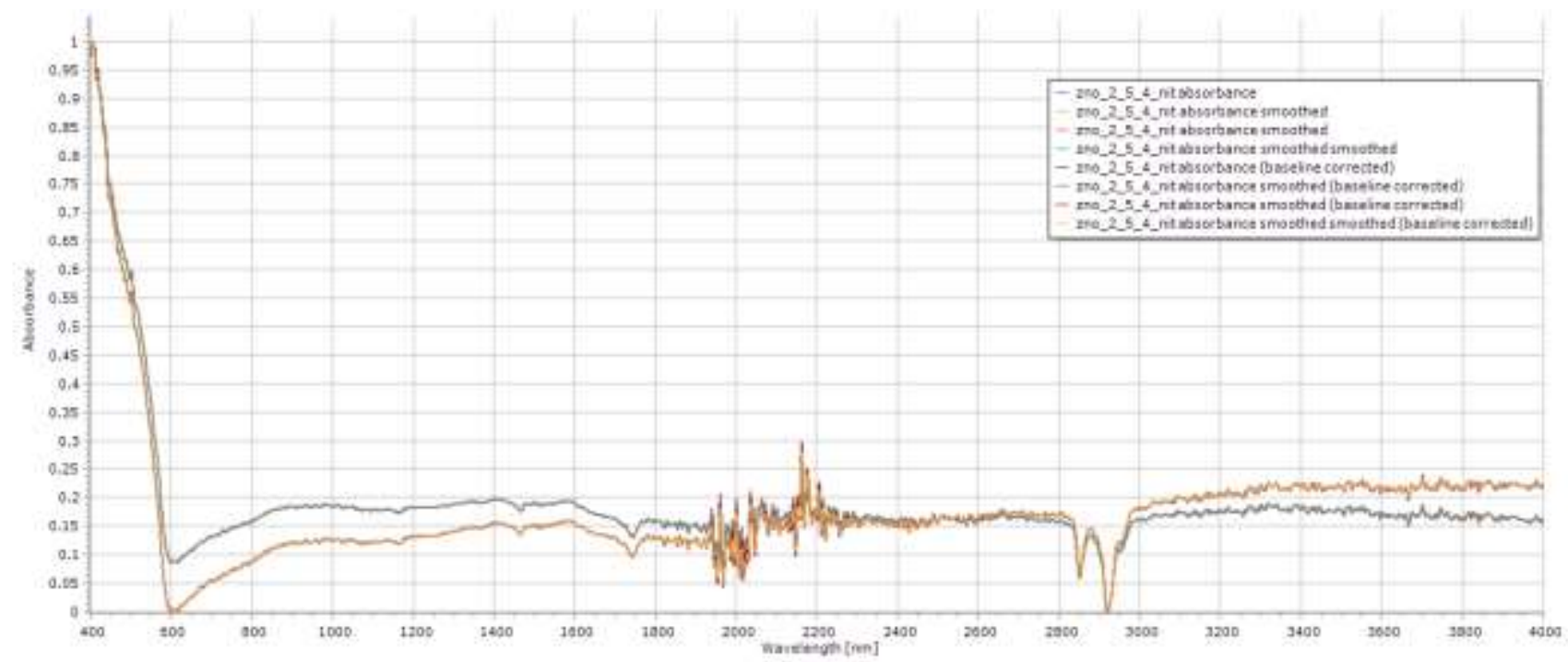

\section{PLOT 5 SPECTROGRAPH RESULTS OF 2_5_4 ZnO MATERIAL}

The above plot 5 is the inverse of the transmittance which is the absorbance for the given wavelengths. As discussed earlier on the transmittance the absorption at different levels can be seen as the reciprocal of the transmittance values. For instance, in between the 400 to $600 \mathrm{~nm}$ the absorption decreases very sharply. The absorption between the $2800 \mathrm{~nm}$ and the $3000 \mathrm{~nm}$ has 2 dropping peaks which indicates that the structural properties during the symmetric and asymmetric vibrations of the $\mathrm{o}-\mathrm{c}=\mathrm{o}$ bonds. 


\subsection{XPS}

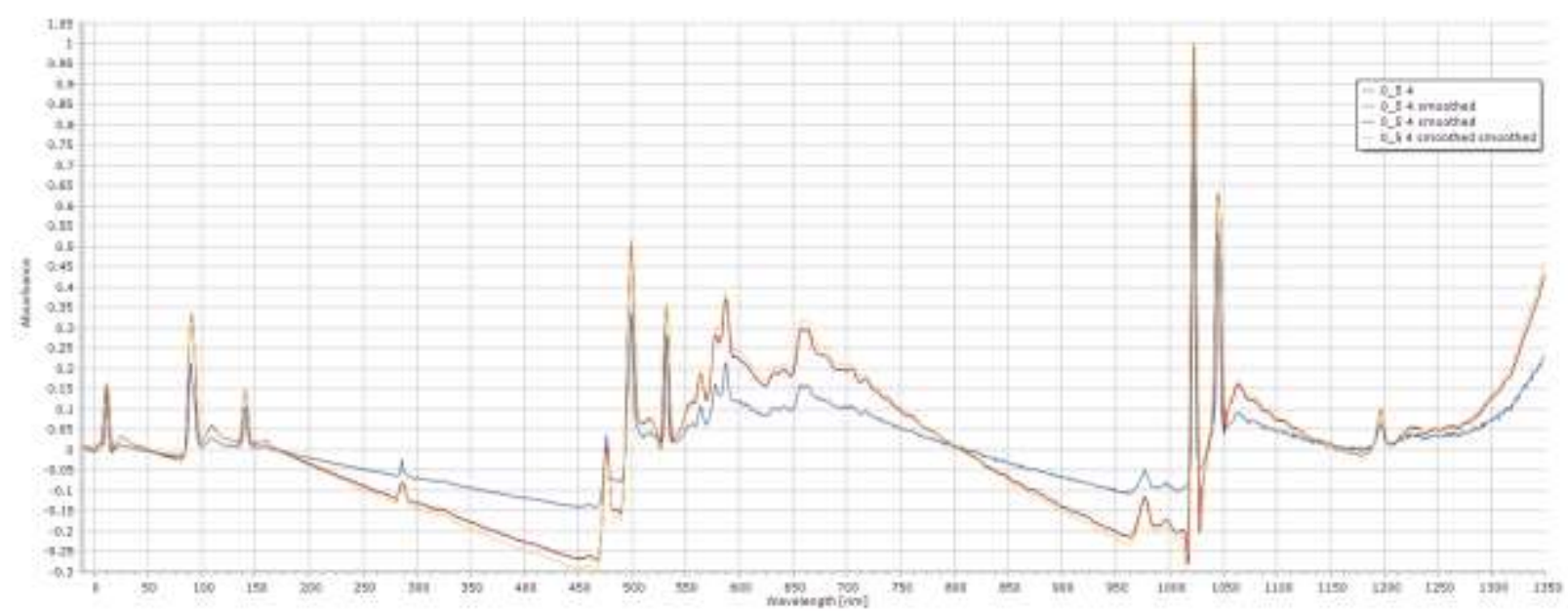

\section{PLOT 6 SPECTROGRAPH RESULTS OF XPS 0_5_4}

In reference to the paper, it can be inferred that the drop near $600 \mathrm{~nm}$ wavelength which corresponds to the same level of wavenumber in FTIR results there occurs substitution of hydrogen in the place of oxygen. It can be understood that the XPS usually give the data on oxygen vacancy bond. I $\mathrm{n}$ this case, when the absorption level rises the oxygen bond are filled and when there is deep dip in the curve it can be called as the vacant oxygen bonds. At this repetition rate of $4 \mathrm{MHz}$ it can be seen there are 20 deep drops in curves which indicates empty oxygen bonds. 


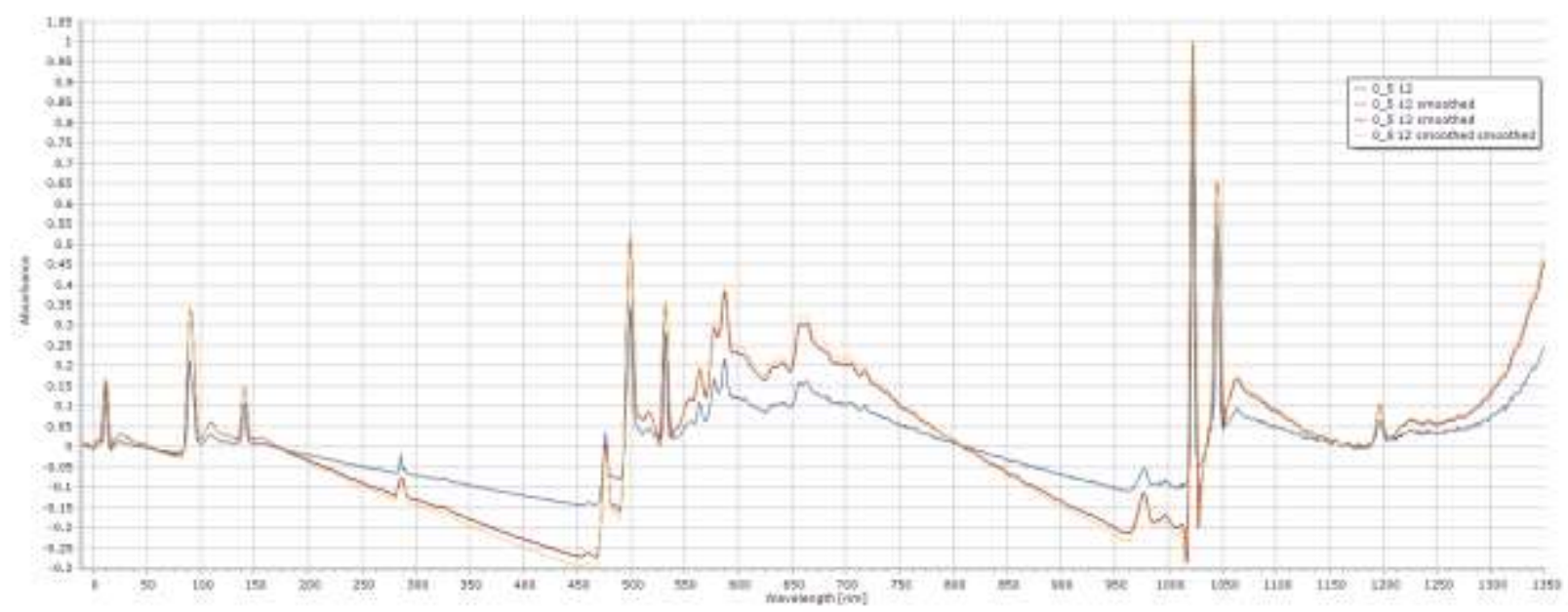

\section{PLOT 7 SPECTRAGRYPH RESULTS OF XPS 0_5_2}

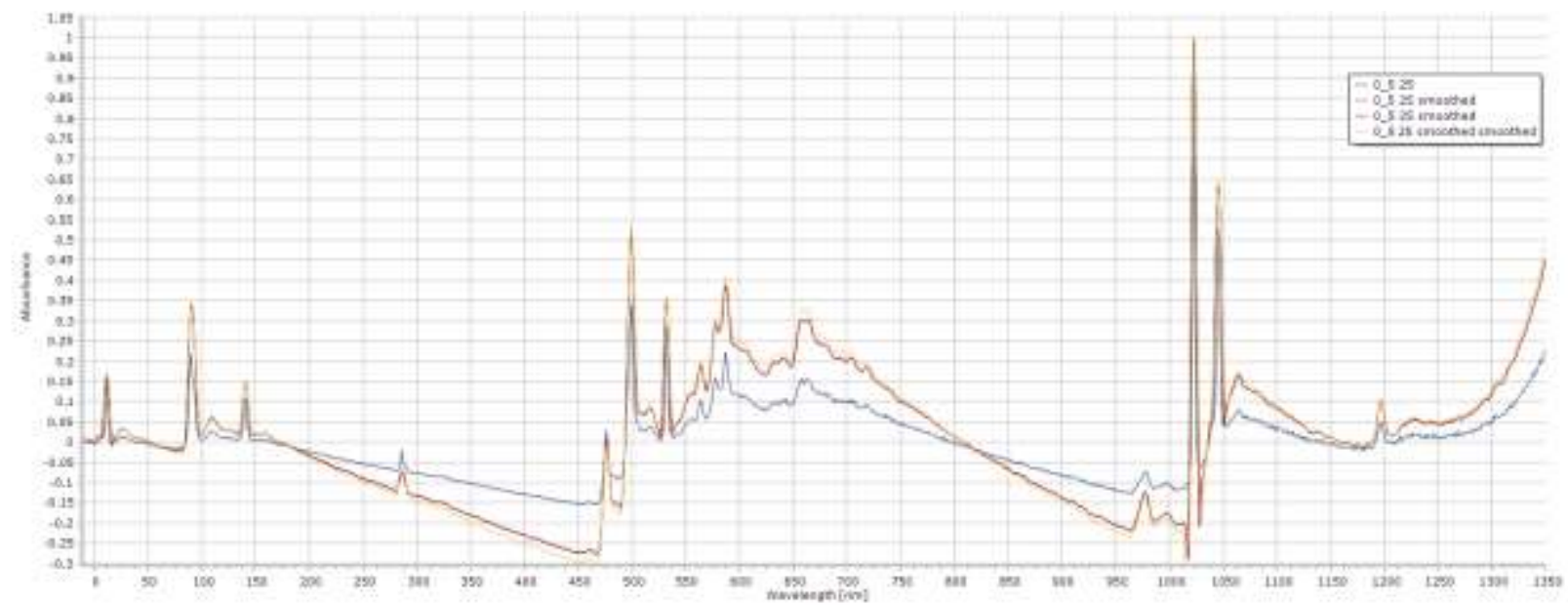

\section{PLOT 8 SPECTROGRAPH RESULTS OF XPS 0_5_25}

The plots 6,7,8 were also analysed in the spectrogryph software. These results show the absorbance and the wavelength plots. Here, similar options which were used in the FTIR analysis were used again. This shows different peaks at different wavelengths. When noticed in all the 3 images the largest peaks are in between the 1000 to $1050 \mathrm{~nm}$ in reference to the paper it can be inferred that the oxygen atoms which were empty until then were absorbed by $\mathrm{H}$ atoms from the ambient conditions to form the hydroxyl groups and again the vibration mode starts which indicates the 
bending modes of hydroxyl groups. Now checking for the 1200 wavelength and from 1250 to 1350 there is gradual increase which is the indication is again of the higher concentration absorptions. In between 0 to $50 \mathrm{~nm}$ of wavelength there is a small peak. In between 50 to $100 \mathrm{~nm}$ there is sharp peak rise in absorption. In between $450 \mathrm{~nm}$ to $650 \mathrm{~nm}$ there are different fluctuations of rise and fall of absorptions. And later there is gradual decrease in the absorption levels. These are happening in the repetitive cycles. These plots are related to the binding energy of the material in accordance with intensity. There is no much difference between the different repetitions of 4 $\mathrm{MHz}, 2 \mathrm{MHz}, 25 \mathrm{MHz}$. 


\section{CHAPTER 4}

\section{CONCLUSION AND FUTURE WORK}

In this project, the analyses were carried out on the different images which were generated through experiments used in the Nanotechnology. These experiments include the Field Emission Scanning Electron Microscopy, High Resolution Transmission Electron Microscopy, Selected Area Electron Diffraction, Fourier Transform Infrared Spectroscopy, X-Ray Photoelectron Spectroscopy. Each of these experiments reveals the morphology of the particles and rods, dspacing, high intense spots, transmittance and absorption respectively. These characteristics of the Zinc Oxide in Nano scale contributes to properties of materials in the bulk form but the nanomaterials in the bulk form in the sense when many nanomaterials combined to form large material. These properties are like structural, electrical, mechanical properties and binding energy which were concluded from the characteristics attained through these analyses.

The average lengths of rods and average areas of the rods are calculated from the FESEM images are matching with the reference paper values. These values indicate highly intense UV emission seems to show higher crystallinity and more perfection in surface states. The particle size of $\mathrm{ZnO}$ used in industry is $500 \mathrm{~nm}$ and in the analysis the mean size of nanoparticles is found to be around 250nm which the same value is approximately. It can be said that the particle size matches so the properties required are also can be achieved in maximum extent. The d-spacing values are also matching $90 \%$ for both manually calculated ones and the software analysed one were matching with the reference paper values. With d- values, miller indices and the planar orientation 
it can be said that the lattice structure is wurtzite lattice structure from its lattice orientations. In FTIR analysis, the binding energy capacity was related from the transmittance versus wavenumber plots in different phases. Through XPS results the empty oxygen bonds occurrence rate is understood. These all are done at different repetition rates. Due to different results, the morphology surface properties, lattice structure properties, electrical properties from FTIR, from the FESEM defects and the picture clarity thr optical properties of the material are understood and finally in XPS the absorption \% reveals the structural properties of the $\mathrm{ZnO}$ material.

When the results are all processed, it can be seen that the characteristics of the $\mathrm{ZnO}$ can be made better in accordance with the demands by different engineering mechanisms like annealing, doping and extruding to form hybrid nanocomposites which as a result gives the required product as per the industry demand. These results which are obtained in this report contributes to the sensitivity of the Raman spectroscopy an other technique to find the morphology in detailed basis .These results help in giving idea to perform Raman spectroscopy in required regime and it will also help in achieving more precise characteristics after the Raman spectroscopy experiment is performed. These further can give accuracy even before the samples are manufactured without the ravage of time and manufacturing costs. 


\section{APPENDICES:}

These are the results of the particle distribution,

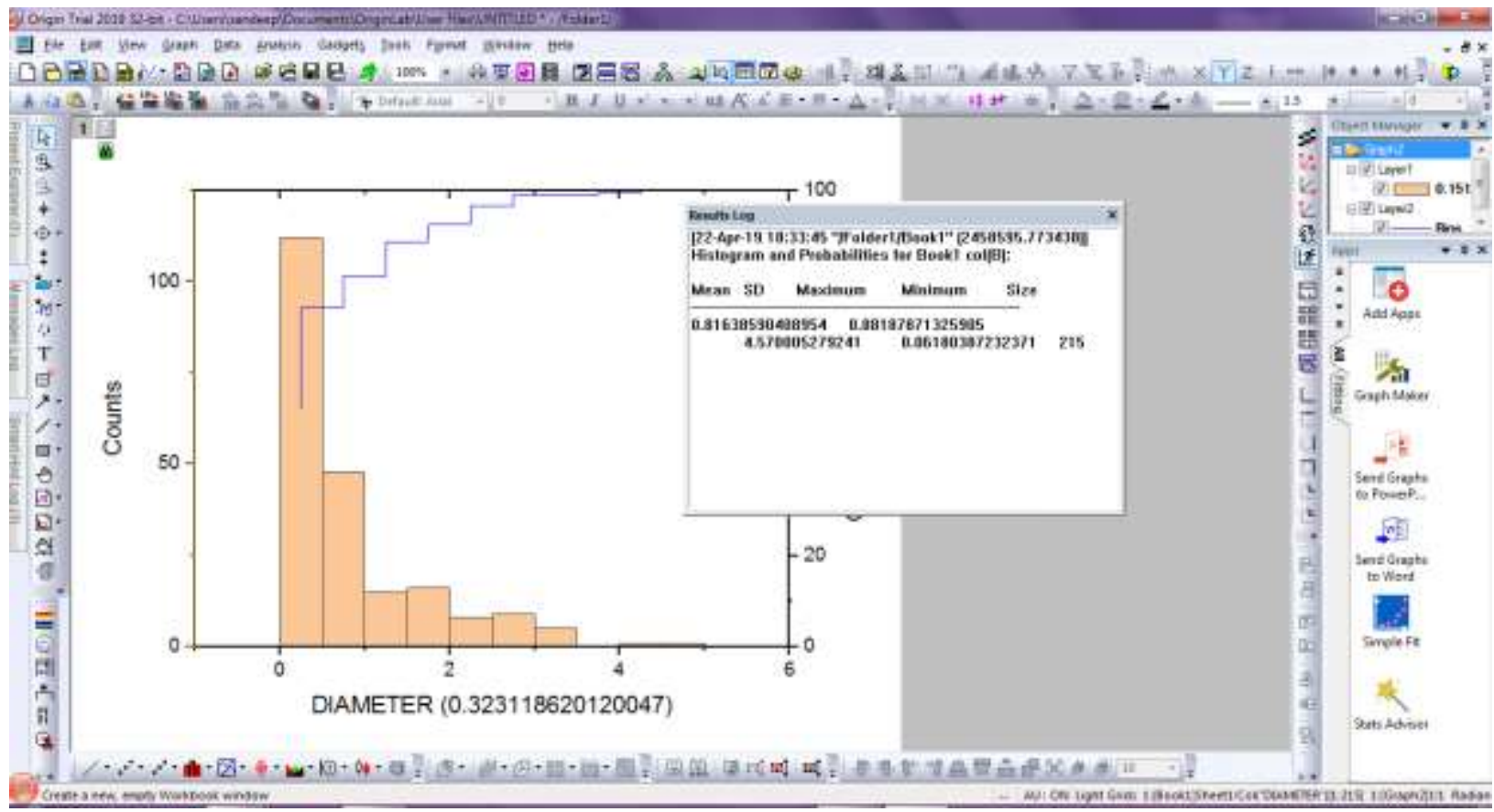

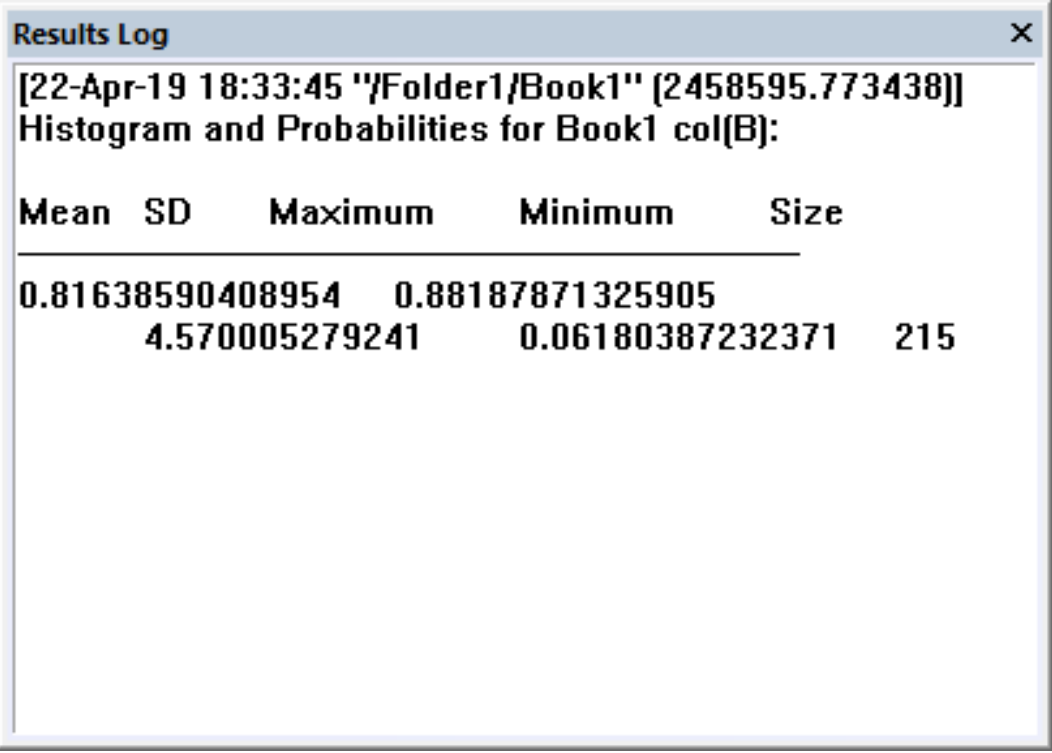




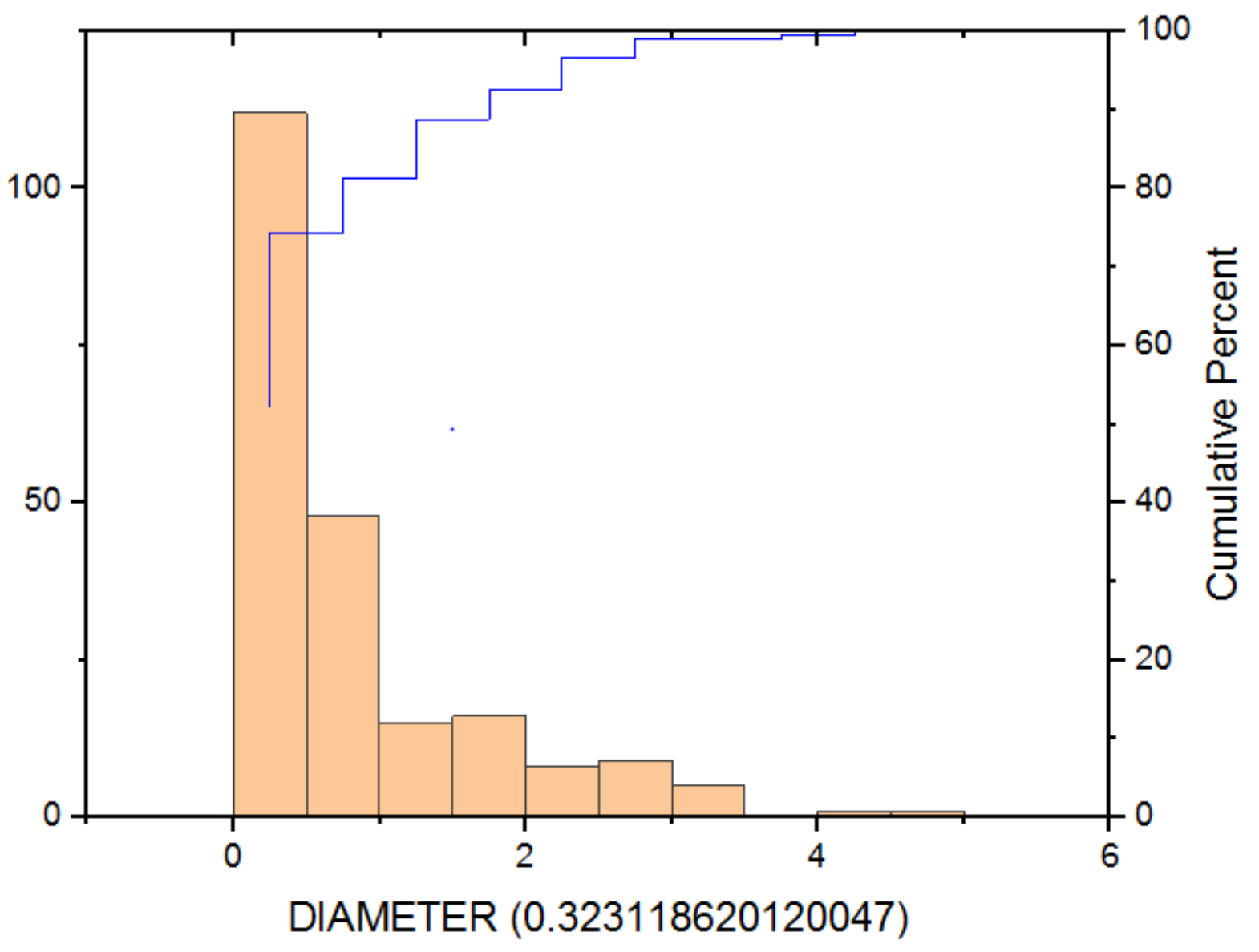

The above histogram shows the plot between counts and the diameter of the particles. 


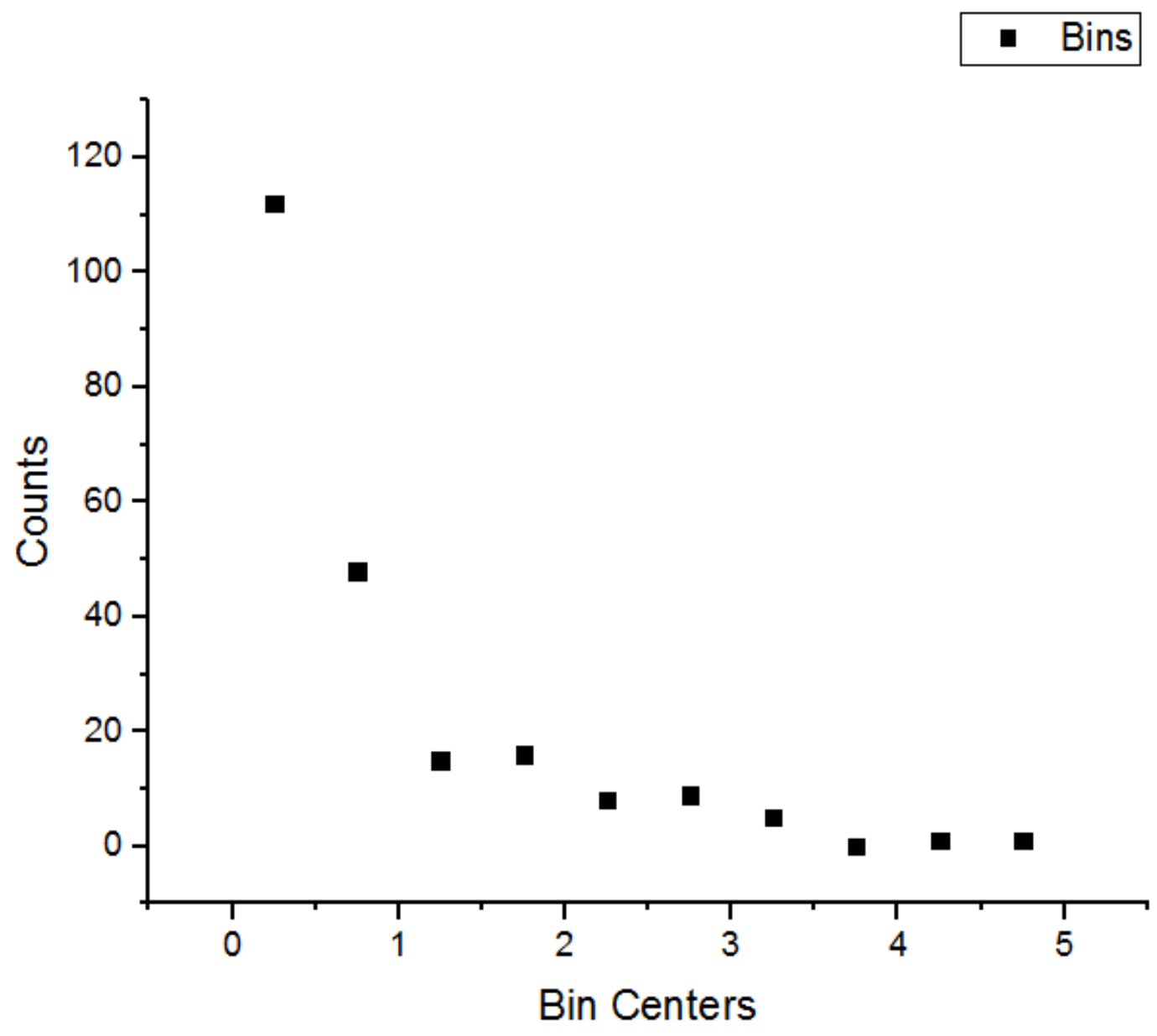

The above curve shows the bell curve binomial distribution for the particles for image 1 in FESEM analysis. 


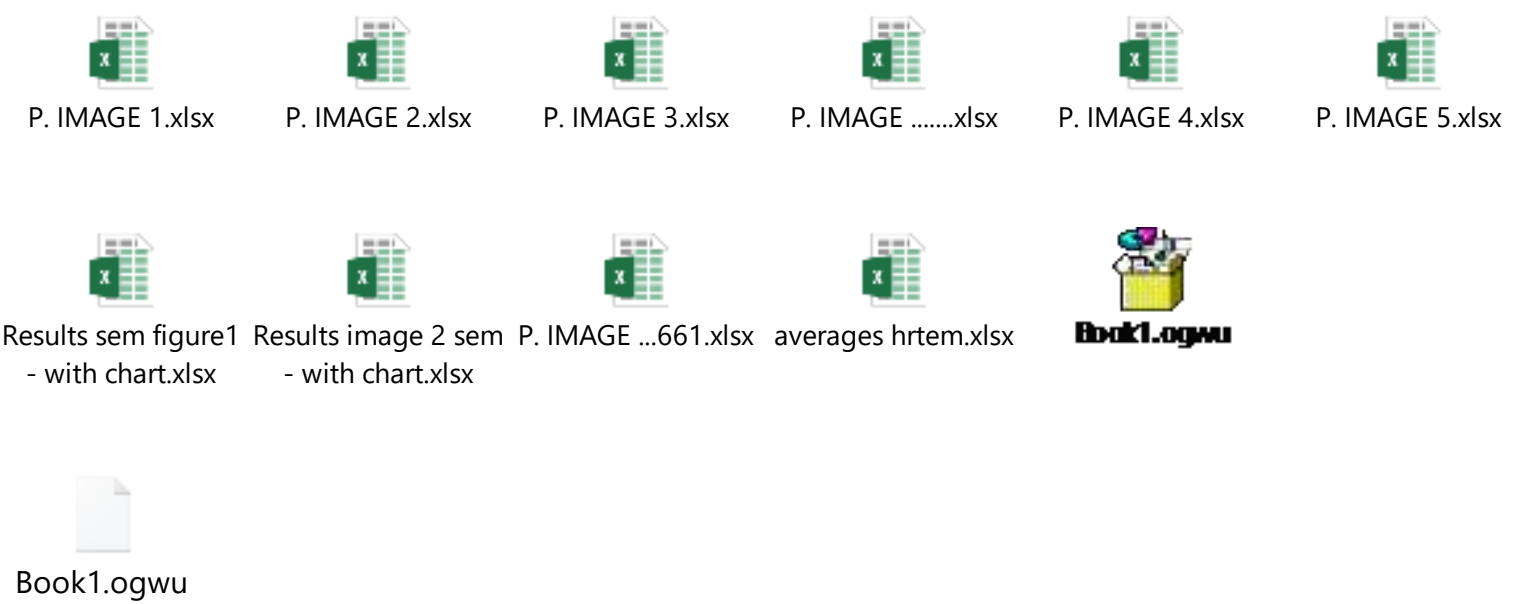




\section{BIBLIOGRAPHY}

Abdulrahman, A. F. (2016, october 10). How Can I calculate the particle size distribution of Nanorods using ImageJ software? Retrieved from research gate: https://www.researchgate.net/post/How_Can_I_calculate_the_particle_size_distribution_ of_Nanorods_using_ImageJ_software

ahmad umar, s. k. (2008, february ). Zinc Oxide Nanonail Based Chemical Sensor for Hydrazine Detection. Retrieved from https://www.researchgate.net/publication/307476319_Zinc_Oxide_Nanonail_Based_Che mical_Sensor_for_Hydrazine_Detection

Anna Mclaren, T. V. (n.d.). Shape and Size Effect of ZnO nanocrystals on Photocatalytic Activity . Retrieved from pubs.acs.org: https://pubs.acs.org/doi/suppl/10.1021/ja9052703/suppl_file/ja9052703_si_001.pdf

CENTRE FOR NANOSTRUCTURE IMAGING. (n.d.). Retrieved from http://www.chem.utoronto.ca/facilities/CNI/jeol-2010.html

Crawford, C. (2016). Structure and Electrophysical Properties of the Transparent Conducting Zinc and Indium Oxides Films V.A. Kulbachinskii V.G. Kytin, O.V. Reukova, D.S. Glebov,. Retrieved from https://slideplayer.com/slide/8079252/

D.singh, y. q. (n.d.). Vertically aligned smooth ZnO nanorod films for planar device applications. Retrieved from research gate: https://www.researchgate.net/publication/255774441_Vertically_aligned_smooth_ZnO_n anorod_films_for_planar_device_applications 
F.C.M. van de Pol, F. v. (n.d.). R.F. planar magnetron sputtered ZnO films I: structural properties. Retrieved from UNIVERSITY OF TWENTE: https://research.utwente.nl/en/publications/rf-planar-magnetron-sputtered-zno-films-istructural-properties

Fadhil K. Farhan1, Z. A.-R.-A. (2017). Electrical and Mechanical Properties of ZnO/(UPEPMMA) Blend Nanocomposites. Retrieved from Scientific ad academic publishing: http://article.sapub.org/10.5923.j.cmaterials.20170702.02.html

FTIR and Raman Spectroscopy . (n.d.). Retrieved from chemistry university of toronto: https://sites.chem.utoronto.ca/analest/content/ftir-and-raman-spectroscopy

G. Wisz, ,. I. (2017). Structural, Optical and Electrical Properties of Zinc Oxide Layers Produced by Pulsed Laser Deposition Method. Retrieved from Nanoscale research letters: https://link.springer.com/content/pdf/10.1186\%2Fs11671-017-2033-9.pdf

https://application.wiley-vch.de/books/sample/3527408134_c01.pdf. (2009). General Properties of $\mathrm{ZnO}$.

Mohammad Islam, M. M. (n.d.). Arrays of CZTS sensitized ZnO/ZnS and ZnO/ZnSe core/shell nanorods for liquid junction nanowire solar cells. Retrieved from research gate: https://www.researchgate.net/publication/286455489_Arrays_of_CZTS_sensitized_ZnO ZnS_and_ZnOZnSe_coreshell_nanorods_for_liquid_junction_nanowire_solar_cells

muhammad saleem, C. Y. (2012, FEBRUARY). Simple Preparation and Characterization of Nano-Crystalline Zinc Oxide Thin Films by Sol-Gel Method on Glass Substrate. Retrieved from SCIENTIFIC RESEARCH AN ACADEMIC PUBLISHER: https://www.scirp.org/journal/CTA.aspx?paperID=17630 
Muhammad Saleem, F. L. (2012, MAY). Simple Preparation and Characterization of NanoCrystalline Zinc Oxide Thin Films by Sol-Gel Method on Glass Substrate. Retrieved from RESEARCH GATE:

https://www.researchgate.net/publication/259889308_Simple_Preparation_and_Character ization_of_Nano-Crystalline_Zinc_Oxide_Thin_Films_by_Sol-

Gel_Method_on_Glass_Substrate

MuhammadAftab Akrama, s. j. (2016, march). Arrays of CZTS sensitized ZnO/ZnS and ZnO/ZnSe core/shell nanorods for liquid junction nanowire solar cells. Retrieved from science direct: https://www.sciencedirect.com/science/article/pii/S0927024815006182

Paranthaman, V. (2016, may 5). How to calculte hkl values from TEM d,spacing values?

Retrieved from research gate:

https://www.researchgate.net/post/How_to_calculte_hkl_values_from_TEM_d_spacing_ values

Prateek Uikey, D. K. (n.d.). REVIEW OF ZINC OXIDE (ZNO) NANOPARTICLES

APPLICATIONS AND PROPERTIES. Retrieved from ijetcse: http://www.ijetcse.com/wp-content/plugins/ijetcse/file/upload/docx/529REVIEW-OFZINC-OXIDE--ZNO--NANOPARTICLES-APPLICATIONS-AND-PROPERTIESpdf.pdf

RenuKumaria, A. N. (n.d.). Effect of nitrogen doping on structural and optical properties of ZnO nanoparticles. Retrieved from science direct: https://www.sciencedirect.com/science/article/pii/S1002007115000817 
Rupa Haldavnekar, D. V. (2018). Non plasmonic semiconductor quantum SERS probe as a pathway for in vitro cancer detection . natures communications.

Sahu, Y. S. (n.d.). Nano Zinc Oxide Market by Application (Paints \& Coatings, Cosmetics, and Others) - Global Opportunity Analysis and Industry Forecast, 2014-2022. Retrieved from allied ,arket reserach: https://www.alliedmarketresearch.com/nano-zinc-oxide-marketl

Sheng Xu, C. L. (2008, JANUARY 28). Density-controlled growth of aligned ZnO nanowire arrays by seedless chemical approach on smooth surfaces. Retrieved from NANO SCIENCE: http://www.nanoscience.gatech.edu/paper/2008new/2008_dga.pdf

wajeeha sultana, s. g. (n.d.). Zinc Oxide Modified Au Electrode as Sensor for an Efficient Detection of Hydrazine. Retrieved from https://www.researchgate.net/publication/263720087_Zinc_Oxide_Modified_Au_Electro de_as_Sensor_for_an_Efficient_Detection_of_Hydrazine

Wang, Z. L. (2004, june 11). Zinc oxide nanostructures: growth, properties and applications. Retrieved from IOP Science: https://iopscience.iop.org/article/10.1088/09538984/16/25/R01/meta

Wen-Jay Lee, J.-G. C.-P.-H.-H. (2011, APRIL 20). Structure-dependent mechanical properties of ultrathin zinc oxide nanowires. Retrieved from Sprinfer open: https://nanoscalereslett.springeropen.com/articles/10.1186/1556-276X-6-352

xinfugu. (2016, november 16). Phase transformation crystallograp. Retrieved from source forge: https://sourceforge.net/projects/tclab/ 
Yoon Myung, D. M. (2010, JUNE 7). Composition-Tuned ZnO-CdSSe Core-Shell Nanowire Arrays. Retrieved from ACS PUBLICATION:

https://pubs.acs.org/doi/abs/10.1021/nn100684q

Zinc Oxide - Properties, Applications and the Future for ZnO. (2011, october 6). Retrieved from AZO Materials: https://www.azom.com/article.aspx?ArticleID=5818 